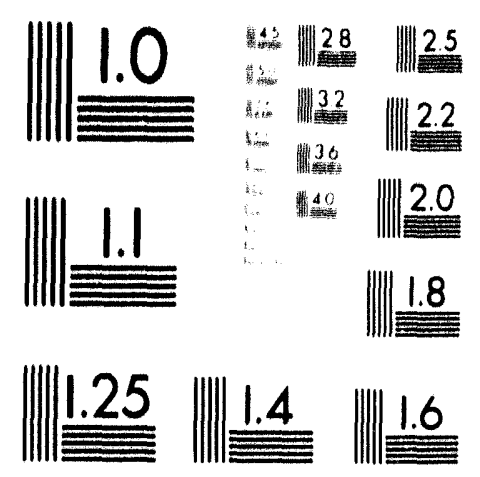



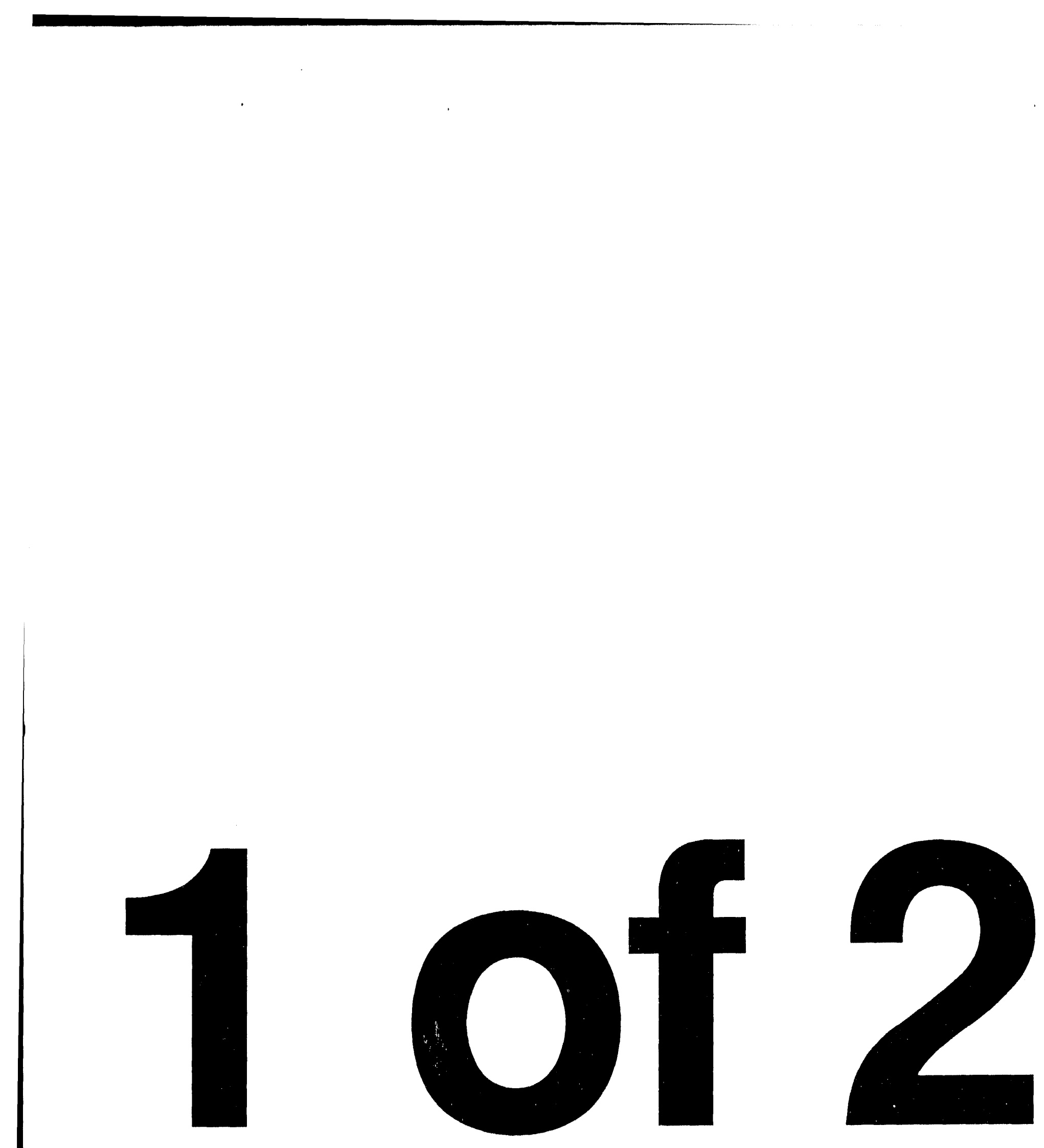
EGG-WTD-10771

Revision 0

\section{Digface Characterization \\ Test Plan (Remote Testing)}

Kevin Croft

Reva Hyde

Scott Allen

Published August 1993

Idaho National Engineering Laboratory

EG\&G Idaho, Inc.

Idaho Falls, Idaho 83415

Prepared for the

U.S. Department of Energy

Offlce of Environmental Restoration and Waste Management

Under DOE Idaho Operations Offlce

Contract DE-AC07-76ID01570 


\section{Digface Characterization Test Plan (Remote Testing)}

EGG-WTD-10771

Prepared by
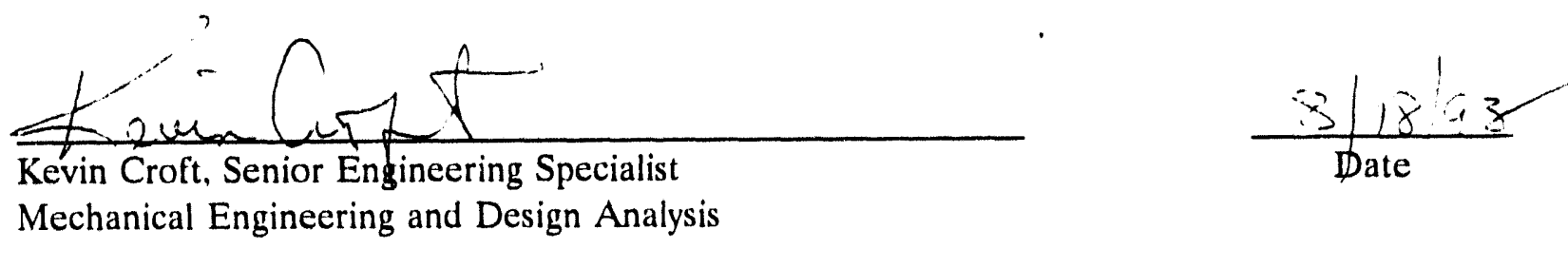

Reviewed by

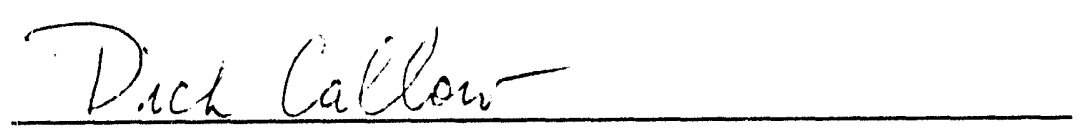

Dick Callow, Project Manager

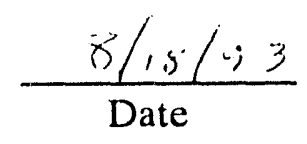

Buried Waste Integrated Demonstration

Approved by

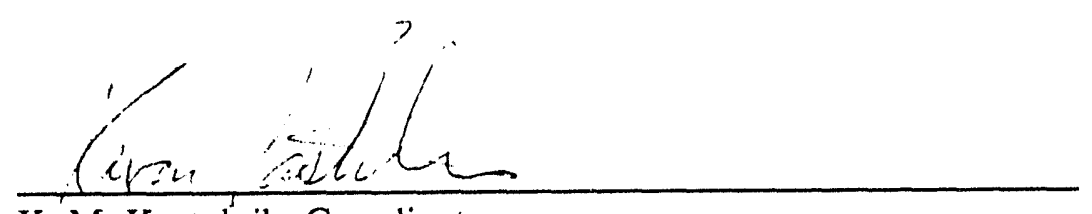

K. M. Kostelnik, Coordinator

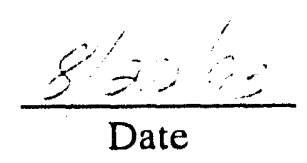

Buried Waste Integrated Demonstration 


\section{ABSTRACT}

The objective of the Digface Characterization (DFC) Remote Testing project is to remotely deploy a sensor head (Mini-Lab) across a digface to determine if it can characterize the contents below the surface. The purpose of this project is to provide a robotics technology that allows removal of workers from hazards, increases speed of operations, and reduces life cycle costs compared to alternate methods and technologies. The Buried Waste Integrated Demonstration (BWID) is funding the demonstration, testing, and evaluation of DFC.

This document describes the test plan for the DFC remote deployment demonstration for the BWID. The purposes of the test plan are to establish test parameters so that the demonstration results are deemed useful and usable and perform the demonstration in a safe manner and within all regulatory requirements. 


\section{ACKNOWLEDGEMENT}

The authors wish to acknowledge Sandia National Laboratories and Deneb Robotics for their role in supporting the tests with Mini-Lab. In addition, the authors would like to acknowledge EG\&G Idaho, Inc. Seosciences for their support in the sensor head testing. 


\section{CONTENTS}

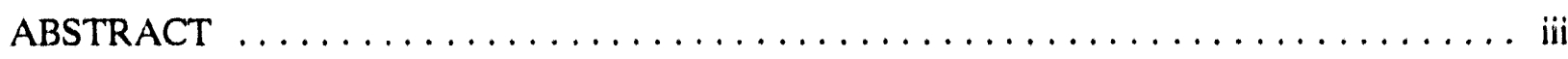

ACKNOWLEDGEMENT $\ldots \ldots \ldots \ldots \ldots \ldots \ldots \ldots \ldots \ldots \ldots \ldots \ldots$

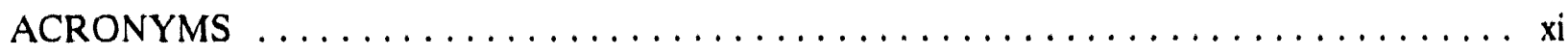

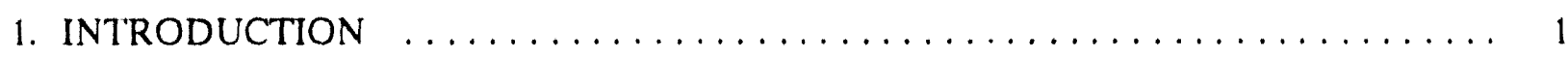

1.1 DFC Technology Description and Background $\ldots \ldots \ldots \ldots \ldots \ldots \ldots, 1$

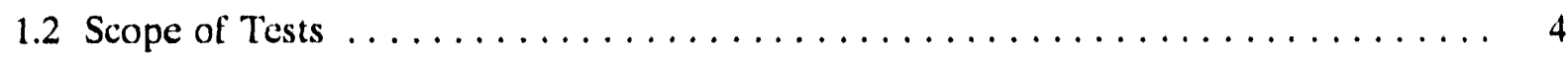

1.3 Purpose and Objectives of Test $\ldots \ldots \ldots \ldots \ldots \ldots \ldots \ldots \ldots \ldots \ldots \ldots$

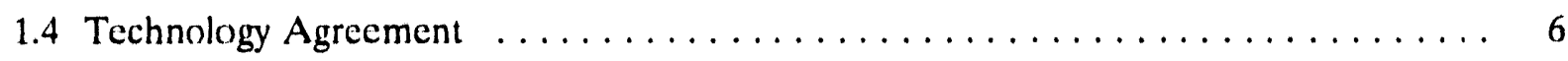

2. ORGANIZATION AND RESPONSIBILITIES $\ldots \ldots \ldots \ldots \ldots \ldots \ldots \ldots \ldots$

2.1 Organizational Responsibilities $\ldots \ldots \ldots \ldots \ldots \ldots \ldots \ldots \ldots \ldots \ldots \ldots, \ldots \ldots \ldots$

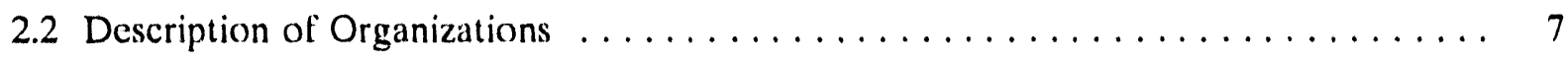

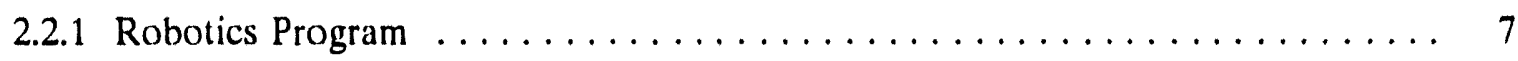

2.2.2 Buried Waste Integrated Demonstration Program $\ldots \ldots \ldots \ldots \ldots \ldots \ldots$

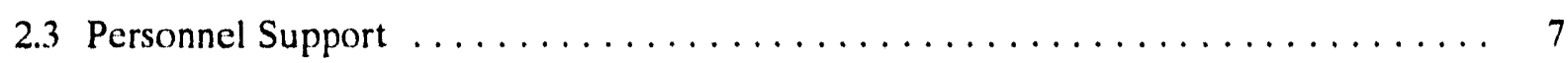

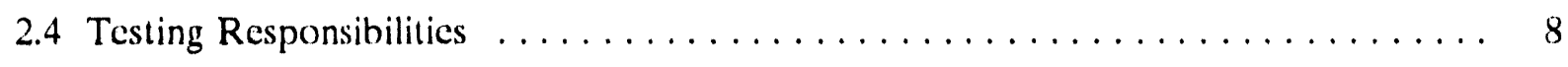

2.5 Qualifications and Training Required $\ldots \ldots \ldots \ldots \ldots \ldots \ldots \ldots \ldots \ldots \ldots \ldots \ldots \ldots \ldots \ldots$

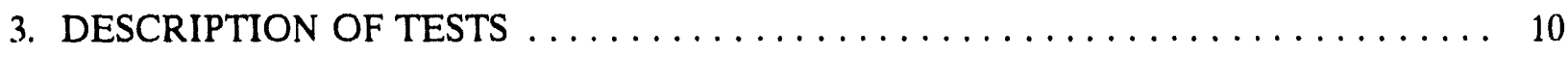

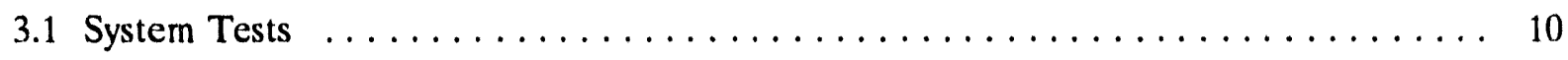

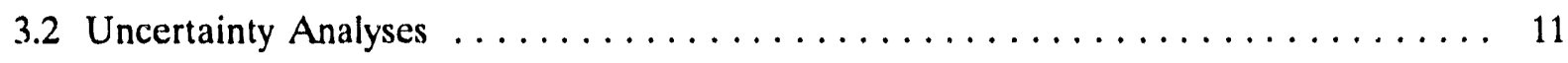

3.3 Contingency $\operatorname{Plan} \ldots \ldots \ldots \ldots \ldots \ldots \ldots \ldots \ldots \ldots \ldots \ldots \ldots \ldots \ldots \ldots \ldots \ldots \ldots \ldots, 12$

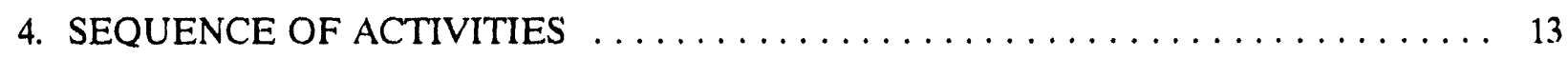

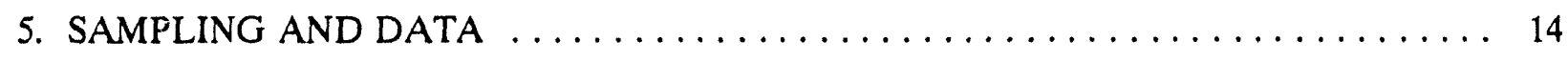

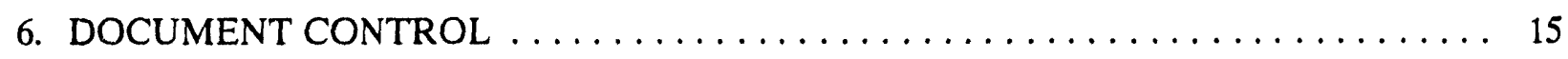




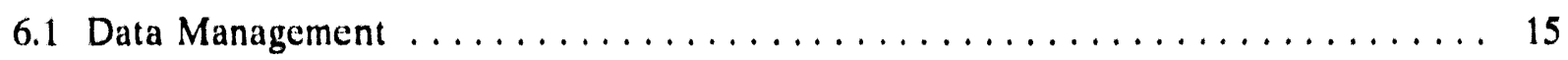

6.1 .1 BWID Requirements $\ldots \ldots \ldots \ldots \ldots \ldots \ldots \ldots \ldots \ldots \ldots \ldots$

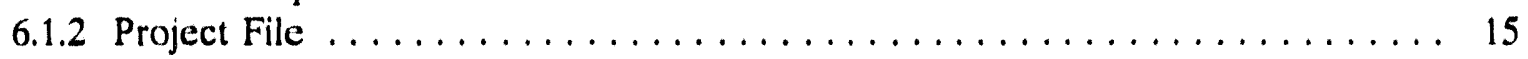

6.1.3 Description of Data .............................. 16

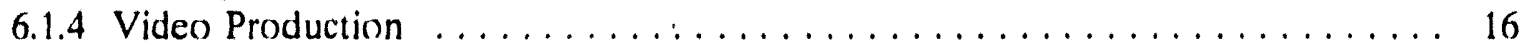

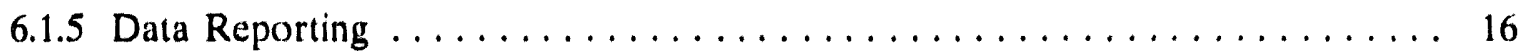

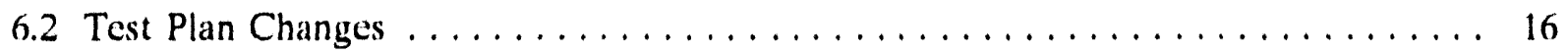

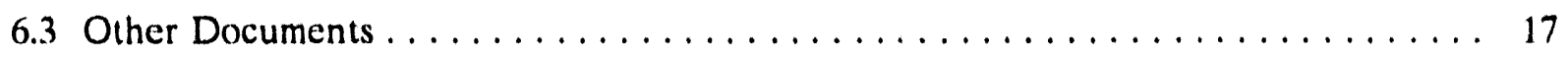

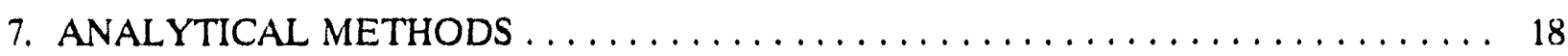

8. DATA REDUCTION, VALIDATION, AND VERIFICATION $\ldots \ldots \ldots \ldots \ldots$

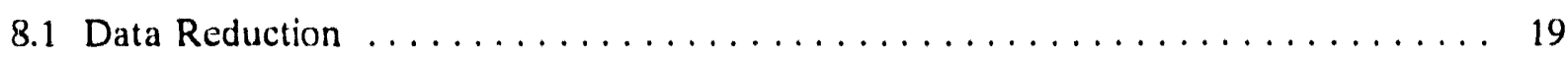

8.2 Data Validation $/$ Verification $\ldots \ldots \ldots \ldots \ldots \ldots \ldots \ldots \ldots \ldots \ldots \ldots$

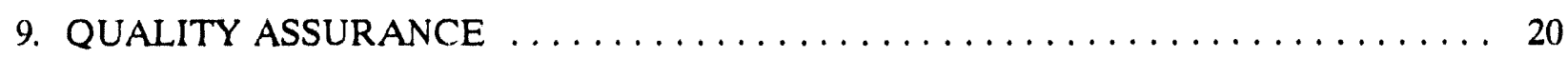

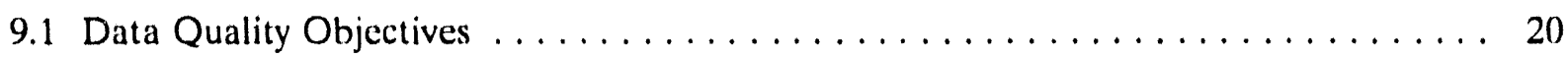

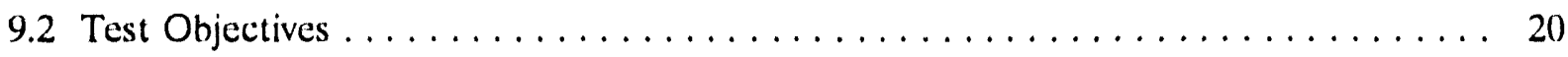

9.3 Internal Quality Control Checks $\ldots \ldots \ldots \ldots \ldots \ldots \ldots \ldots \ldots \ldots \ldots \ldots \ldots \ldots \ldots, 22$

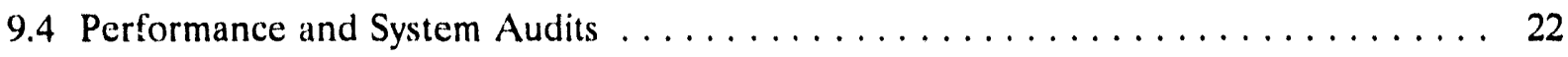

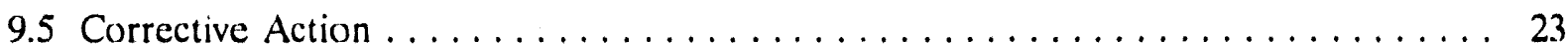

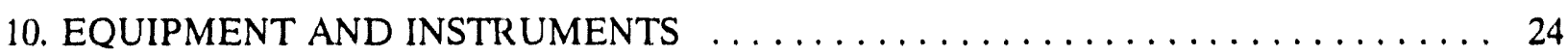

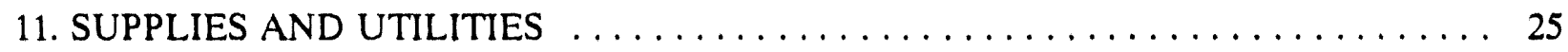

12. HEALTH AND SAFETY $\ldots \ldots \ldots \ldots \ldots \ldots \ldots \ldots \ldots \ldots \ldots \ldots \ldots \ldots \ldots \ldots \ldots, 26$

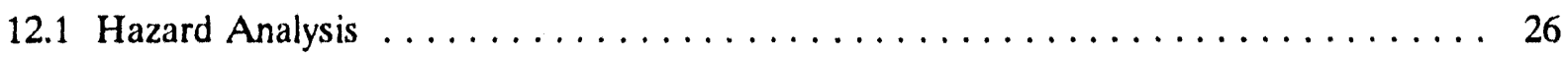

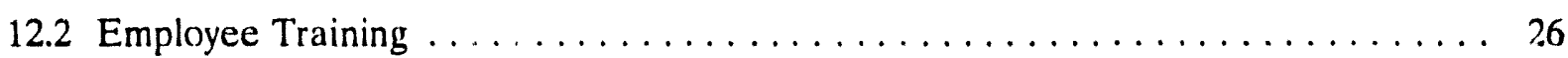

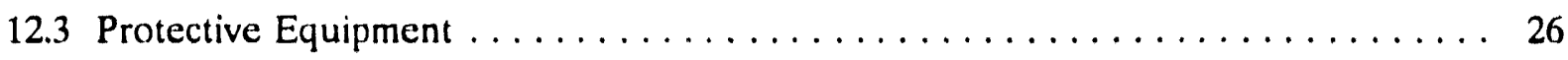

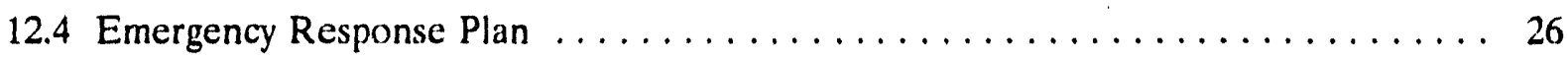

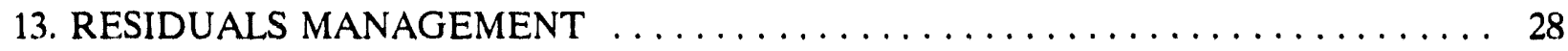


14.1 National Environmental Policy Act . . . . . . . . . . . . . . . . 29

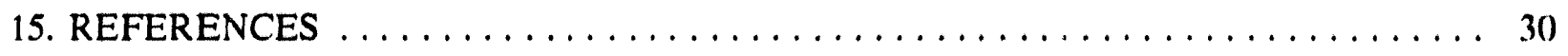

Appendix A-Intormation on Mini-Lab $\ldots \ldots \ldots \ldots \ldots \ldots \ldots \ldots \ldots \ldots \ldots \ldots \ldots$

Appendix B-Engineering Test Sequences $\ldots \ldots \ldots \ldots \ldots \ldots \ldots \ldots \ldots \ldots \ldots \ldots \ldots$

Appendix $\mathrm{C}$-Instrumentation Data Sheets $\ldots \ldots \ldots \ldots \ldots \ldots \ldots \ldots \ldots \ldots \ldots \ldots$

\section{FIGURES}

1. The gantry crane, with a Schilling arm, will be used to deploy the DFC sensors ..... 4

2. Diagram showing the soil box for the robotics gantry crane demonstration $\ldots \ldots \ldots 6$

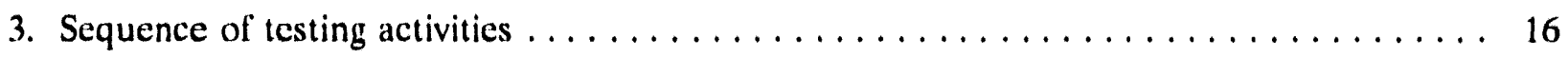


ACRONYMS

BWID Buried Waste Integration Demonstration

BWRP Buried Waste Robotics Program

UFC Diglace Characterization

DOE U. S. Department of Energy

DQO Data quality objectives

INEL Idaho National Engineering Laboratory

IRC Idaho Research Center

NBRC North Boulevard Robotics Center

NEPA National Environmental Policy Act

PM Project manager

QA Quality Assurance

SNL Candia National Laboratories

$x i$ 


\section{Digface Characterization Test Plan (Remote Testing)}

\section{INTRODUCTION}

Chafacturization provides informulion that is necessary to determine which remedial action is bew suited for a particular waste site. Churacterization of all U.S. Department of Energy (DOE) slow with huried hazardoun and/or radionctive waste is necessary to provide information to aid in the sleanup and reatoralion of the envirunment at these sites. Digface Characterization (DFC) provides several emential advantages over current manual characterization:

- $\quad$ I improven sulety hy removing workers from potentially hazardous waste sites (before and during removial of soil (everhurden).

- Il decreanen lime for characterization by allowing for the simultaneous use of multiple eneors pather than one sensor at a time.

- If decreases cokts by supperting rapid characterization of waste sites with multiple sensors

- Il increases the lociational precision and accuracy of where the contents are beneath the wil.

Thin section provides an introduction to the test plan. Section 1.1 discusses the technology and provider hackground inlormation. Section 1.2 addresses the scope of the test. Section 1.3 gives the purpuse of the lest and the lest objectives. Section 1.4 idenifies the technology agreement with Buried Waste Integrated Demonstration (BWID).

\subsection{DFC Technology Description and Background}

The DFC prototypicial deployment system eonsists of an array of remotely controlled seuphysical, radiolugicul, and chemical sensors packaged in a sensor head; a gantry crane with a Schilling arm fur deployment of the sensor package; Mini-Lab for data acquisition, storage, reduction, and display: and a control station. Sensors being deployed by the crane include (a) a metal detector, (b) magnelomelurs, (c) a chemical detector, and (d) a gamma radiation detector. The sensor head wan develuped io be a platiorm for deploying a variety of sensors that may be interchanged for ipecillic appliculions.

The guniry crane is a 3-ton unit that includes three axes of motion. The first axis (referred to aw the $x$-axis) provides upproximately $30 \mathrm{ft}$ of linear travel distance. The second axis (referred to as the $y$-axis) is the trolley, exhibiting approximately 9-ft of movement. The third axis of motion (rolerred in as the z-axis) is the mast assembly, which has approximately $40 \mathrm{in.}$ of vertical motion.

The ganiry system is an industry available unit that has been modified to allow for remote uperations. The mast assembly was designed and fabricated at the INEL, then interfaced with the crane at the crune manufacturer's facility. The crane has variable speed capability in each of the three-axen of motion. The $x$ - and $y$-axes are designed for speeds of 0 to $30 \mathrm{ft} /$ minute. The $z$-axis has 
capability of 0 to $80 \mathrm{in} . /$ minute. Each axis is provided with closed loop position feedback by the implementation of incremental encoders.

Mounted to the mast assembly is a six axes hydraulic servo-controlled manipulator system. The manipulator system provides for the deployment of end effectors (tools) of various configurations and uses. Examples of some of these tools are a plasma arc cutting torch, mechanical cutting equipment (saws), and sensor packages (for hazardous material characterization). Each of the six axes on the manipulator also includes closed loop position feedback. Mounted in the manipulator wrist is a six axis force/torque sensor that provides for controlling the amount of force that the arm may apply. The force levels are adjustable at the operator station between 0 and $750 \mathrm{lb}$.

Closed circuit television cameras are mounted around the room to provide real-time viewing for operations personnel during system operations. The camera pan/tilt units are controlled by the system to automatically follow the movements of the manipulator end effector.

The gantry, manipulator, and camera pan/tilt units are controlled by a 16 -axis controller that interfaces the system with the operations person(s) and provides supervisory control to the system. The controller also includes real-time simulation graphics capability, which allows the operator to visualize operations through the simulation. Operations may be performed in any of three modes. Modes 1 and 2 will be used most frequently for the unstructured environments that are anticipated. The three modes are

1. Teleoperated-The operator, using available control interfaces (joy sticks, a computer mouse, spaceball, and Schilling master control device), manually operates the system.

2. Telerobotic-The operator teaches paths to the system via the previously mentioned interfaces, manipulates and combines paths, stores them to file, and replays them as necded.

3. Robotics-The operator programs (using $\mathrm{C}$ or another appropriate computer language) the controller and replays the program as needed.

The system is supported by a sophisticated simulation graphics workstation. 'The workstation, built by Silicon Graphics, Inc., provides the capability of system simulation modeling. Motions performed within each operating mode can be seen as they happen on 3-D simulations of the work cell. A drawback to the simulation is that the system does not automatically update changes to the workcell. Currently, these require manual updating of the models. Automatic updating is being investigated.

The system is controlled and data are collected at a control station, which is housed in a room adjacent to the crane in the North Boulevard Robotics Center (NBRC). The system is shown in Figure 1.

Sandia National Laboratories (SNL) has developed a miniaturized in situ characterization laboratory, called Mini-Lab. Mini-Lab consists of a flexible software and hardware architecture for the acquisition, display, interpretation, and archival of sensor data. 


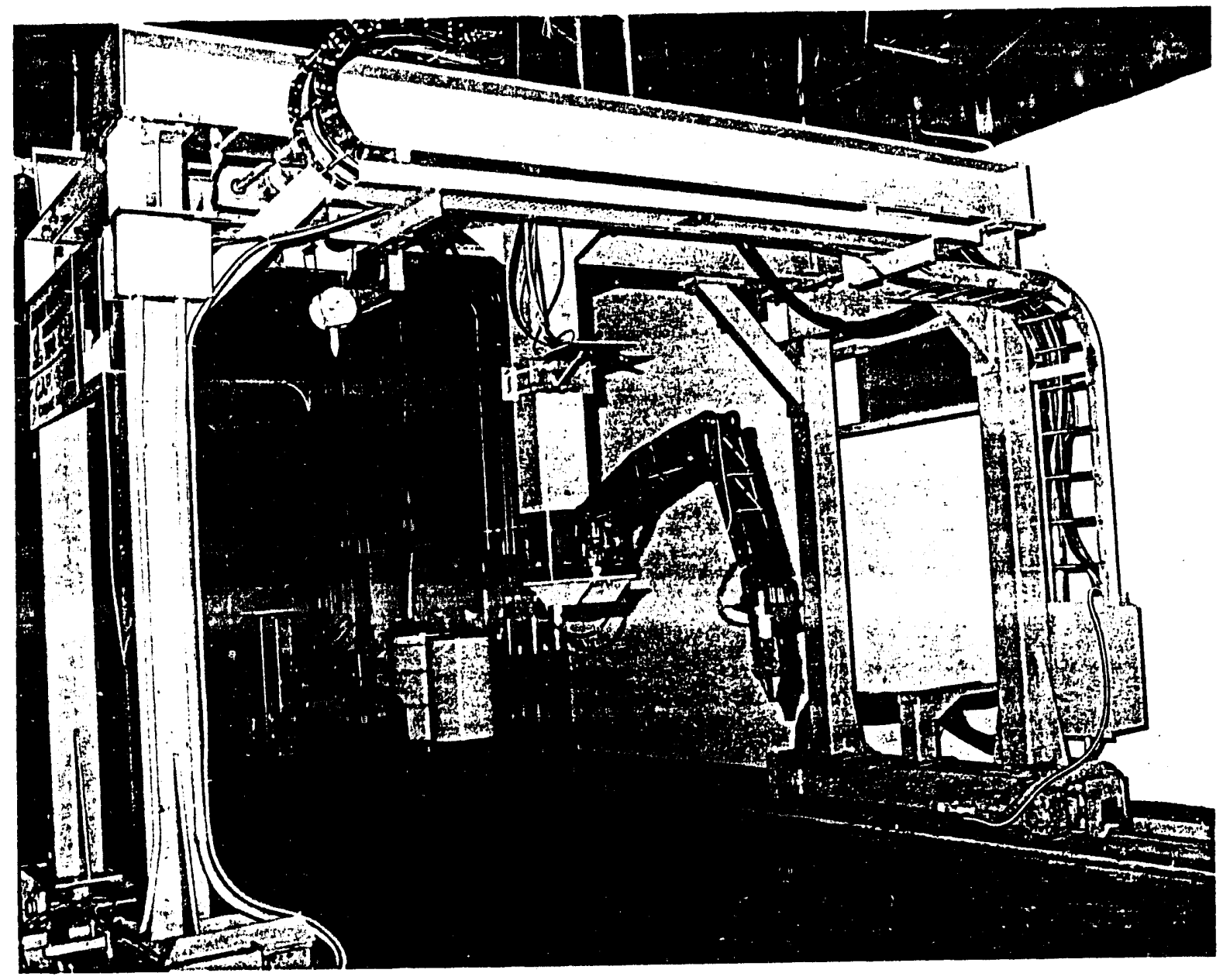

Figure 1. The gantry crane, with a Schilling arm, will be used to deploy the DFC sensors. The crane system is located at the NBRC. 
Mini-Lab consists of three main parts: (1) remote sensor package, (2) data acquisition and interface electronics, and (3) computer base station. The computer base station (SUN Microsystems Sparc 10 workstation) is attached to an Ethernet that ties the robotic controller. This communications interface allows the system components to exchange data and system commands with each other. Because of this interface, Mini-Lab can tell the robot controller what to do. Mini-Lab also positions and time-stamps data. Appendix A provides more information on Mini-Lab.

\subsection{Scope of Tests}

DFC is being developed to provide remote characterization of waste forms during remediation of a buried waste site. A DFC prototypical deployment system will be demonstrated, tested, and evaluated for the BWID Program at the NBRC, located at the Idaho National Engineering Laboratory (INEL). This test plan addresses testing of the gantry crane and Schilling arm (prototypical deployment system), Mini-Lab, as well as the deployment of the sensor package using the crane. The Test Plan for Digface Characterization Performance Testing ${ }^{1}$ covers testing of the sensor package without the use of the crane.

A nonmetallic box has been developed that will contain soil and simulated buried waste configurations that may be encountered during characterization/remediation efforts on buried waste at various DOE sites. This box has been designed to fit beneath the gantry crane. Its function will be to house various physical, chemical, and radiological targets for the demonstrations. During the tests, the sensors that are being deployed by the gantry system will be passed over the waste box at a variety of speeds and at varying heights from the targets. From the data collected during these passes, the effectiveness of the delivery process, sensing elements, and data acquisition and data reduction systems will be determined. A pictorial of the soil box is shown in Figure 2.

\subsection{Purpose and Objectives of Test}

The purpose of this project is to demonstrate remote delivery of multiple geophysical sensors to a buried waste site, obtain data, and display data at the control station. The overall product will include test data on thie control system, data display package (Mini-Lab), crane, and sensor deployment capabilities of the crane. The sensor package is being tested separately in a field test environment under Test Plan for Digface Characterization Performance Testing ${ }^{1}$.

The DFC gantry system is (for these tests) comprised of the three-axis gantry, Schilling manipulator, camera pan/tilt units, system controller, and Mini-Lab. The test objectives are

- Demonstrate and measure the accuracy of instrument placement by the DFC gantry system-The overall system will be tested to determine the degree of positional accuracy obtainable using this deployment system. These tests will include the placement of sensors by the gantry, manipulator, and combined placement by both devices. Tests will be repeated several times for statistical purposes.

- Determine the time required to perform a digface survey-The system will be subjected to testing that will determine the amount of time required to setup and run an operation and 

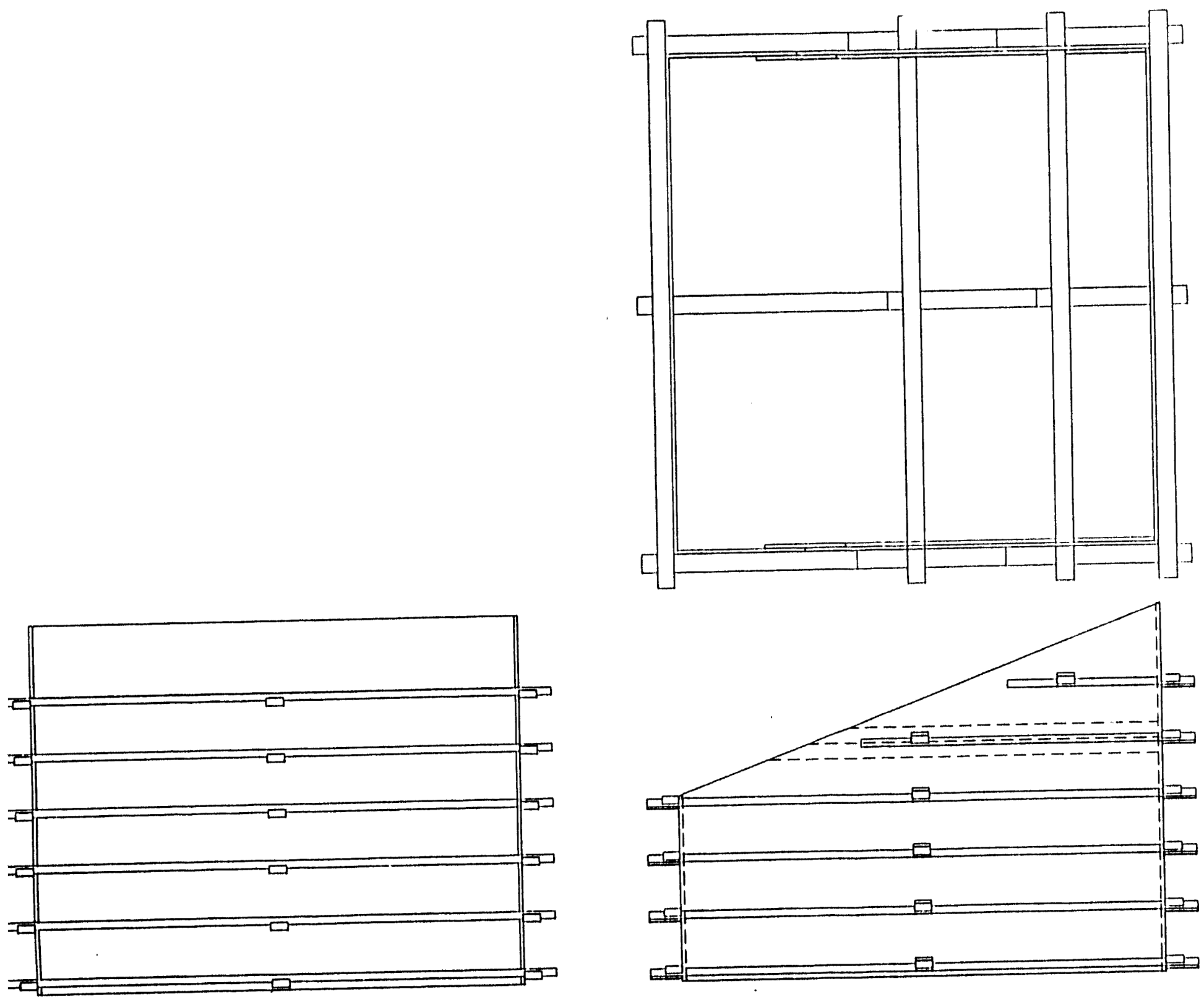

Figure 2. Diagram showing the soil box for the robotics gantry crane. 
the required personnel and equipment that are needed to perform the operation. The effectiveness of data collection and interpretation utilizing these methods will be addressed.

- Demonstrate and measure the ability to detect and locate radioactive and hazardous chemical hot spots-This test will deploy a gamma and gas specific sensors over the digface to locate materials that have been strategically located within the waste box. The tests will be run at varying speeds and distances from the digface to generate optimum data. The tests will be repeated several times for statistical purposes. Both of these sensors are mounted in the sensor head that is a part of Mini-Lab.

- Demonstrate and measure the ability to detect and locate metal objects buried in the digface-A 5-gal can will be placed in the soil box for use with the metal detector and magnetometer. Soil will be removed between tests to obtain a data base of sensing strength versus soil depth. The tests will be run at varying speeds and distances from the digface to generate optimum data. The tests will be repeated several times for statistical purposes. Both of these sensors are mounted in the sensor head that is a part of MiniLab.

- Demonstrate the capability and measure the accuracy of the automatic camera tracking system-This test will investigate how well the camera pan/tilt units (which are servocontrolled by the system controller) will follow the end effector of the Schilling manipulator as it is moved around within the work space.

- Assess and measure system availability-A log of system operations will be maintained. System/component failures will be logged, and the cost and time required to repair these faults will be recorded. From the data collected, a figure for system availability will be stated.

- Determine and measure the terrain following capabilities of the Shilling arm with Mini-Lab sensors attached-To obtain data that are representative of the environment, the system will deploy the sensor package over the terrain in the soil box at specified standoff distances. This will be accomplished by the installation of ultrasonic sensors to the Mini-Lab sensor head. The ultrasonic sensor head is coupled with the Schilling controller and provides for terrain following at constant distances above the terrain.

- Evaluate the control system to determine needed human factor improvements-This test will provide qualitative feedback from operations personnel relative to the "user [riendliness" of the system. This test is found in Appendix B.

\subsection{Technology Agreement}

DFC is being developed through the BWID Program and the Buried Waste Robotics Program (BWRP). The BWID Program and BWRPs are funding the demonstration, testing, and evaluation of DFC remote deployment under Technical Task Plans \#ID-1320-03 and AL-2132-02. 


\section{ORGANIZATION AND RESPONSIBILITIES}

\subsection{Organizational Responsibilities}

The DFC project manager (PM) has overall responsibilities for the project. Engineering, Geosciences, and other required support personnel receive direction from the project manager through approved work packages.

\subsection{Description of Organizations}

The DFC project is funded primarily by the BWID Program. The program is supported by the Robotics Technology Development Program and EG\&G Idaho, Inc. Geosciences personnel. A description of the BWID Program and support groups is provided below.

\subsubsection{Robotics Program}

Participants from both the INEL and SNL provide support for digface characterization. SNL is the lead laboratory for developing and providing the Mini-Lab, and the INEL is the lead laboratory for upgrading the crane and performing the demonstration.

\subsubsection{Buried Waste Integrated Demonstration Program}

The mission of the BWID Program is to demonstrate and evaluate technologies that are potentially faster, better, cheaper, and/or safer for restoring buried waste sites. BWID provided funding for this demonstration, test, and evaluation to show the capabilities of a remotely controlled system to safely characterize buried wastes.

BWID is supported by various functional organizations within EG\&G Idaho, Inc. In particular, Geosciences personnel support the BWID DFC project in specifying and testing of the sensor head package. ${ }^{1}$ In addition, Geosciences is supporting the testing of the sensors using the gantry crane and Schilling arm. Data reduction and interpretation of data will be provided by Geosciences personnel.

\subsection{Personnel Support}

This section covers personnel support for the tests at the NBRC. At the INEL, a BWID NFC PM will have the overall responsibility in decision making during the demonstration. If a safety concern arises, the DFC PM and safety engineer will decide how to solve the problem or terminate testing. If the DFC tests at the INEL take longer than planned, the PM will have the authority to delay or defer testing as necessary to balance overall project objectives.

Equipment operators will be supplied by the INEL BWRP. Their main responsibilities will be to operate the equipment from the control station and monitor the data displays.

The Idaho Research Center (IRC) emergency response team will be responsible for responding to any emergencies related or unrelated to the DFC tests at the NBRC. The INEL DFC Robotics demonstration PM will be responsible for ensuring that all of the appropriate tests are conducted in 
accordance with the procedures identified in this test plan. The PM will also coordinate activities to ensure that data logbooks are completed and stored properly, test changes, and photography and video production. The INEL DFC PM will coordinate any activities associated with maintenance of the gantry crane, Schilling arm, and control station.

The SNL Robotics PM will coordinate any activities associated with maintenance of Mini-Lab. The SNL Robotics PM will also be responsible for evaluating the data received during start-up of the DFC testing to verify that no obvious problems in the system have been incurred during set-up.

The main personnel supporting this task are listed below.

$\begin{array}{lll}\text { George Schneider } & \text { DOE-ID } & \text { DOE ID DFC PM } \\ \text { Aran Armstrong } & \text { DOE-ID } & \text { BWID Oversight } \\ \text { Kevin Kostelnik } & \text { INEL } & \text { BWID Integrated Demonstration Coordinator } \\ \text { Richard Callow } & \text { INEL } & \text { BWID DFC PM } \\ \text { Reva Hyde } & \text { INEL } & \text { Robotics PM } \\ \text { Kevin Croft } & \text { INEL } & \text { DFC Robotics Demonstration PM } \\ \text { Scott Allen } & \text { INEL } & \text { Robotics support } \\ \text { Nick Josten } & \text { INEL } & \text { Geosciences support } \\ \text { John Feddema } & \text { SNL } & \text { Robotics PM } \\ \text { Peter Boissiere } & \text { SNL } & \text { Robotics support }\end{array}$

\subsection{Testing Responsibilities}

The responsibilities of the personnel involved in the testing of DFC are listed below.

- SNL test responsibilities-The manager at SNL is responsible for the following test:

- Installation of Mini-Lab in accordance with the objectives specified in Section 1.3 in the NBRC environment.

- INEL test responsibilities-The program responsibilities are

- Determine the precision and accuracy in locating waste

- Assess the ability to detect and locate radioactive and hazardous chemical hot spots

- Assess the response time and cost to characterize the simulated waste (time per area and cost per area)

- Assess system availability

- Determine the terrain following capabilities of the system

- Evaluate the control system

- Evaluate the camera system 
- Evaluate the gantry crane

- Evaluate the Schilling arm

- Coordinate audits

- Media interfaces (through BWID)

The Geosciences responsibilities are

- Evaluate the sensors

- Evaluate the data and results

- Evaluate Mini-Lab.

- Data interpretation and evaluation-Interpretation and evaluation of the data taken during testing will be the responsibility of the personnel most familiar with the equipment, as listed below. Data interpretation will be explained and discussed in the Technology Evaluation Report.

- Sensors (Geosciences)

- Mini-Lab (SNL)

- Gantry crane (Robotics Program)

- Schilling arm (Robotics Program).

\subsection{Qualifications and Training Required}

All personnel operating equipment will be properly trained. This includes Incidental Crane Operating Training (Hoisting/Rigging) and control system vendor training.

Persons handling radioactive and/or chemical sources shall be properly trained and certified for that function. 


\section{DESCRIPTION OF TESTS}

Tests on the DFC prototypical deployment system will be performed at the NBRC. The testing will focus on seven separate efforts. These efforts will be to test the geophysical sensors, determine gantry speed capability, determine gantry repeatability, investigate manipulator speed capability and repeatability, and evaluate the Mini-Lab. The tests are designed to run independently of other testing, and therefore, no specific order is required. Tests will be repeated as necessary to acquire meaningful data. General descriptions of each test are given below; test procedures are included in Appendix B. Test results will be provided in a technology evaluation report.

\subsection{System Tests}

All testing of the DFC prototypical deployment system will support system test objectives. Test procedures are included in Appendix B. The DFC gantry tests, including data reduction and conclusions, shall address the system test objectives as listed below:

- Determine the precision and accuracy of instrument placement by the DFC gantry system

This test will determine the ability of the robotics system to effectively deploy the MiniLab sensor package and acquire data that are sulficient to determine waste location. Target materials will be strategically placed in the soil box to support the testing. A 5-gal container will be placed inside for use with the metal detector and magnetometer. Soil will be removed between tests to obtain a data base of sensing strength versus soil depth. A volatile organic compound /nonhazardous and National Environmental Policy Act (NEPA) approved] will be strategically placed into the waste box to be used with the specific gas sensor, and a gamma source will be strategically located in the waste box to be used with the gamma sensor.

- Assess the ability to detect and locate radioactive and hazardous chemical hot spots

The system's ability to detect and locate any radioactive and/or hazardous chemical hot spots will be determined by putting retrievable chemical and radioactive sources down the tubes located in the box containing the simulated buried waste. The DFC prototypical deployment system would then survey the box containing the simulated waste. The system's performance in meeting this objective depends on the chemical sensor, radiation detector, gantry crane, Schilling arm, data communications, and control system.

- Assess the response time to characterize the simulated waste

To assess the time to characterize the simulated waste, an average time to survey the specified area will be calculated from multiple surveys. The speed the crane travels will be documented. To assess the cost to characterize an area of this size, several items will be considered, including but not limited to operating costs, maintenance costs, capital costs, and remedial action costs. 
- Assess the system availability

The most important result of this test is to provide useful information so that this system can be evaluated for use as a part of a remedial alternative. The input to Environmental Restoration will be the Technology Evaluation Report. Environmental Restoration will also have access to BWID's data base that will house all project information. Section 6.1.1 discusses what information will be inserted into the BWID data base. This project is in its infancy and is planned for continued funding and development improvements in subsequent fiscal years. Therefore, the Technology Evaluation Report will document the status of digface characterization as of this fiscal year, give results for the current system. and provide suggestions for improvements.

- Determine the terrain following capabilities of the system

The ability of the control system to deploy the manipulator over the digface and using the ultrasonic sensors to provide for constant distance following of the terrain will be the focus of this test.

- Evaluate the control system to determine necded human factor improvements

This will be a cursory evaluation to examine the "friendliness" of the system operating interfaces. This procedure is outlined in Appendix B.

- Adequacy of the automatic tracking capability

This test will investigate how well the camera pan/tilt units will follow the end effector of the Schilling arm as it is moved around within the workspace.

- Evaluate the ability to detect and locate metal objects buried in the digface

A 5-gal can will be placed in the soil box for use with the metal detector and magnetometer. Soil will be removed between teats to obtain a data base of sensing strength versus soil depth. The tests will be run at varying speeds and distances from the digface to generate optimum data. The tests will be repeated several times for statistical purposes. Both of these sensors are mounted in the sensor head that is part of Mini-Lab.

\subsection{Uncertainty Analyses}

Uncertainty analyses will te performed for measurements and tests relating to the DFC prototypical deployment system tests requested by BWID. Results will be documented in the Technology Evaluation Report.

Two quantitative performance characteristics of a measurement system are precision and accuracy, and these both will be determined, either experimentally or by engineering judgment. They will be given for systems that affect any of the system test objectives discussed in Section 3.1. Precision and accuracy parameters will be developed for the system. 
The precision and accuracy of the measurement system will be estimated from test measurements, and both a best estimate and a $95 \%$ confidence interval will be given for precision and accuracy. In the event that a particular test is invalid for some reason or the data are lost, best engineering judgement will be used to determine precision and accuracy of the system. This will be documented in the final report.

\subsection{Contingency Plan}

Tests will be discontinued in the event of adverse conditions that seriously affect testing (e.g., spills and fires), an equipment failure or an accident or emergency at the testing site. The INEL DFC Robotics Demonstration PM and the BWID DFC PM will evaluate the situation to determine the most appropriate method to meet the test objectives. In the event that testing deviates from this test plan, the test procedures will be "red-lined" in the field and initialled by the INEL DFC Robotics Demonstration PM and the BWID DFC PM and copics of these altered procedures will be provided to BWID within 2 weeks and will become a lifetime quality record. 


\section{SEQUENCE OF ACTIVITIES}

The sequence of activities for the remote testing portion of the DFC experiments is not critical. Each test is designed to run indepe the test to be performed.

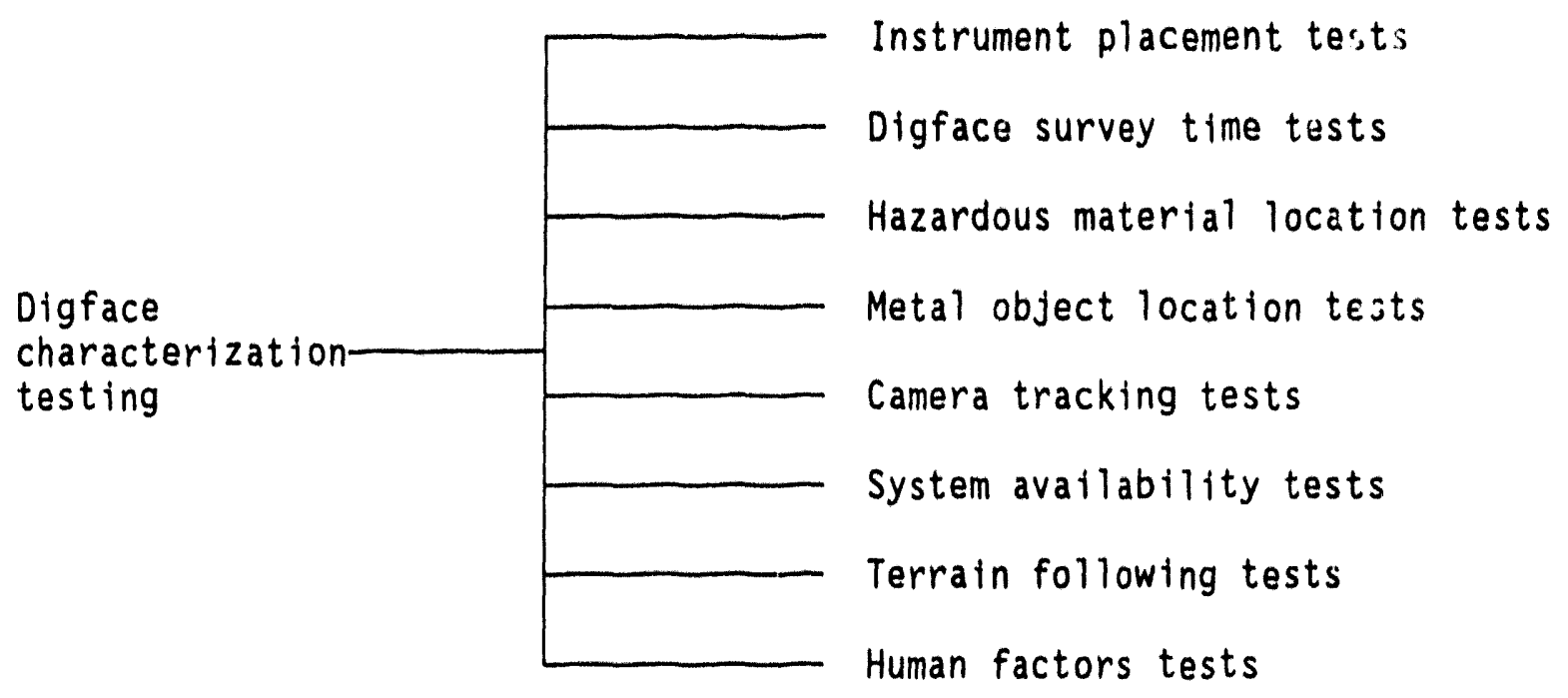

Figure 3. Testing activities. 


\section{SAMPLING AND DATA}

The data obtained from operation of the Mini-Lab system will be collecled into a data hase. archived on tape, and copied for long-term storage for BWID. The data will be scrutinized by professional personnel who are familiar with the instruments and data acquisition equipment. qualified to interpret data of this nature. In addition, the Mini-Lab system provides the capahility of providing output in forms that have already undergone a certain degrec of data reduction and interpretation. Sampling and data acequisition will be as defined in the testing procedures lound in Appendix $B$. 
The guntry system is an industry available unit that has been modified to allow for remote aperations. The mast assembly was designed and fabricated at the INEL, then interfaced with the crane at the crane manufacturer's facility. The crane has variable speed capability in each of the three axes of motion. The $x$ - and $y$-axes are designed for speeds of 0 to $30 \mathrm{ft} /$ minute. The $z$-axis has

\section{DOCUMENT CONTROL}

EO\&O Idaho procedures for document control will be followed for this project.

\subsection{Data Management}

\subsubsection{DWID Requirements}

Data will be managed in the manner that best protects the credibility of the data and is in compliance with the BWID Project Management Plan. In addition, the project shall comply to the following BWID data management policy:

1. Management of electronic data

a. The project shall define the format, acquire the data, back up the data, control the configuration of the data, technically document the data, generate processed data, and archive the data.

b. The project shall submit to BWID a copy of all configuration controlled data (raw and processed) and appropriate technical documentation acquired during the course of the demonstration testing. Project shall submit complete copies of final conliguration controlled raw and processed data with appropriate technical documentation to BWID with the final report.

2. Management of reports

a. The project shall draft reports, obtain and incorporate review comments, obtain approvals, archive, and control the configuration of data via a project Technology Demonstration File.

b. Copics of all draft reports shall be submitted to BWID. Copies of all final reports shall be submitted to BWID with an electronic copy.

3. Management of logbooks

a. Data shall be recorded in logbooks in accordance with EG\&G Idaho guidelines.

b. All logbook entries shall be photocopied at the end of each week of the demonstration, with copies delivered to BWID.

\subsubsection{Project Flle}

The project shall establish a project file that complies with all the requirements of the BWID program. The project file shall be a repository of all hard copy data (e.g., letters, reports, and engineering analysis) and electronic copy, original, and backup (e.g., data and processing software) information. The file shall have an index to configuration control file contents and facilitate locating 
items in the file. Originals shall not be released but dated copies will be available to anyone. At the end of the testing, all data records from the project file will be scanned into the BWID data base.

\subsubsection{Description of Data}

Data contained in the project file will include the Technical Task Plan, authorized work packages, any change control document requests, and other administrative documentation. In addition, the project file will contain engineering drawing, analysis, and technical communication information. Vendor information that applies to the project will be contained in the file.

\subsubsection{Video Production}

A video will be taken of the DFC demonstration at the NBRC. The purpose of the video is to document the demonstration as well as serve as a means of communicating information on the robotics tests to the media and public.

\subsubsection{Data Reporting}

To ensure that the demonstration results are reported to interested parties, the following two methods of data reporting will be used.

1. Technology Evaluation Report-The data generated by the demonstration as well as information on the planning and conductance of tests will be assembled and documented in a Technology Evaluation Report. The Technology Evaluation Report will summarize the tests, test results, and lessons learned and will provide recommendations for further development.

2. Publications-Information on the demonstrations and results will be submitted for publication to the Waste Management ' 94 Conference and other waste management or environmental restoration related journals, conferences, and meetings.

\subsection{Test Plan Changes}

Change requests to this plan may be initiated by any person participating in demonstration, test, and evaluation activities but must be approved by the DFC Robotics Demonstration PM. There will be two levels of changes as follows.

Level one changes are modifications to the configuration of this plan that will nullify previously performed verification and validation efforts. Simply stated, such a change would raise uncertainty about whether or not the same test results would be achieved if the test were repeated. Level one change requests must be clearly documented. The documentation must specify the reasons for the change, current condition, proposed condition following the change, explanation of the increased benefits versus increased costs, and secondary changes that will be necessary as a result of the primary change. Level one change requests will be reviewed and approved by the DFC Robotics Demonstration PM. The reviews and approvals will be clearly documented. Level one changes will require revalidation of the system for testing. Implementation of level one changes and revalidation of the system for testing will be under the direction of the DFC Robotics Demonstration PM. 
Level two changes are those changes to the configuration of this plan that will not nullify the verification and validation achieved during testing. Simply stated, such a change would not raise uncertainty about whether or not the same test results would be achieved if the test were repeated. Level two changes shall be clearly documented in the daily logbook and reviewed, approved, and implemented according to the appropriate operating procedures and test plan. Level two changes will not require revalidation of the system before the continuation of testing.

In the event that testing deviates from this test plan, the test procedures will be "red-lined" in the field and initialled by the INEL DFC Robotics Demonstration PM. and copies of these altered procedures will be provided to BWID within 2 weeks and will become a lifetime quality record.

\subsection{Other Documents}

Logbooks will be controlled in accordance with EG\&G Idaho procedures. All logbook entries shall be photocopied at the end of each week of the demonstration and copies delivered to BWID. 


\section{ANALYTICAL METHODS}

Data reduction algorithms are described in detail in the applicable Mini-Lab user's manual. 


\section{DATA REDUCTION, VALIDATION, AND VERIFICATION}

\subsection{Data Reduction}

Mini-Lab displays analysis of sensor data within seconds of its acquisition. The system not only provides real-time display of in situ sensor data, but it also archives and recalls data from previous sensor scans. The real-time data interpretation provided by Mini-Lab will be compared with data from both the preprocessed data and the known location of the objects in the box containing simulated waste. This work will be accomplished by individuals qualified to perform this function.

\subsection{Data Validation/Verification}

Geosciences personnel will evaluate DFC test data real-time using their experience and knowledge to verify that the test and acquired data are credible. Test results or data that are not credible will be considered a test failure, and an engineering evaluation will be made to decide if the test will be repeated, modified, or the test failure simply documented and the next test started. Data will not be accepted if they were not taken in accordance with the estahlished procedures. 


\section{QUALITY ASSURANCE}

\subsection{Data Quality Objectives}

Data will be obtained with the best available instrumentation within the stated budget of the project. Instrumentation will be calibrated as necessary and operated within the stated calibration range for the instrument.

The data quality objectives (DQOs) include reviews by the DFC PM, project engineer, SNL personnel, and Geosciences personnel to verify that data are within required specifications. Tests will run to meet quality level B requirements, and will comply to the requirements of Quality Program Plan, QPP-377.

The following discussion of the detailed DQO includes a restatement of the test objective, the DQO for that test objective, and a statement of the uncertainty for the measurements to be taken to meet the DQO with a short discussion of how each uncertainty specification was developed.

The tests will be divided into two categories: (1) system test objectives and (2) component test objectives. The nverall product will include test data on the control system, data display package (Mini-Lab), crane, and sensor deployment capabilities of the crane. The sensor package is being tested separately, in a field test environment, under Test Plan for Digface Characterization Performance Testing. ${ }^{1}$

\subsection{Test Objectives}

The DFC gantry system, is (for these tests) comprised of the three-axis gantry, Schilling Titan 7F manipulator, camera pan/tilt units, system controller, and Mini-Lab. The system tests will have the following system test objectives:

- Test Objective-Demonstrate and.measure the accuracy of instrument placement by the DFC gantry system. The overall system will be tested to determine the degree of positional accuracy obtainable using this deployment system. These tests will include the placement of sensors by the gantry, manipulator, and combined placement by both devices. Tests will be repeated several times for statistical purposes.

Data Quality Objective-Determine with a $95 \%$ confidence that the system is repeatable within $+/-1$ in.

Uncertainty- +/- $1 / 4$ in. The uncertainty is derived from the calibration of the measurement instruments and the methods use for reading those instruments.

- Test Objective-Determine the time to perform a digface survey. The system will be subjected to testing that will determine the amount of time required to setup and run an operation and the required personnel and equipment that are needed to perform the operation. The effectiveness of data collection and interpretation utilizing these methods will be addressed. 
Data Quality Objective-Determine with a 95\% confidence the time to suney a given amount of surface area.

Uncertainty- +1. 30 seconds. This uncertainty is derived using enginecring judgment.

- Test Objective-Demorstrate and measure the ability to detect and locate metal objects buried in the simulated dirface. This lest will determine the sensor package's ability to locate buried metal objects is the digface. A 5 -gal can will be placed inside the digface for use with the metal detector and magnetometer.

Data Quality Objective-Determine with a $95 \%$ confidence the location of buried metal objects within $+1.6 \mathrm{in}$.

Uncertainty- + $l$ in. This uncertainty is derived from the accuracy of the instrumentation, their calibration, and the positioning equipment.

- Test Objective-Demonstrate and measure the ability to detect and locate radionctive and hazardous chemecal hot spots. This lese will deploy gamma and gias specilic sensors aver the digface to locate materials that have been strategically locialed within the waste hox. The tests will be run at varying speeds and distances from the digfice lo gencrate optimum data. The lests will be repeated several times for statistical purposes. Both of these sensors are mounted in the sensor head that is a part of Mini-Liab.

Data Quality Objective-Determine with a 950 comfidence the location of burted materials, chemical and radioactive hot spots within $+1.6 \mathrm{in}$.

Uncertainty- + $l-l \mathrm{in}$. This uncertainty is derived from the accuracy of the instrumentation, their colibration, and the positioning equipment.

- Test Objective-Demomstrnte the capability and measure the arcuracy of the anuromatic camera tracking syistem. This lest will investigate how well the camera pan/tilt units (which are servo-controlled by the system controller) will follow the end effector of the Schilling manipulator as it is moved around within the work space.

Data Quality Objective-Determine with a $95 \%$ comfidence the accuracy of the antomatic camera tracking system to follow the end effector of the Schilling arm. Success will be 10 keep the end eflector in the eenter of the monitor picture $+/-3 \mathrm{in}$. (1/4 of the monitor's screen width).

Uncertainty $-+1.1 \mathrm{in}$. This uncertainty is derived from enginecring judgment.

- Test Objective-Assess and measure system availability. A log of system operations will be maintained. System/eomponent lailures will be logged, and the cost and time required to repair these faults will be recorded. From the data collected, a ligure for system availability will be stated. 
Data Quality Objective-Determine with a $9.5 \%$ confidence that the system availability is $99 \%$.

Uncertainty - +1. 50\% This uncertainty is derived from engincering judgment. The uncertainty is extremely high due the short duration of the lest time and that only one system will be tested. One system is not a representative sample, and life testing would require months of continuous operation.

- Test Ohjective-Determine terrain following capabilities of the Shilling arm with Mini-Lab sensors attached. To ohtain data that are representative of the environment. the system will deploy the sensor package over the terrain in the soil box at specified standolf distances. This will be accomplished by installing ultrasonic sensors to the Mini-Lab sensor head. The ultrasonic sensor head is coupled with the Schilling controller and provides for terrain following at specilied distances off of the terrain.

Data Quality Objective-Determine with a $95 \%$ confidence then the sensor head can be controlled to maintain a constant height +1.1 in. above the terrain dering a surney:

Uncertainty - +1. $/ \mathrm{in}$. This uncertainty is derived from enginecring judgment and the error involved in taking measurements.

- Test Objective-Evaluate the control system to determine needed human factor improvements. This esit will provide qualitative lecelhack from operations personnel relative (o) the "user friendliness" of the system. This lest is lound in Appendix B.

Data Quality Objective-No confidence level will be provided. The data taken will he of a subjective nature. However, the ease of operation of the system will be evaluated and reported on.

Uncertainty-Nol appliciable.

\subsection{Internal Quality Control Checks}

Internal quality control checks will be performed during and after testing. These include the INEL DFC Robotics Demonstration PM responsible for the lests reviewing eompleteness and accuracy of the loghooks, exceuting pertormance and system audits (sec Section 9.4), and checking (6) ensure that the established procedures are being followed.

\subsection{Performance and System Audits}

Periormance audits are conducted to quantitatively evaluate the output of a measurement system. System audits are eonducted to qualitatively evaluate the operational details of a quality assurance (QA) program. These audits will be conducted internally. 
A performance audit will be conducted by a QA engineer at the time of the demonstration at the NBRC. This audit will involve developing a checklist of eritical operations and determining whether the operation was completed satisfactorily. Section 9.5 discusses corrective action.

A system audit to verify that the instrument(s) are operating within expected parameters will be done before and alter the NBRC demonstration by the respective operations personnel. This information will be locumented in logbooks. In addition, a post system audit will be perlormed to determine how well the data correlates lo known data for the simulated waste box.

\subsection{Corrective Action}

If it is delermined that the data heing laken will not meet the test objectives beciluse of an equipment malfunction or other reasons, the criteria lo continue the demonstration will be based on the following:

1. If the BWID DFC PM and the INEL. DFC Robotics Demonstration PM can establish and implement a corrective action using the existing procedure and without compromising the lest ohjectives, or drastically ellecting either cost ur schedule, then they may implement the eorrective action

2. If the corrective action determined by the DFC PM and INEL. Robotics Demonstration PM does compromise the lest ohjectives, changes the existing procedures, or drastically affects cost or schedule, then the DFC PM. Robetics Demonstration PM. and $Q A$ engineser must approve of the plan heliore implementation. 


\section{EQUIPMENT AND INSTRUMENTS}

To the greatest extent possible, all instruments and equipment will be calibrated with approved calibration procedures. Before all tests, the responsible test engineer will ensure all equipment requiring calibration is within their calibration dates. Specific details (including range, accuracy, tolerance requirements, calibration procedures. a preventative maintenance schedule, and a list of critical spare parts) on all the test equipment and instrumentation is given in the manufacturer's data sheets found in Appendix C. All equipment will be locked up at night and on days it will not be required inside the NBRC. 


\section{SUPPLIES AND UTILITIES}

This section addresses the supplies, utilities, and facilities that will be required 10 demonstrate DFC at the NBRC.

Utilities are conveniently available and will supply electricity for the control systems and data collection and transfer equipment. Fire extinguishers and the IR( emergency response team will also be available during the demonstration in ciase of lire or release of hazardous mallerial (hydraulic lluid spill).

Office space, water, and lavatory liacilities are provided in the NBRC. 


\section{HEALTH AND SAFETY}

This section addresses the health and satety issues for the demonstration. All work performed at the NBRC must be reviewed and approved by the Facility Health and Safety Representative and documented in Safe Work Permits. All work will be performed in full compliance with all of the health and safety requirements for the BWID project as spelled out in the BWID Project Management Plan.

\subsection{Hazard Analysis}

The demonstration will be performed on clcan, simulated waste. A chemical and radiation source will be used in the lubes in the simulated waste box under very controlled conditions. Safety is the highest priority for operations at DOE facilities, and risks to workers must be removed to the greatest extent possible. Providing operators with the ability to control the equipment at a safe distance from the waste is the most reliable method of protecting them from the hazards mentioned above. The remotely controlled crane, then, involves less risk than conventional manned equipment and is a safer method of hazardous/radioactive waste characterization. Since safety is increased by developing remote technologies, and the demonstration will involve only very limited risk, regulatory and public acceptance of DFC is expected.

The hazard classification determined for the DFC demonstration is "routinely accepted by the public." $^{\text {"B }}$

\subsection{Employee Training}

All personnel operating equipment will be properly trained. This includes Incidental Crane Operating Training (Hoisting/Rigging) and control system vendor training. All personnel involved in the demonstrations (other than short-term visitors who must be escorted by a qualified person at all (imes) must have up-lo-date blue card training hefore receiving aceess to the NBRC and crane area.

\subsection{Protective Equipment}

Specific protective equipment will be as specificd in the testing procedus as and in the Safe Work Permits. The INEL. will provide hard hats and safety glasses, where needed (in the crane area). Safety shoes may be required for those entering the crane area but will not be available at the NBRC.

\subsection{Emergency Response Plan}

The tests will be conducted at the NBRC. The IRC emergency team will be alerted to the demonstrations and will be available in case of an accident. In the event of an emergency, the NBRC

a. R. Peatross, "Tentative Hazard Classification for Demonstration of Digface Characterization, June 1993. 
Emergency Response Plan would be followed. In the event of a spill (such as hydraulic fluid), the NBRC spill plan will be lollowed. ${ }^{b}$

b. Letter from Doug Ardry to Ron Hilker, "ERAD In-Town Facility Spill Control Plan," DEA-10-93. 


\section{RESIDUALS MANAGEMENT}

This section addresses residuals management. For the NBRC demonstration of DFC, a radioactive source and a nonhazardous chemical $\left({ }^{2.17} \mathrm{Cs}\right.$ and ethanol) will be used to demonstrate the radiation detector and chemical sensor on the sensor head. The radiation source is used for equipment calibration at the INEL and will be returned to storage after use. A radienclive source custodian will supply the source to the NBRC. accompany it at all times, and will be responsible for its return. The nonhazardous chemical used for the chemical sensor will be disposed of properly in a landlill after the demonstration.

The simulated waste box will be stored at the NBRC for future tests of this system as well as other systems. 


\section{REGULATORY REQUIREMENTS}

This section addresses regulatory requirements for the DFC demonstration. Since the demonstration will be performed at on simulated waste and not on actual waste the only regulatory requirement that needs to be complied with is NEPA.

\subsection{National Environmental Policy Act}

The environmental impact from this demonstration will be minimal. Characterizing the simulated waste will result only in short-term noise. The crane and noise effects are negligible. The simulated waste in the test box is nonhazardous and nonradioactive and will not have a significant impact on the environment.

An environmental checklist was submitted to BWID for these activities. For these demonstrations, BWID prepared a categorical exclusion that has been approved by DOE Idaho Operations Oflice. 


\section{REFERENCES}

1. N. Josten and L. Roybal, Test Plan for Digface Characterization Performance Testing, EG\&G Idaho, Inc., EGG-WTD-10766, May 1993. 
Appendix A

Information on Mini-Lab 
A-2

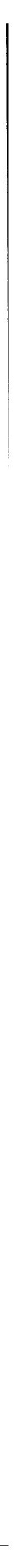


Milin: 150

1

if

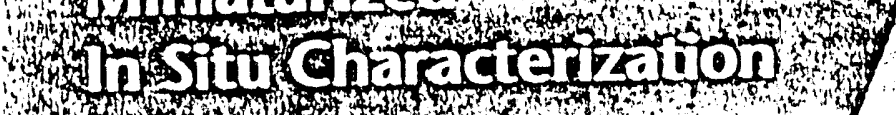

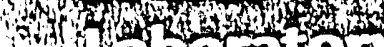

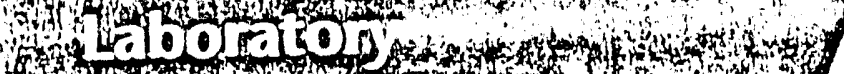

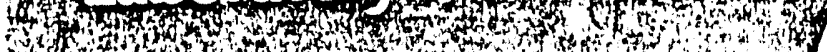

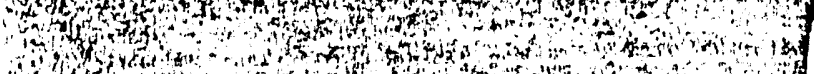

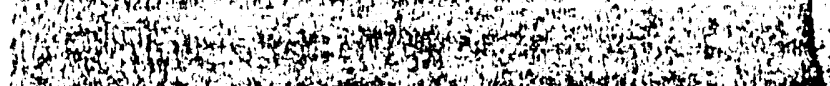

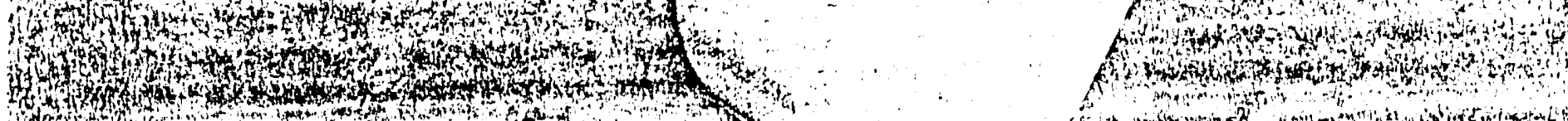

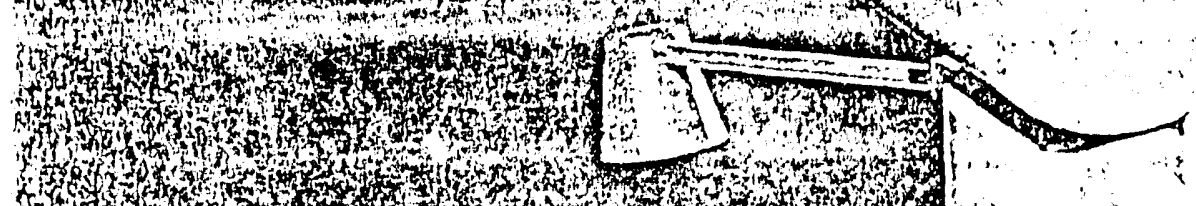

TH

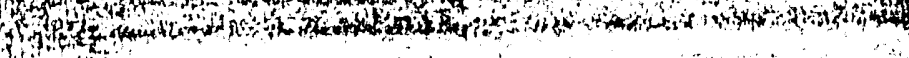

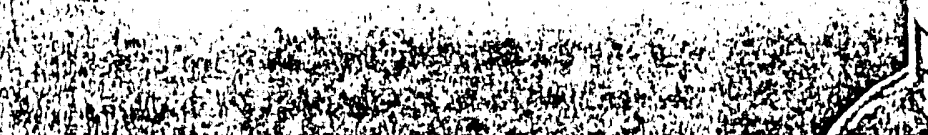

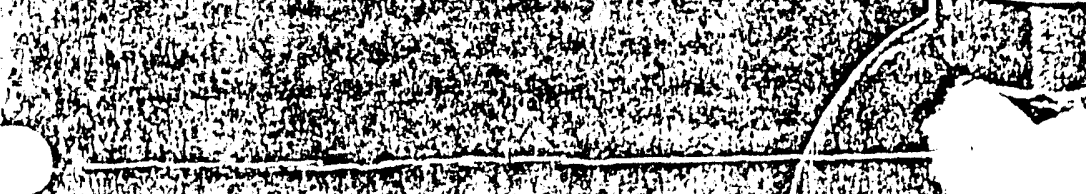

37 (n)

(3) M.

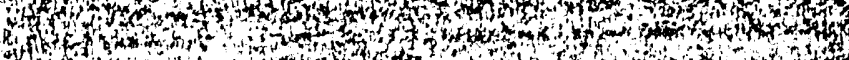

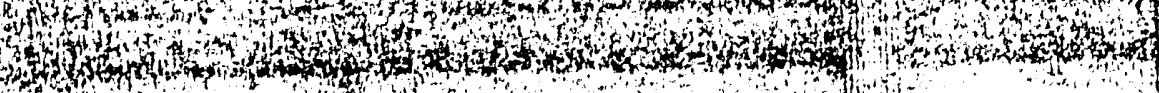

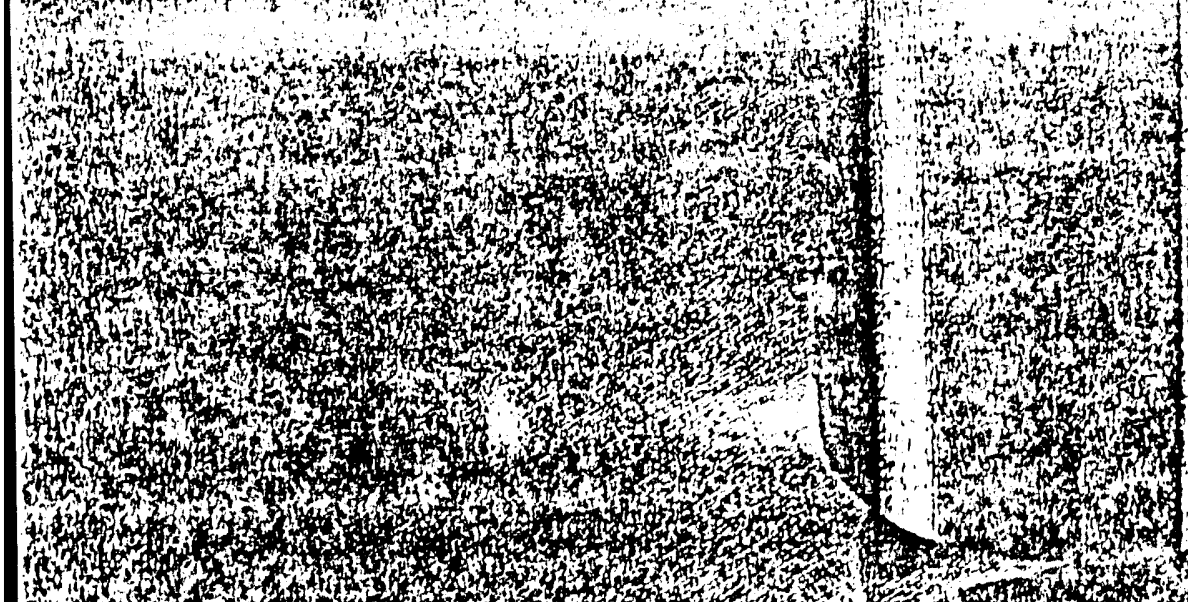

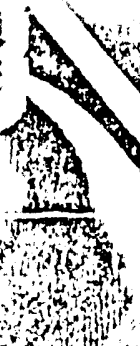

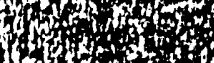


A-4

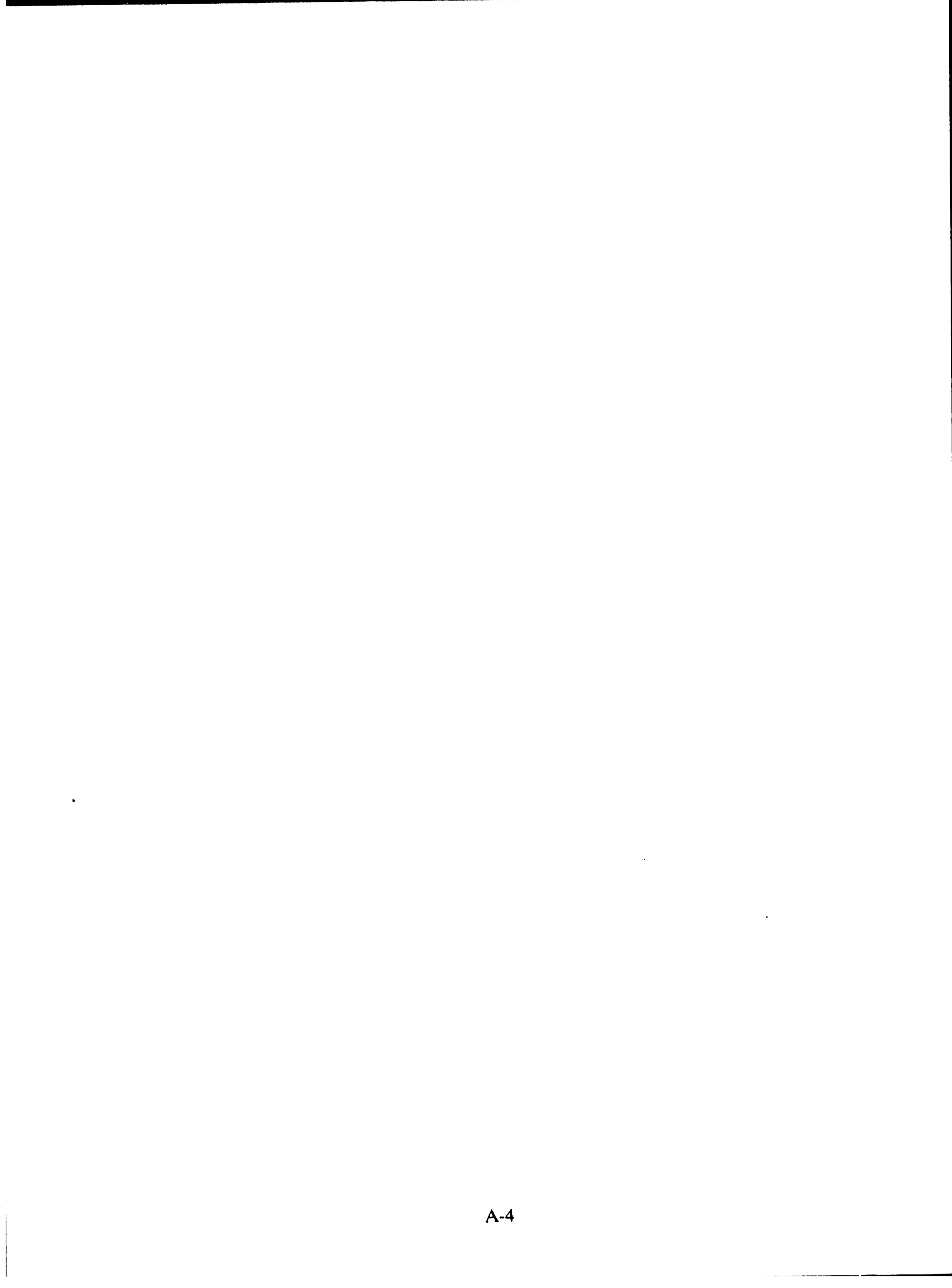




\section{Mini-Lab}

Sandia National Laboratories has developed a miniaturized in situ characterization laboratory, called Mini-Lab, for on-site analysis of hazardous materials. The focus of the Mini-Lab project is not to invent the sensors and transducers needed for characterization, but to develop a flexible software and hardware architecture for the acquisition, display, interpretation, and archival of sensor data. By creating a robust framework that can accept off-theshelf and custom sensors, characterization systems can be more rapidly and: cost-effectively deployed. An operator can quickly reconfigure the system to incorporate new or different types of sensors as the application requires.

The Need:

Mini-Lab provides a faster, safer, and cheaper way of characterizing hazardous sites than present field sampling. The sensor package can be positioned by a variety of means including robotic or teleoperated arms, mobile vehicles, or the package may be positioned over a conveyor belt with hazardous materials. This in situ method of characterization removes the operator from the hazardous environment. Applications in which Mini-Lab would be beneficial include:

- Remediation of underground storage tanks and hazardous waste landfills,

- Mapping, surveillance and reconnaissance in space and other dangerous environments,

- Waste segregation for decommissioned production facilities, and

- An emergency response tool for nuclear accidents.
As an example, present field sampling for underground rad-waste storage tanks are expensive, time-consuming, and hazardous to human health. Core sampling, a common technique used in the characterization of waste tanks, can take up to six months and can cost more than $\$ 300,000$ per sample. Additionally, there is a real risk to human health because of the large number of people exposed to the waste during the removal, transportation, analysis, and disposal of the samples. This conventional process also generates additional waste because the handling devices and instrumentation that come into contact with the samples also become contaminated and must be properly disposed of. In contrast, using Mini. Lab, operators are able to remotely analyze the waste by in-tank mapping without the risk to human health and without generating waste. Although this may not completely eliminate the need for core sampling, it could dramatically reduce the number of samples that would otherwise be required.

Mini-Lab's in situ measurements have the additional benefits of providing a much faster turnaround time than off-site lab analysis. The data can be analyzed as they are being acquired so that if additional data is required, real-time decisions can be made to repeat a sensor pass over a site or take additional readings.

\section{The Architecture:} Mini-Lab consists of three main parts:
(1) the remote sensor package, (2) the data acquisition and interface electronics, and ( 3 ) the computer base station. These parts are described below:

(1) Mini-Lab's remote sensor package is a small, lightweight, low power module that can be positioned under robotic or tele-operated control. This module is made up of a decon. taminable shell that houses the suite of chemical, radiological, and physical property sensors. The size of sensor package and type of sensors included depend on the site and application. specific needs. The design of the architecture was governed by the philosophy to make it as flexible as possible so that the users would have a "plug and play" system to quickly evaluate various sensors.

(2) The data acquisition and interface electronics hardware is needed to support the sensor package. This specially designed circuitry was developed to reduce the signal noise present when communicating with

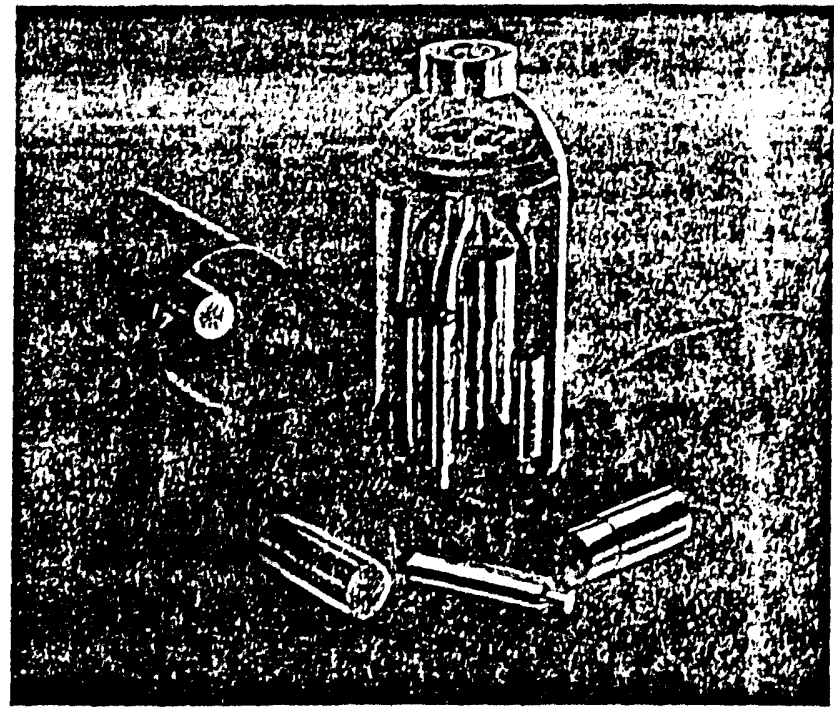

Mini-Lab Interchange Capabilities 
remotely deployed sensors in harsh environments. The design also reduces the cotal number of data lines connecting the base station with the sensor package, because additional wiring (or RF communication equipment in the case of mobile vehicles) reduces the reliability, increases the complexity for cable routing, and adds additional weight to the deployment system. The interface module for Mini-Lab consists of high bandwidth analog-10-digital converters, a multiplexer, and a synchronous serial communication board. The functionality of this module is being incorporated into an Application Specific Integrated Circuit (ASIC) 10 ensure reliable, low power operation in a compact package. The final version will be constructed using radiation-hardened micioelectronics capable of surviving in severe radiation environments.

\section{3) The computer base station is} responsible for acquiring, combining. interpreting, displaying, and archiving a wide range of sensor data. The menu-driven operator interface was designed to be a highly visual, easy-touse system that an operator can quickly undersiand and control. Softivare routines create accurate and reliable statistical analysis of sensor data within seconds of its acquisition. The computer base station provides a visual, real-time display of in situ sensor data as well as the capability to archive and recall data from previous sensor scans. The base station also contains a library of routines that add to the flexibility and speed of characterization by allowing the operator to quickly change the sensor configuration and reuse hardware and software needed for the acquisition, interpretation, display, and archival of data. Craphical programming is used for configuring the sy'iem and

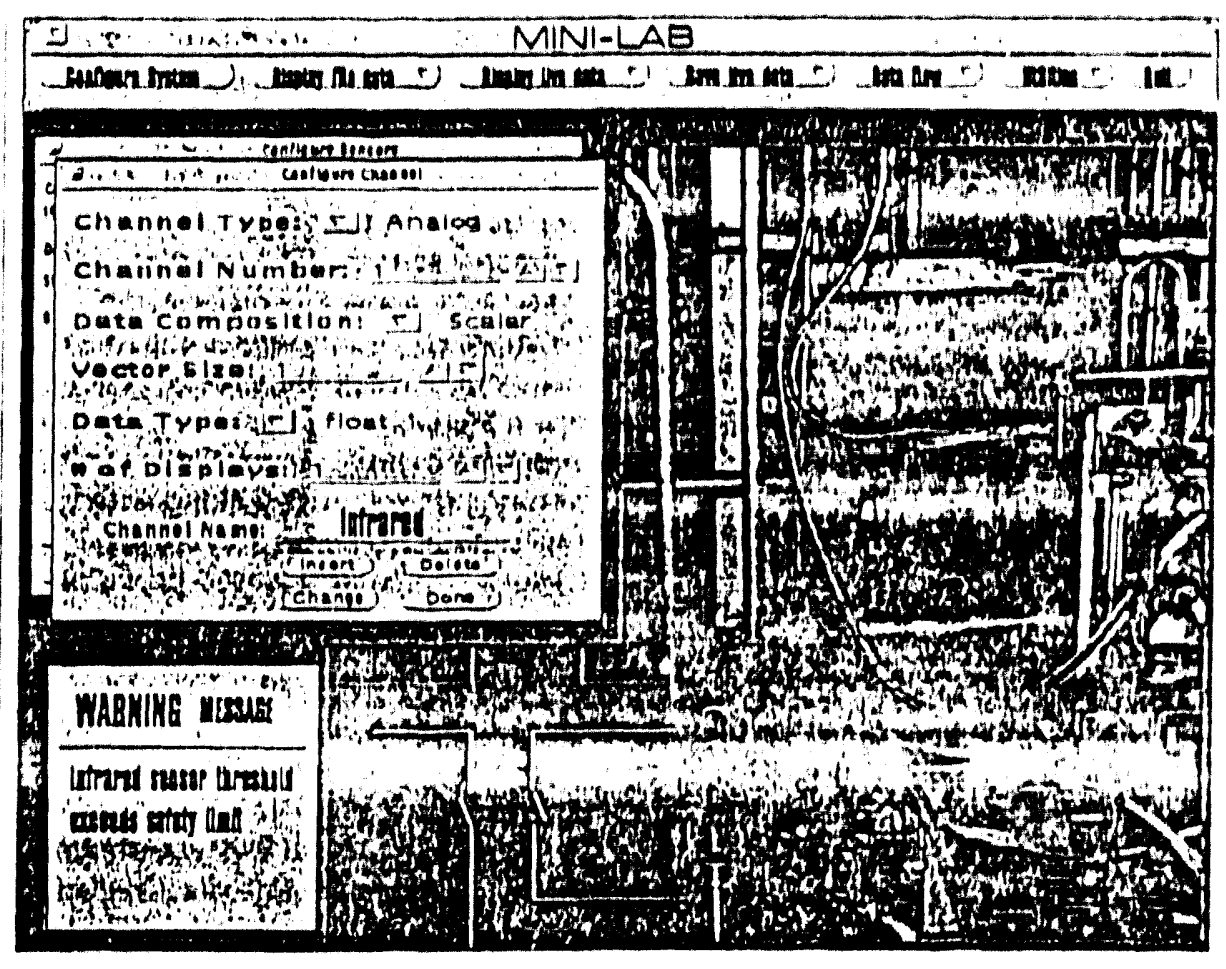

Representative sten

includes transparent volumetric rendering to aid in the viewing of complex, three-dimensional data. This design is flexible enough so that the same base station can be reused for many different types of waste characterization applications.

As an example of Mini-Lab's data combination and display leatures, the image above shows a representative screen that can be generated. The picture shows a black and white image from a TV camera with a color overlay from another sensor such as infrared (IR) camera. By having a color overlay from the IR camera on the $N$ image, the operator can clearly sce the intensity of temperature differences and, more importantly, exactly where these "hot spots" occur. This leature would also be valuable in remediation of waste sites for segregating different radioactive, toxic, or explosive materials from other nonharardous waste. A dramatic cost reductirn can be realized by segregating waste streams because of the high cost associated with the disposal of mired hazardous waste. The representative gcreen above also show; the monu.

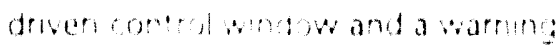
screen that alerts and directs the operator in case of emergencies. To assist the operator in teepung tract of the location of the remote sensor package, a special window inset in the lower, left side of the screen shows the location of the sensor package and or robotic vehicle on a blueprint of the building layout. The base computer can automatically compute the movement of the sensor pactagn, calculate its position in the building coordinate frame and display if 10 the operator. 


\section{Unique Features:}

Mini-Lab provides features that enhance and improve the characterization effort:

- Faster: Automated generation of site maps detailing tr e location of chemical, radiological, and physical constituents in real. time.

- Safer: Early warning system: ability to detect and react to hazardous conditions prompted by data collection and interpretation system.

- Cheaper: Less expensive than traditional sampling techniques and dramatic reduction in new waste generated.

- Better: Provides higher resolution data for more arcurate characterization by performing repeated scans in areas of interest.

\section{Current status:}

Dunng FY91, Sandia National Laboratones developed and demonstrated the first generation Mini-lab for in situ waste characterization of chemical and radiological constituents. This first laboratory prototype contains eight sensors: a gas chromatograph. garnma spectrometer, and broddband gamma, oxygen, hydrogen, temperature, pressure, and humidity sensors. The resulting sensing system was scanned over a mockup of a waste storage tank by a gantry style robot. While the robot arm scanned the sensing package over the waste, a distributed computing system acquired sensor data, correlated the data with the position of the robot, and produced maps of the chemical and radiological contents of the mockup tank in real-lime.

During FYo2, Sandia worked on improvements to the Mini-Lab. Based on perceived LOE site needs. additional sensor: were intagrated into the system. Sandiv incorporated a miniaturized peneltometer capable of measuring viscous properties of sludge. type materials. Alin, a Sandia developed sensor for measuring volatile organic compounds was added along with improved humidity and hydrogan sensors. A capacitive based proximity sensor was added to guide the robot a fixed distance away from the waste surface.

For Fy93, plans are to integrate prototypes of Mini-Lab into a variety of other projects including remediation efforts for buried waste sites, inspection and inventory of radioactive storage vaults, and an expleration tool for a planetary rover.

The Department of Energy is remediating it's sites around the country which are environmentally contaminated. Currently, waste site characterization is extremely time. consuming and expensive. Miniliab represents an advanced lechnology soluten that will makes :he characterization of hazardous waste sites proceed laster, safer, and cheape: than conventional methods. Mini.Lab was developed by DOE's Office of Technology Development as part of the Robotics Technology Development Program. This work is being pertormed at Sandia by the staff in the Intelligent Systems and Robotics Center. For more inforrnation, contact:

$$
\begin{array}{ll}
\text { Perry Molley } & (505) 844.2627 \\
\text { lohn Feddema } & (505) 844.0827
\end{array}
$$
laboratories

Department of Energy 


\section{Appendix B}

\section{Engineering Test Sequences}

B. 1 



\section{CONTENTS}

B-1. GEOPHYSICAL SENSOR TESTS $\ldots \ldots \ldots \ldots \ldots \ldots \ldots \ldots \ldots \ldots$ B-5

B.1.1 References ................................. B.5

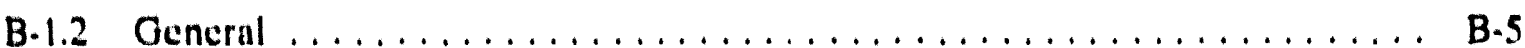

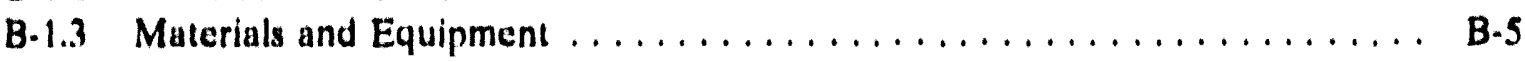

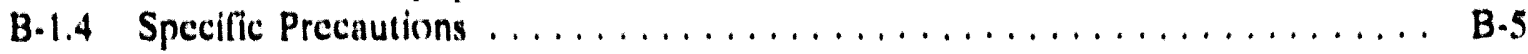

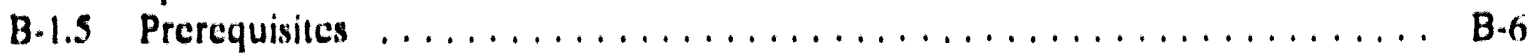

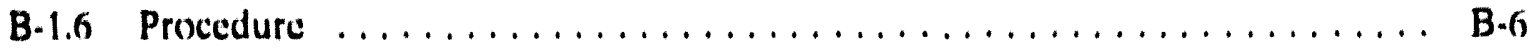

B.2. SYSTEM SPEED CAPABILITY $\ldots \ldots \ldots \ldots \ldots \ldots \ldots \ldots \ldots \ldots \ldots \ldots \ldots \ldots$. . . . . . .

B.2.1 References ................................ B.9

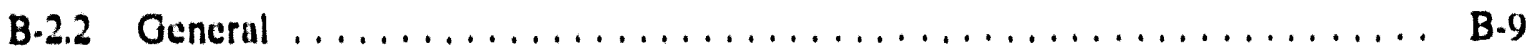

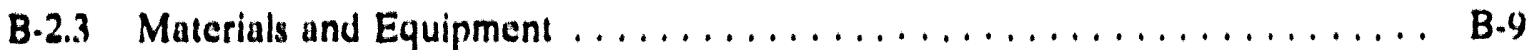

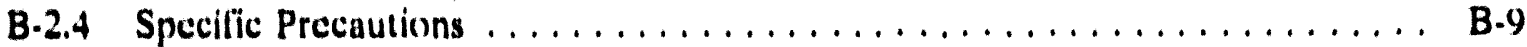

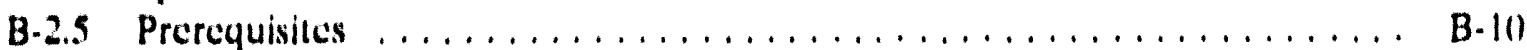

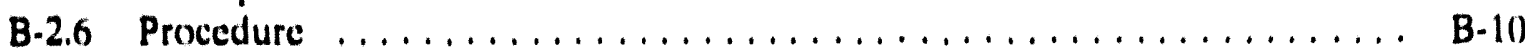

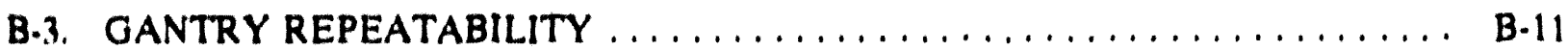

B.3.1 References . . . . . . . . . . . . . . . . . . . . . . . . . B.11

B.3.2 Gencral .................................

B.3.3 Matcrials and Equipment ...........................

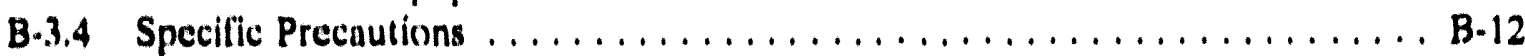

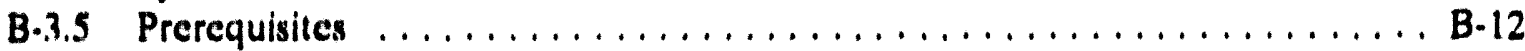

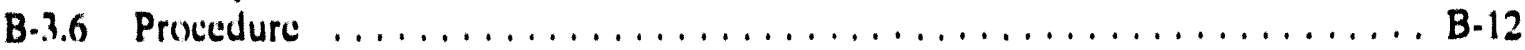

B.4. MANIPULATOR SPEED CAPABILITY $\ldots \ldots \ldots \ldots \ldots \ldots \ldots \ldots \ldots \ldots \ldots$

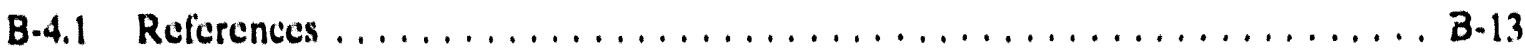

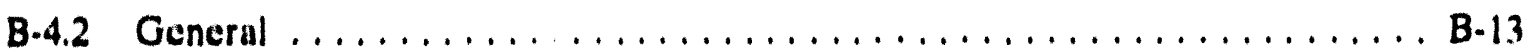

B.4.3 Materials and Equipment $\ldots \ldots \ldots \ldots \ldots \ldots \ldots \ldots \ldots \ldots \ldots \ldots \ldots$

B.4.4 Specific Precautions ............................. B.14

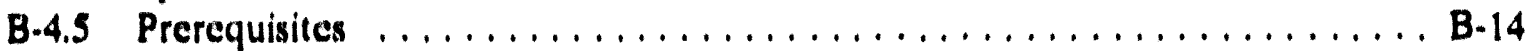

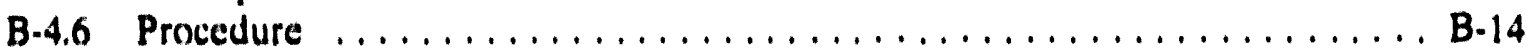

B.5. MANIPULATOR REPEATABILITY $\ldots \ldots \ldots \ldots \ldots \ldots \ldots \ldots \ldots \ldots \ldots$

B-5.1 References ................................. B-16

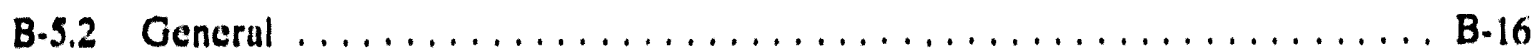

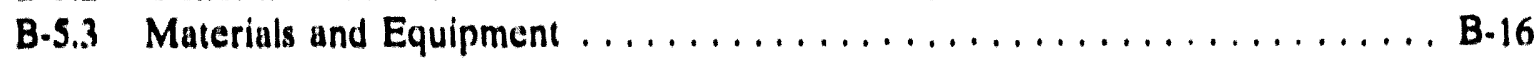

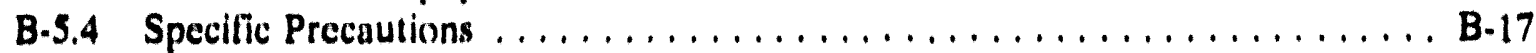

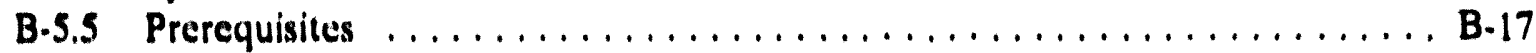

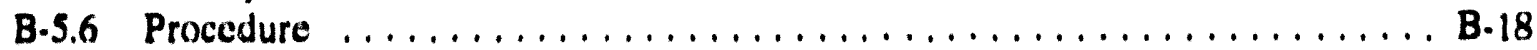


B-6.1 References . . . . . . . . . . . . . . . . . . . . . . . . . . . . . . . B-19

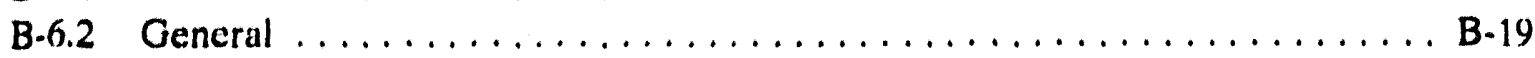

B-6.3 Materials and Equipment $\ldots \ldots \ldots \ldots \ldots \ldots \ldots \ldots \ldots \ldots \ldots \ldots, \ldots \ldots \ldots$

B-6.4 Specific Precautions $\ldots \ldots \ldots \ldots \ldots \ldots \ldots \ldots \ldots \ldots \ldots \ldots \ldots \ldots \ldots \ldots \ldots, 19$

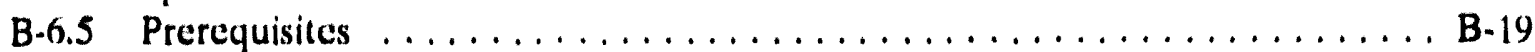

B.6.6 Procedure $\ldots \ldots \ldots \ldots \ldots \ldots \ldots \ldots \ldots \ldots \ldots \ldots \ldots, \ldots, \ldots \ldots \ldots$

B-7. HUMAN FACTORS EVALUATION OF THE CONTROL SYSTEM $\ldots \ldots \ldots \ldots$ B-20

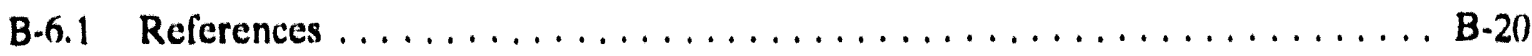

B-6.2 General $\ldots \ldots \ldots \ldots \ldots \ldots \ldots \ldots \ldots \ldots \ldots \ldots \ldots \ldots \ldots \ldots \ldots \ldots \ldots \ldots \ldots, 21$

B-6.3 Materials and Equipment $\ldots \ldots \ldots \ldots \ldots \ldots \ldots \ldots \ldots \ldots \ldots \ldots \ldots \ldots \ldots \ldots, 22$

B-6.4 Specific Precautions $\ldots \ldots \ldots \ldots \ldots \ldots \ldots \ldots \ldots \ldots \ldots \ldots \ldots \ldots \ldots \ldots \ldots, 22$

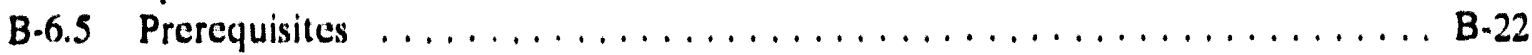

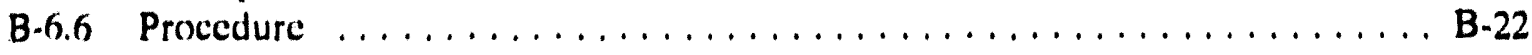




\section{B-1. GEOPHYSICAL SENSOR TESTS}

\section{B-1.1 References}

None.

\section{B-1.2 General}

The purpose of this test sequence is to evaluate the geophysical sensors that are mounted on the crane to determine their capability to indicate the presence of hazardous materials buried in the digface. Vendor data sheets for the sensors used in this test are shown in Appendix $C$.

1. The tests will evaluate the following performance lactors:

A series of tests to evaluate these factors is oullined below. Tests will be performed at the North Boulevard Robotics Center (NBRC); however, it is intended that most of the basic operating characteristics of the geophysical sensors will be defined and documented belore the test/demonstration. This will permit activities at the NBRC to be focused on deploying the sensors and on collecting the site-specilic survey data needed (1) evaluate the ability to detect and map (locate) the simulated wastes.

\section{B-1.3 Materlals and Equipment}

The following materials and equipment will be required to perform the tosts outlined above and described below.

- 1 lab notcbook

- Gantry crane

- Schilling arm

- Mini-Lab

\section{B-1.4 Speciflc Precautions}

The operation of the geophysical sensors on the crane present no direct risks to personnel or equipment and require no particular precautions during tests or other activities. However. precautions will be taken to eliminate the minor risks that are associated with the operation of the large equipment such as the cranc. It will be standard operating procedure to ensure that crane movement is not initiated until all nearby personnel are in a safe position and are aware of the planned mancuvers. 


\section{B-1.5 Prerequisites}

Perform pretest briefings before the initiation of testing sequences, as required by the testing engineer. These briefings will outline the scope and objectives of the tests and review the procedures.

Step 1. Personnel Qualifications

It is expected that these tests will be performed by engineers and scientists who are familiar with the crane and the geophysical sensors. The operation of the geophysical sensors during the tests, processing of the recorded test data, analysis of the data, and evaluation of the performance of the sensors and their platform (crane) will be by the Buried Waste Robotics Program and EG\&G Idaho, Inc. Geosciences.

Step 2. Facilities/Utilitics

No utilities other than normal 115-V AC power are needed when the crane is operated by means of the controller. All crane tests will be performed at the NBRC.

\section{B-1.6 Procedure}

Step 1. Preliminary actions. These preliminary actions shall be performed to guarantee the proper test set up and that all equipment and the test area is ready and functional. The performance of these actions will be noted in the logbook. Before operating the crane and its sensors for test purposes, the following preliminary actions will be taken:

Step 1.1 Verify that all pertinent mechanical and electrical mountings and connections are secure.

Step 1.2 Verify that the required electrical power supply voltages are present.

Step 1.3 Verify that the video cameras and displays are operational.

Step 1.4 Verify that the Emergency Stops are functional.

Step 1.5 Ensure that the test area is clear of other equipment that could damage the crane and/or sensors or be damaged by it.

Step 1.6 Ensure that the test area is clear of nonessential personnel and that nearby personnel are cognizant of the crane's operation and safety precautions associated with it.

Step 2. Evaluate the effects of terrain following on the sensors. Data will be collected every 6 in. 
Step 2.1 Perform a test using a camera to evaluate terrain following without any sensors attached. The video will be considered the data, but 1 -in. lines behind the terrain should indicate the crane's ability to follow the terrain.

Step 2.2 Attach the sensor head to the arm. The only sensor that needs to be "on" is the volatile organic compound (VOC) sensor.

Step 2.3 Move the arm with the sensor head horizontally over the simulated waste box, i.e., at a constant height. Repeat this step so that it is performed twice.

Step 2.4 Move the arm so that the sensors follow the terrain with a 6-in. offset. Repeat this step so that it is performed twice.

Step 2.5 Move the arm so that the sensors follow the terrain with a 3-in. offset. Repeat this step so that it is performed twice.

Step 2.6 Move the arm such that the sensors follow the terrain with a 1-in. offset (if the results of Step 2.1 indicate that this is a safe distance for the equipment). If this is not a safe distance, redline this procedure to indicate at what distance (as close as possible while maintaining safety) the test was performed. Repeat this step so that it is performed twice.

Step 2.7 Evaluate the results from Steps 2.4-2.6 to determine the furthest offset distance that gives sufficient results. Move the crane so that the sensors follow the terrain at this offset at four different speeds. Each speed should be repeated so that two separate measurements are taken. The first speed will consist of moving the crane to each data collection point (every 6 in.), stopping the crane, and then collecting the data. The other speeds will vary but will all be continuous. The speeds to be tested are $25,50,75$, and $100 \%$ of maximum speed.

Step 3. Evaluate the interference of the crane on the sensors.

Step 3.1 Remove dirt from the simulated waste box so that the dirt is level and 3 $\mathrm{ft}$ deep.

Step 3.2 The following sensors should be attached to the sensor head and mounted on the arm: electromagnetometer (EM), VOC, and gamma-ray.

Step 3.3 At a distance of 6 in. above the dirt, take data in an $x-y$ grid of $6 \times 6$ in. in a serpentine manner.

Step 3.4 Change the sensor head so that the magnetometer is the only sensor "on." Data should be taken in the same $6 \times 6$-in. grid as Step 3.3.

Step 3.5 Remove 6 in. of dirt depth from the simulated waste box. 
Step 3.6 Still using the magnetometer, take data 6 in. above the dirt level in the same manner as Step 3.3.

Step 3.7 Change the sensor head so that the EM, VOC, and gamma-ray sensors are "on." Take data 6 in. above the dirt level in the same manner as Step 3.3.

Step 3.8 Remove 6 in. of dirt depth from the simulated waste box.

Step 3.9 Still using the EM, VOC, and gamma-ray sensors, take data 6 in. above the dirt level in the same manner as Step 3.3.

Step 3.10 Evaluate the gamma-ray sensor data results based on 25, 50, 75, and $100 \%$ maximum speed capability of the system.

Step 3.11 Change the sensor head so that the magnetometer is the only sensor "on." Take data 6 in. above the dirt level in the same manner as Step 3.3.

Step 4. Evaluate the sensor head for electromagnetic interference.

Step 4.1 The sensor head should be changed so that the magnetometer and EM are "on."

Step 4.2 Fix the Schilling arm, but allow that crane to move. Take data on a $1 \times$ $1 \times 1-\mathrm{ft}$ grid in the crane envelope. The closest the sensor head should get to the floor is 3 in.

Step 4.3 Fix the crane, but allow the Shilling arm to move. Take data on a $1 \times$ $1 \times 1-\mathrm{ft}$ grid in the arm envelope. The closest the sensor head should get to the floor is 3 in.

Step 4.4 Based on the results of Steps 4.2 and 4.3, predict what the crane and arm interference will be at five random locations within the crane/arm operational envelope.

Step 4.5 At the five separate locations of Step 4.4, in the crane and arm envelope, take measurements in a $3 \times 3 \times 3$ - $\mathrm{ft}$ grid. The pitch of the Schilling arm should be varied.

Step 4.5 Evaluate the recorded sensor data for the effects of EM interference. 


\section{B-2. SYSTEM SPEED CAPABILITY}

\section{B-2.1 References}

None.

\section{B-2.2 General}

The purpose of this test is to assess the operating speed range of the gantry system. To understand the ability of the system to deploy sensors and equipment at varying rates (based on the particular device being deployed), knowledge of the variable speed capability of the system is required.

The overall objective of the study is to perform testing to be able to generate a system speed curve that defines the boundaries of speed capability for the equipment. Specific objectives of the study will be to determine (axis-by-axis) the speed capability of the gantry system.

\section{B-2.3 Materials and Equipment}

The following materials and equipment will be required to perform the tests outlined above and described below.

- 1 lab notebook

- Predesigned data tables for data collection

- 2 black pens

- Stop watch

- $\quad$ Tape measure (25 fi)

- Gantry system

- 1 equipment opcrator

- 1 person for obtaining measurements

- 1 person for recording measurements

- 1 video recording system for recording of tests.

\section{B-2.4 Specific Precautions}

During testing, access to the operational envelope of the gantry will be physically restricted by labeled barriers. ACCESS TO THE RESTRICTED AREA WILL NOT BE PERMITTED WITHOUT FIRST SECURING THE SYSTEM ELECTRONIC POWER SUPPLIES. 


\section{B-2.5 Prerequisites}

Perform pretest briefings before the initiation of testing sequences as required by the testing engineer. These briefings will outline the scope and objectives of the tests and review the procedures.

\section{B-2.6 Procedure}

The following provides the procedures for determining the variable speed capability of the gantry system. Anytime one of the steps refers to recording data, an entry to the logbook will be made.

Step 1. Collect all materials, procedures, and equipment required to perform the testing. Notify personnel and perform pretest briefings.

Step 2. For each of the three axes of motion on the gantry $(x, y$, and $z)$, determine the middle travel range which occupies $60 \%$ of the operating length for that axis. Legibly and permanently mark each stationary extreme (leaving $20 \%$ on each end of travel). This $20 \%$ on either end will allow for achieving constant speed for the test measurements.

Step 3. Install indicating devices (pointers, arrows, etc.) at the midpoint of each translating axis of motion to provide indication for the timekeeper when the travel extremes have been met.

Step 4. The following tests will be run to determine the speed rangeability of the gantry $x$-axis:

$X$-axis: From home position, run the $x$-axis at the following speed increments (percent of full speed) and time and record the movement between points established in Step 3 above:

$25 \%, 50 \%, 75 \%, 100 \%$

Repeat each incremental test five times.

Step 5. The following tests will be run to determine the speed rangeability of the gantry y-axis:

Y-axis: Repeat the procedure of Step 4, for the y-axis.

Step 6. The following tests will be run to determine the speed rangeability of the gantry z-axis.

Z-axis: Repeat the procedure of Step 4, for the z-axis. 
Step 7. Average the data collected for each axis of motion and plot independent curves (distance versus time) on a graph within the logbook.

\section{B-3. GANTRY REPEATABILITY}

\section{B-3.1 References}

None.

\section{B-3.2 General}

The purpose of this test is to assess the repeatability of the gantry system. To understand the ability of the system to deploy sensors and equipment, determination of the systems ability to repeat positioning is very important.

The overall objective of the study is to perform gantry testing to be able to generate repeatability data for each axis of motion. This information will reinforce confidence that the locational information being gathered, during the experiments, is sufficient to accurately characterize the area being scrutinized.

Specific objectives of the test will be to perform repeatability tests for each axis of motion of the gantry. The tests will be performed independently of each other and tabulated in the logbook.

\section{B-3.3 Materials and Equipment}

The following materials and equipment will be required to perform the tests outlined above and described below.

- 1 lab notebook

- Predesigned data tables for data collection

- 2 black pens

- 2 Dial indicator, 3-in. (spring loaded)

- Various clamps (up to 4-in.)

- 1 roll duct tape

- 1 target plate

- $\quad$ Tape measure $(25 \mathrm{ft})$

- Gantry system

- 1 equipment operator 
- 1 person for obtaining measurements

- 1 person for recording measurements

- 1 video recording system for recording of tests.

\section{B-3.4 Speciflc Precautions}

During testing, access to the operational envelope of the gantry will be physically restricted by labeled barricrs. ACCESS TO THE RESTRICTED AREA WILL NOT BE PERMITTED WITHOUT FIRST SECURING THE SYSTEM ELECTRONIC POWER SUPPLIES.

\section{B-3.5 Prerequisites}

Perform pretest briefings before the initiation of testing sequences, as required by the testing engineer. These briefings will outline the scope and objectives of the tests and review the procedures.

\section{B-3.6 Procedure}

The following tests will determine the repeatability of each axis of the gantry system. The testing will be performed for each individual axis of motion ( $x, y$, and $z$ ). Anytime a step indicates recording of data, entries will be made into the logbook.

Step 1. Collect all materials, procedures, and equipment required to perform the testing. Notify personnel and perform pretest briefings.

Step 2. For each of the three axes of motion on the gantry ( $x, y$, and $z)$, determine the "HOME" position and permanently mark on both the stationary and translating member of that axis such that when the axis is at "HOME" the two marks line up.

Step 3. The following tests will be run to determine the repeatability of the gantry $x$-axis.

$X$-axis: Install the dial indicators on the $\mathrm{x}$-axis at locations where they will not become damaged, but yet be able to engage strategically placed targets at "HOME" and along the axis of concern.

Establish a dial gage target at the following locations, perform five repeated tests on each target, before moving to the next target. Record the axis, location, and measured deviations for both "HOME" and the location being tested:

Target locations $25 \%, 50 \%, 75 \%, 100 \%$ of maximum travel.

Step 4. The following tests will be run to determine the repeatability of the gantry $y$-axis.

Y-axis: Repeat the procedure of Step 3 for the $y$-axis. 
Step 5. The following tests will be run to determine the repeatability of the gantry $z$-axis.

Z-axis: Repeat the procedure of Step 3, for the z-axis.

Step 7. Plot the data as a function of deviation versus distance for each test and axis performed, on a graph within the logbook.

\section{B-4. MANIPULATOR SPEED CAPABILITY}

\section{B-4.1 References}

None.

\section{B-4.2 General}

The purpose of this test is to envelope the operating speed capability of the Schilling Titan 7F manipulator. Information obtained from this test will assist in determining the overall capabilities of the gantry system.

The overall objective of the study is to perform manipulator testing to be able to generate operating speed data for the manipulator. By determination of manipulator speed capability, system limitations may be identified.

Specific objectives of the test will be to perform speed (velocity) tests for two major axes of the system. The axes to be tested are rotation about the base (joint 1, approximately 270 degrees) and vertical lift (joint 2). The tests will be performed independently of each other and tabulated in the logbook.

\section{B-4.3 Materials and Equipment}

The following materials and equipment will be required to perform the tests outlined above and described below.

- 1 lab notcbook

- Predesigned data tables for data collection

- 2 black pens

1 target plate

- $\quad$ Tape measure $(25 \mathrm{ft})$

- Stop watch (1/100 second resolution)

- Gantry system 
- 1 equipment operator

- 1 person for obtaining measurements

- 1 person for recording measurements

- 1 video recording system for recording of tests

- 1 closed circuit television camera and monitor

- 1 camera tripod.

\section{B-4.4 Speciflc Precautions}

During testing, access to the operational envelope of the gantry will be physically restricted by labeled barriers. ACCESS TO THE RESTRICTED AREA WILL NOT BE PERMITTED WITHOUT FIRST SECURING THE SYSTEM ELECTRONIC POWER SUPPLIES.

\section{B-4.5 Prerequisites}

Perform pretest briefings before the initiation of testing sequences as required hy the testing engineer. These brielings will outline the scope and objectives of the tests and review the procedures.

\section{B-4.6 Procedure}

The following will determine the speed capahility of the two manipulator axes heing tested. The testing will be performed for each individual axis of motion. Anytime a step indicates recording of data, entrics will be made into the logbook.

Step 1. Collect all materials, procedures, and equipment required to pertorm the testing. Notify personnel and perform pretest briefings.

Step 2. Extend the manipulator to its full length, to the right extreme position of the base (joint 1), and full down (joint 2). For the two axes being considered establish a "HOME" position and permanently mark on both the stationary and translating member of that axis so that when the axis is at "HOME." the two marks line up.

Step 3. The following tests will be run to determine the speed of the basc rotation axis (joint 1) of the manipulator:

Joint 1: At a distance of 180 degrees opposite from home position, place a line on the stationary member of joint 1. Place the closed circuit television camera on a tripod and position out of the operating range of the manipulator so that the view of the stationary mark on joint 1 will have an unobstructed view during testing. Focus the camera so that the mark is very obvious. 
Set the manipulator control for joint I $165 \%$ of maximum specd, using the teach capability of the system, leach the "home" position as the starting point for the path.

Manually rotate the system around to the stationary mark. line up the (wo) marks and teach this point as the "stop" point.

Return Io "home" and replay the path. Correct as required.

Step t. The following tests will be run to determine the speed capability of joint 1 at speeds of $25 \%, 50 \%, 75 \%$, and $1(x) \%$ of maximum:

25\%: Set the munipulitur control to $25 \%$ of maximum speed. As the path is replayed, start the stop watch and stop the watch at the end of iravel. Record the data in the loghook. Repeat the procedure 5 limes. Resed the system Io "home."

50\%: Set the manipulator control to s0\% of maximum speed. As the path is repliyed, start the stop) watch and step the watch at the end of trisel. Record the data in the loghook. Repeat the procedure 5 times. Resel the system to "home."

75\%: Set the manipulator control to $75 \%$ of muximum speed. As the path is replayed. start the stop walch and stop the willeth at the end of travel. Record the dala in the logboos. Repeill the procedure 5 limex. Reset the system o "home."

lok): Sol the manipulator eontrol to lok)r: of maximum speed. As the path is replayed, start the stop watch and stop the watch at the end of iravel. Record the data in the logheook. Repeill the procedure 5 times. Reset the system to "home."

Step 5. The following tests will be run to determine the speed of the shoulder joint (joint 2) axis of the manipulator.

Joint 1: Al a distance of $9($ ) degrecs opposite (up) from home position. place a line on the stationary member of joint 2. Place the clessed circuit television camera on a tripod and position out of the operating range of the manipulator so that the view of the stalionary mark an joint 2 will have an unobstructed view during lesting. Focus the camera so that the mark is very obvious.

Set the manipulator eontrol for joint 2 to $5 \%$ of maximum speed, using the teach capability of the system, teach the "home" position as the starting point for the path.

Manually rotate the system up to the stationary mark, line up the two marks, and teach this point as the "stop" point.

Return to "home" and replay the path. Correct as required.

Step 6. The following tests will be run to determine the speed capability of joint 2 at speeds of $25 \%, 50 \%, 75 \%$, and $10(1) \%$ of maximum: 
25\%: Set the manipulator control $1025 \%$ of maximum speed. As the path is replayed, start the stop watch and stop the watch at the end of travel. Record the data in the loghook. Repeat the procedure 5 times. Reset the system to "home."

50\%: Set the manipulator control to $\$ 0 \%$ of maximum speed. As the path is replayed, start the slop watch and stop the watch at the end of travel. Record the data in the loghook. Repeat the procedure 5 times. Reset the system to "home."

75\%: Set the manipulator control to $75 \%$ of maximum speced. As the path is replayed, start the stop watch and stop the watch at the end of iravel. Record the data in the loghook. Repent the procedure 5 times. Reset the system to "home."

10(k): Sot the manipulator control to follor: of maximum spece. As the path is replayed, start the stop watch and stop the watch at the end of iravel. Record the data in the loghook. Repeat the prosedure 5 times. Reset the system to "home."

Step 7. Plot the data as a lunction of time versus angle (distance) lior ench lest and axis perliormed, on a graph within the loghorok.

\section{B.5. MANIPULATOR REPEATABILITY}

\section{B.5.1 Reforences}

None.

\section{B-5.2 General}

The purpese of this lest is (1) assess the repeatuhility of the manipulator system. To understand the ability of the system to deploy sensors and equipment. determination of the systems ahility to repeat positioning is very importunt.

The overall abjective of the lest is 1 (1) he ahle 10 gencrate repeatability data for the manipulator system. This informution will reinforce confidence that the lociational inlormation being gathered. Juring the experiments, is sulficient lo aceuritcly characterize the area being scrutinized.

Specilic objectives of the lest will he 10 perlorm repeatubility cests for several points within the envelope of the manipulator. The tests will be pertiormed independently of each other and tabulated in the loghook.

\section{B-5.3 Materlals and Equipment}

The following materials and equipment will be required to perliorm the tests outlined above and described helow.

- 1 lab notebook 
- Predesigned data tables for data collection

- 2 black pens

- 3 Dial indicator, 3-in. (spring londed)

- Various clamps (up to 4-in.)

- I roll duct tape

- 1 target plate

- Tape measure (25 li)

- Oaniry system with Titan manipulator

- 1 equipment operator

- I person for ubluining measurements

- 1 person for recording measurements

- I video recording system for recording of tests

- I pointing rod (.5 in. diameter).

\section{B-5.4 Speciflc Precautlons}

During testing, aceess to the operational envelope of the gantry will be physically restricted by labeled harricrs. ACCESS TO THE RESTRICTED AREA WILL NOT BE PERMITTED WITHOUT FIRST SECURING THE SYSTEM ELECTRONIC POWER SUPPLIES.

\section{B-5.5 Prerequlaites}

Perform pretest brielings hefore the initiation of testing sequences as required by the testing engineer. These brielings will outline the scope and objectives of the tests and review the procedures.

Position the gantry crane such that the z-mast is in the center of travel of the $y$-axis. The gantry will remain stationary during this testing sequence. Power to the crane motors is to be turned off and the switch locked out.

Position the manipulator arm so that it is fully extended and that all subsequent points measured will be in a region that is outside of the manipulators ability to reach. 
Setup a table with $x, y$, and $z$ coordinates and use the dial indicators as the axes. Establish and mark a datum $(0,0,0)$ for $x, y$, and $z$. Make allowance for $+/ .1$-in. variance in each axis and the ability to measure this variance using the dial indicators. Note that this device is intended to measure variations from an established point, not to identify the system relative to the world model.

\section{B-5.6 Procedure}

The following tests will provide and indication of the repeatability of the Schilling Titan manipulator system. The testing will be performed for several points within the working envelope of the manipulator. Anytime a step indicates recording of data, entries will be made into the logbook.

Step 1. Collect all materials, procedures, and equipment required to perform the testing. Notify personnel and perform pretest briefings. Install the pointer rod into the manipulator jaws and secure with a bolt through the jaws.

Step 2. For each of point tested a reference point will be established and using the teach function of the manipulator will be taught. The manipulator will then be randomly moved from that point and instructed (o) repeat the position of that point. The deviation from the reference point will then be measured using the three-axis table and dial indicators.

Point 1: Position the manipulator at a point in the far left extreme quadrant of the operating envelope at a vertical position of approximately $5 \mathrm{ft}$ off the floor. Freeze the arm in this position. Teach this point to the control system, and using the prebuilt $x, y, z$ table, establish the 0,0,0 reference point (about 1.5-in. of the 3-in. travel for the dial indicators) for the pointer that is held in the jaws.

Test: Move the manipulator from point 1 and move the arm around its operating envelupe (cycling all of its joints). Replay point 1 and frecze the joints when the manipulator has returned to the point. Using the $x, y, z$ table, measure the variation of position from the reference point and record the data in the logbook. Repeat this test three times.

Point 2: Position the manipulator at a point in middle quadrant of the operating envelope at a vertical position of approximately $5 \mathrm{ft}$ off the thoor. Freeze the arm in this position. Teach this point to the control system and using the prebuilt $x, y$, 2 table, establish the $0,0,0$ reference point (about 1.5 -in. of the 3 -in. travel for the dial indicators) for the pointer that is held in the jaws.

Test: Move the manipulator from point 2 and move the arm around its operating envelope (cycling all of its joints). Replay point 2 and freeze the joints when the manipulator has returned to the point. Using the $x, y, z$ table, measure the variation of position from the reference point and record the data in the logbook. Repeat this test three times.

Point 3: Position the manipulator at a point in the extreme right quadrant of the operating envelope at a vertical position of approximately $5 \mathrm{ft}$ off the lloor. Freeze 
the arm in this position. Teach this point to the control system and using the prebuilt $x, y, z$ table, establish the 0,0,0 reference point (about 1.5-in. of the 3-in. travel tor the dial indicators) for the pointer that is held in the jaws.

Test: Move the manipulator from point 3 and move the arm around its operating envelope (cycling all of its joints). Replay point 3 and frecze the joints when the manipulator has returned to the point. Using the $x, y, z$ table, measure the variation of position from the reference point and record the data in the logheok. Repeat this test three times.

Step 3. Compile the data obtained from the tests and average the deviations obtained for the $x$-axis, $y$-axis, and $z$-axis.

\section{B-6. MINI-LAB INVESTIGATIONS}

\section{B-6.1 References}

Sec Appendix $A$ of this document for a description of Mini-Lab.

\section{B-6.2 General}

The purpose of this investigation is 10 qualitatively assess the overall performance of Mini-Lab. The system will be evaluated for accuracy and resolution of data and its ability to classify, identify. and characterize waste matcrials in the digface mockup.

The overall objective of the test is to determine if the implementation of robotics controls (Mini-Lab), for the purpose of characterization will provide better data than could be oblained by existing manual methods.

\section{B-6.3 Materlals and Equipment}

Actual reference data regarding the type, concentration. and placement of simulated hazardous materials within the mockup.

Characterization data obtained during the course of the system test.

\section{B-6.4 Specific Precautions}

None.

\section{B-6.5 Prerequisites}

All characterization testing has been completed, the data collected, and the reference data available for evaluation. 


\section{B-6.6 Procedure}

Step 1. Provide a written evaluation of the accuracy and resolution of data provided by the Mini-Lab system as compared with conventional methods of obtaining the same information.

Step 2. Provide a written evaluation of the systems ability to classify, identify, and characterize waste materials as compared with the methods currently used (and based on the known materials in the mockup).

Step 3. Provide a written evaluation of the systems availability. This will include (but not be limited to) system problems, failures, time to repair, data lost, etc.

Step 4. Provide a written evaluation of the useability of the system graphics as compared to the situation without their presence.

Step 5. Provide written suggestions relative to system improvements that may be incorporated to enhance the usage and value of the system.

\section{B-7. HUMAN FACTORS EVALUATION OF THE CONTROL SYSTEM}

\section{B-7.1 References}

1. O. D. Duncan and M. Stenbeck, "Are Likert Scales Unidimensional?" Social Science Research, Vol. 16, 1987, pp. 247-259.

2. G. E. Cooper and R. P. Harper, The Use of Pilot Rating in the Evaluation of Aircraft Handling Qualities, National Aeronautic and Space Administration, Ames Research Center, Moffett Field, California, NASA Report TN-D-5153, April 1969.

3. G. B. Reid, C. A. Shingledecker, and F. T. Eggemeier, "Application of Conjoint Measurement to Workload Scale Development," Proceedings of the Human Factors Society 25th Annual Meeting, 1981.

4. S. G. Hart and L. E. Staveland, "Development of NASA-TLX (Task Load Index): Results of Empirical and Theoretical Research, Human Mental Workload, Hancock and Meshkati (eds.), Elsevier Science Publishers, B. V., 1988, pp. 139-183.

5. M. S. Sanders and E. J. McCormick, Human Factors in Engineering and Design, McGraw-Hill Book Company, 1987, pp. 51-53.

6. Casali and W. W. Wierwille, "On the Measurement of Pilot Workload: A Comparison of Assessment Techniques Addressing Sensitivity and Intrusion Issues," Ergonomics, Vol. 27(10), 1984. 


\section{B-7.2 General}

The purpose of this test sequence is to assess the usability of the control systems operator interface by performing a cursory human factors evaluation.

This evaluation can be divided into three objectives. The first objective is to assess the usability of the control station. This includes evaluating operator control over crane speed, operator control over position of crane, ease of operation, quality of viewing screens, performance of control devices, and usefulness of graphics. The second objective is to identify factors that may affect performance. The third objective is to identify any deficiencies.

The step by step procedures are given later in this test sequence. Data will be determined valid by the test administrator. If the procedu'es are deviated from, the test administrator will red line this procedure to reflect those changes.

Where possible, quantitative data will be recorded; however, qualitative data regarding the subject's thoughts on the system such as operator satisfaction will also be collected. Qualitative data will be measured using a subjective scale. Techniques for quantifying subjective judgements have been developed in the field of psychometics. Psychometric techniques are subjective measurement methods and have been used to subjectively measure a person's perceptions of mental workloid and quality, and other applications. These are two types of psychometric techniques: ranking and rating. Ranking is a method in which a list is ordered from lowest to highest or from highest to lowest. Rating is a method used to obtain some type of classifiable quantity. There are several types of rating scales, including (1) global or straight point scales such as bipolar and Likert scales ${ }^{1}$; (2) global-guided or scales that use network of questions that guide the evaluator to a point on a straight point scale such as the Cooper-Harper scale ${ }^{2}$; (3) multidimensional global-guided or scales that break down the subject into more detailed subparts and rate the subparts, such as the Subjective Workload Assessment Technique ${ }^{3}$ or Task Load Index ${ }^{4}$; and (4) multidimensional global-guided or scales the break down the subject into subparts and rate those subparts using a global-guided scale. The scale to be used for measuring operator satisfaction will be a global-guided scale. This scale used a flowchart to help structure the evaluation process. By doing this, the technique allows for a ten point scale, which is more reliable than the traditional global five or seven point scale. Because human beings typically can one distinguish between seven $+/$ - two things, ${ }^{5}$ the method uses a flowchart that only requires humans to distinguish between two or three things at a time but for several episodes-making it a ten point scale. The scale is quick, easy to use, and requires minimal training. This technique has been proven to be sensitive, reliable, and valid. ${ }^{6}$ The global-guided scale is shown in Figure B-1.

\section{B-7.3 Materials and Equipment}

The following materials and equipment will be required to perform the tests outlined above and described in detail below.

1 lab notebook

- 2 pens 
- Watch (resolution of one second)

- Tape measure $(25 \mathrm{ft})$

- A system operator

- Digface characterization system.

\section{B-7.4 Specific Precautions}

No personnel shall be in the room with the crane while subjects are operating the equipment for this test.

\section{B-7.5 Prerequisites}

None.

\section{B-7.6 Procedure}

Following are the procedures for testing the control system for Digface Characterization. Any time that one of the steps refers to recording some data, it will be recorded in a logbook. Only one subject will be tested at a time.

Step 1. Assess the usability of the control station.

Step 1.1 Explain the control system and how it can be used io control the crane. This training session should last approximately 10 minutes. The contents of the training will be kept in the project file.

Step 1.2 Operator control over crane speed. The subjects will be asked to survey the simulated waste box in a precise, predetermined manner at four different speeds. The four speeds to be tested are $25,50,75$, and $100 \%$ of maximum speed. At each speed the following data shall be recorded: (1) the actual speed the crane moved, (2) operator's thoughts on the controls and displays, (3) perceived level of control, and (4) perceived difficulty. The crane speed will be measured by timing the cranes movements over a specified length. The operators will be asked to verbalize their thoughts while operating the crane. The global-guided scale shown in Figure B-1 will be used to measure the operator's perceived level of control and perceived difficulty. These thoughts will be recorded in a logbook. The global-guided scale shown in Figure B-1 will be used to measure the operator's perceived level of control and perceived difficulty. 


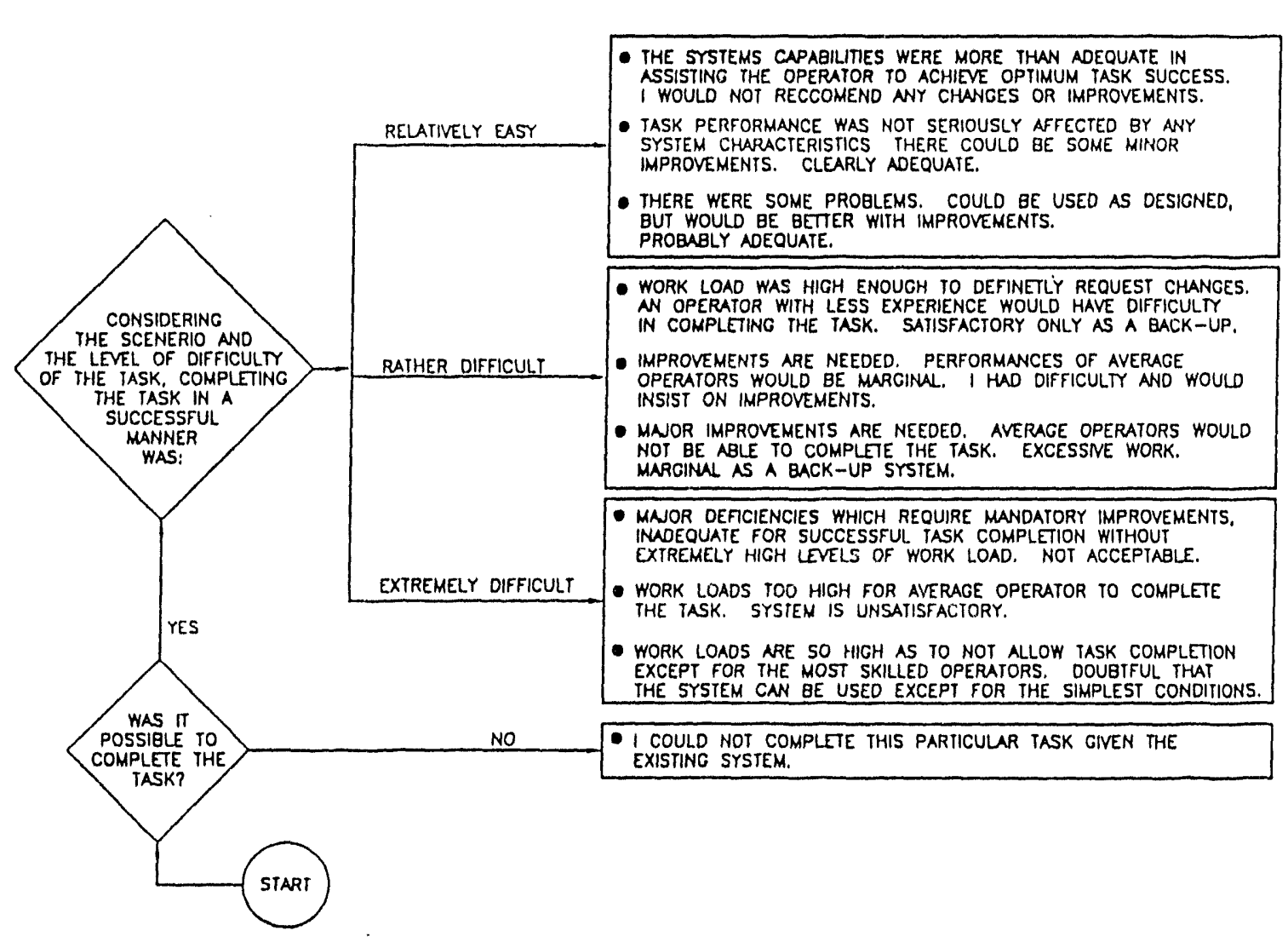

RATING

10

9

8

7

6

5

4

3

2

1

Figure B-1. Global-guided scale. 
Step 1.3 Operator control over position of crane. The subject will be asked to survey the simulated waste box in a precise way. The following information will be recorded: (1) time it takes the subject to perform this task, (2) number of errors, (3) operator's thoughts on the controls and displays, (4) perceived level of control, (5) perceived difficulty, and (6) accuracy of movements. Time will be measured using a stop watch and will be recorded to the nearest second. The number of errors will be determined subjectively by counting the number of times the operator must perform a corrective action. An example of this would be for the operator to have the arm move in the opposite direction than intended. The operators will be asked to verbalize their thoughts while operating the crane. The global-guided scale shown in Figure $C-1$ will be used to measure the operator's perceived level of controt and perceived difficulty. These thoughts will be recorded in a logbook.

Step 1.4 Ease of operation. The operators will be asked to perform the following: (1) leave the crane stationary, but move the arm; (2) leave the arm stationary, but move the crane: (3) move both the arm and crane simultaneously. The following will be recorded: (1) operator's thoughts on the controls and displays, (2) perceived level of control, and (3) perceived difficulty. The operators will be asked to verbalize their thoughts while operating the crane. The global-guided scale shown in Figure B-1 will be used to measure the operator's perceived level of control and perecived difficulty. These thoughts will be recorded in a logbook.

Step 1.5 Quality of viewing screens. The operators will be asked their opinion on the quality of the viewing screens. Any suggestions will be recorded.

Step 1.6 Performance of eontrol devices. The operators will be asked their opinion on the performance of the controls. Any suggestions will be recorded.

Step 2. Identify factors that may affect performance.

Step 2.1 The human factors engineer will record information in a logbook based on judgement and results of the previous tests. Information to be considered includes: lighting, anthropometrics, noise, workload, alarms, environment, controls, displays, feedback, physical space and layout, and cameras.

Step 3. Identify any deficiencies.

Step 3.1 As a result of the previous tests, the human factors engineer shall record any system control deficiencies that affect the usability of the system. In addition, the safeguards against loosing control, communication, or data will be recorded. 


\section{Appendix C}

\section{Instrumentation Data Sheets}




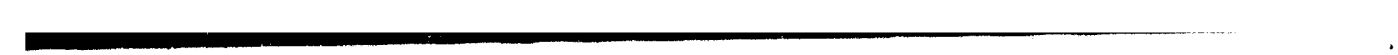

C-2 


\section{Sandia National Laboratories}

Albuquerque, New Mexico 87185

June 16, 1993

Kevin Croft

Idaho National Engineering Laboratory

EG\&G Idaho, Inc.

P.O. Box 1625

Idaho Falls, ID 83415

Dear Kevin:

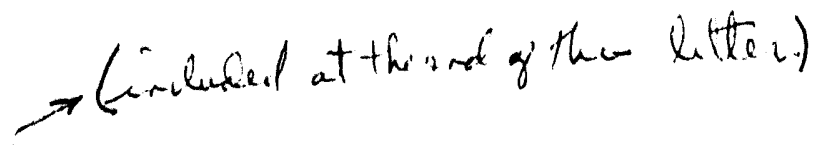

In your June 1 letter, you requested some details about the Mini Lab sensor heads. John Feddema provided drawings of the size and layout of the main sensor head. In this letter, I will address the remaining questions including those mentioned in John's June 11 letter to you.

DC Power Supply: Mini Lab has several on board DC-DC converters that require a nominal 12 VDC input. The converters will operate over a fairly wide range $(10-20$ VDC). Due voltage drop in the lines, a supply capable of providing $15 \mathrm{VDC}$ at 5 amps is required.

Cabling from VME to Schilling: Two twisted pairs of 22 AWG for data plus one pair of $16 \mathrm{AWG}$ for power. If such a cable is not available, six pairs of $22 \mathrm{AWG}$ could be substituted using two pairs for data and four pairs in parallel to provide power.

Magnetometer: The magnetometer has been received at Sandia. Our original concept of a long tubular sensor head resulted in a 30 " long package to maintain sufficient separation between the sensor and the electronics. This length severely restricts the work envelope. Instead, the sensor will now consist of two parts. The sensor head will be a 4 " diameter by 10 "long cylinder containing the sensor coils only. The sensor electronics, signal conditioner and multiplexer will be in a similarly sized package permanently mounted to the tool rack near the base of the Schilling. This approach will not effect cable management for the sensor head since a single cable of similar size is required for either approach. The $5^{\prime}$ cable provided on the mag sensor must be replaced with a $15^{\prime}$ cable. The manufacturer said the effect of a longer cable is quite small and, if necessary, the sensor can be tined at the factory to accommodate this length. The magnetometer will also be powered from the $15 \mathrm{VDC}$ supply used for the main sensor head. I have enclosed a block diagram showing the cabling and power connetions required. 
Connectors: Connectors to the sensor heads have not been chosen. A minimum of six pins is required and a military type (ITT Canon) connector will be used. Sandia will provide the connectors. They will be sent to INEL to be attached to the cabling.

Sensors: You requested specific information concerning the sensors and modifications for Mini Lab. Below, each of the five sensor types is discussed in detail.

Ultrasonic Proximity Sensors:

3 Sensors with a range of $2-24 "$, resolution $0.005^{\prime \prime}$.

These are commercially available from:

Contaq Technologies

15 Main Street

Bristol, Vermont 05443

The sensors used are based on a Part Number: ISU-101-IS-HRD-EN2-PCB.

The sensors are ordered with a close range adjustment alteration to reduce the minimum sensing distance from 6" to 2". In addition the usual 2" NPT stainless steel case is omitted. The sensors provide 4-20 mA analog output (the IS option), provide high resolution output (HRD), will operate in a sequential non-interfering mode (EN2), and are equipped with an RS-232 port used for programming the setpoints and range.

Metal Detector:

The coil is a commercial 6" coil Part Number 624-0263 manufactured by:

White's Electronics

Sweet Home, OR

The coil has been only slightly modified by removing the conductive case and replacing it by applying a conductive layer to the inside of the MiniLab case. The associated electronics are designed and built by Sandia. I have included a schematic. The sensitivity and resolution of the system has not yet been characterized.

Optical Pyrometer:

The surface temperature device is an infrared thermocouple from:

Exergen

1 Bridge Street

Newton, MA 02158 
It is a model $\mathrm{IRt} / \mathrm{c} .2 \mathrm{~K}-140.3$ which provides a Type $\mathrm{K}$ thermocouple response of the temperature of the surface being viewed. The thermocouple has a $2 \%$ accuracy (compared to a Type $\mathrm{K}$ thermocouple) from 80 to 180 degrees $\mathrm{F}$. The device is connected through cold junction compensation circuitry (Part Number CJ-K) from:

\section{Omega Engineering \\ P.O. Box 2284 \\ Stamford, CT 06906}

This provides a signal that is a measure of absolute (rather than differential) temperature. The compensator is accurate to 1 degree $F$ over an ambient range of 60 to 100 degrees F. The compensator has been modified to operate on 5 VDC rather than the $1.35 \mathrm{~V}$ battery that was originally supplied.

Dosimeter:

The dosimeter is Geiger counter available from:

Eberline Instrument Corp.

P. O. Box 2108

Santa Fe, NM 87504-2108

It is a Model E-120 with a HP-270 probe. It provides full scale ranges of 0.55 and $50 \mathrm{mR} / \mathrm{hr}$. The counter has been modified to operate on 5 VDC instead of the original 3 volt battery. Also wires have been attached to obtain an analog voltage output proportional to dose rate.

Gas Sensor:

The gas sensor is a tin oxide semiconductor based sensor available from:

Figaro USA, Inc.

1000 Skokie Blvd. Suite 575

Wilmette, II 60091

The circuitry will operate with a number of specific gas sensors by simply plugging in a different sensing module. We plan on using an organic solvent vapor sensor (TGS 822) for detecting ethanol vapor, but any of the sensors listed below could be used: 
Gas Threshold (approx.) Part Number

Chlorofluorocarbons

$$
\begin{array}{r}
100 \mathrm{ppm} \\
5 \mathrm{ppm} \\
30 \mathrm{ppm} \\
10 \mathrm{ppm} \\
500 \mathrm{ppm} \\
50 \mathrm{ppm}
\end{array}
$$$$
\text { Ammonia }
$$$$
\text { Hydrogen }
$$$$
\text { Combustible Gases }
$$

TGS 831

TGS 825

TGS 824

TGS 821

TGS 813

TGS 822

Other sensors are available with relatively short lead time.

I hope this has answered all current questions about Mini Lab. I would be happy to obtain further details on these sensors or discuss the above information. Please feel free to call me at (505)-845-9835.

Sincerely,

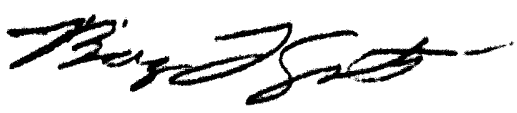

Barry Spletzer

Intelligent System Sensors and

Controls Department 1611

Copy to:

INEL Nick Josten

1611 J. T. Feddema

1661 P. T. Boissiere

1661 D. S. Horschel

1661 C. Q. Little

1611 Day File 


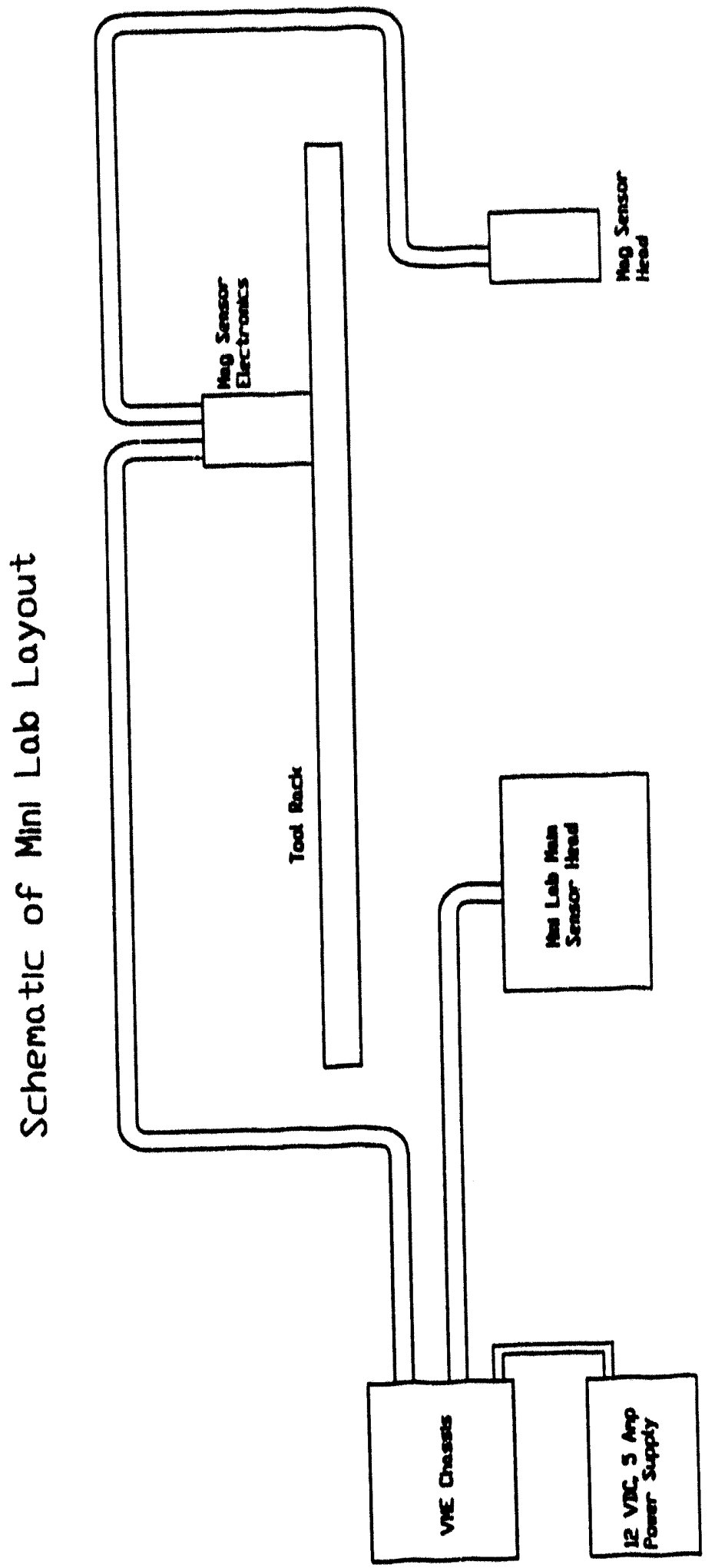




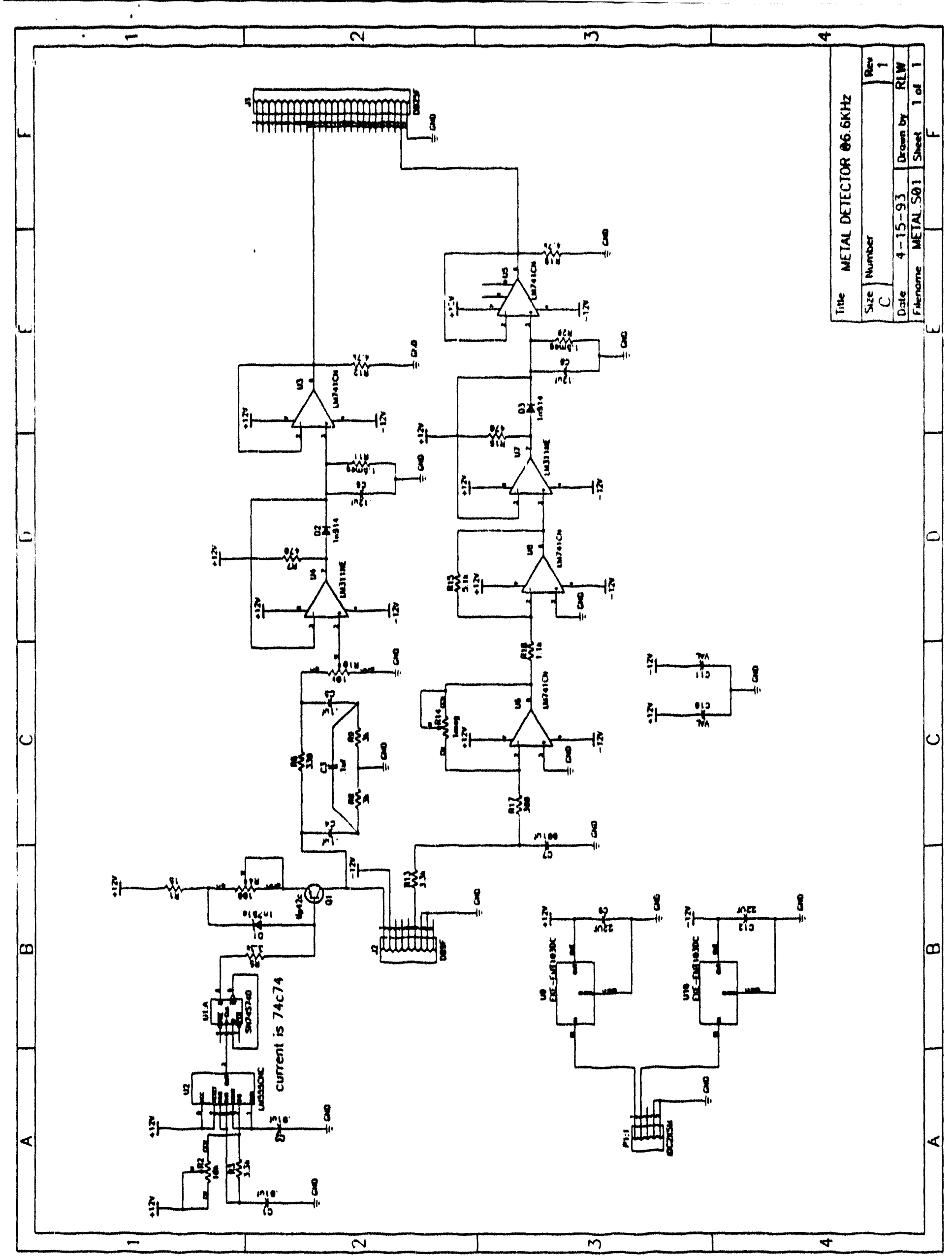




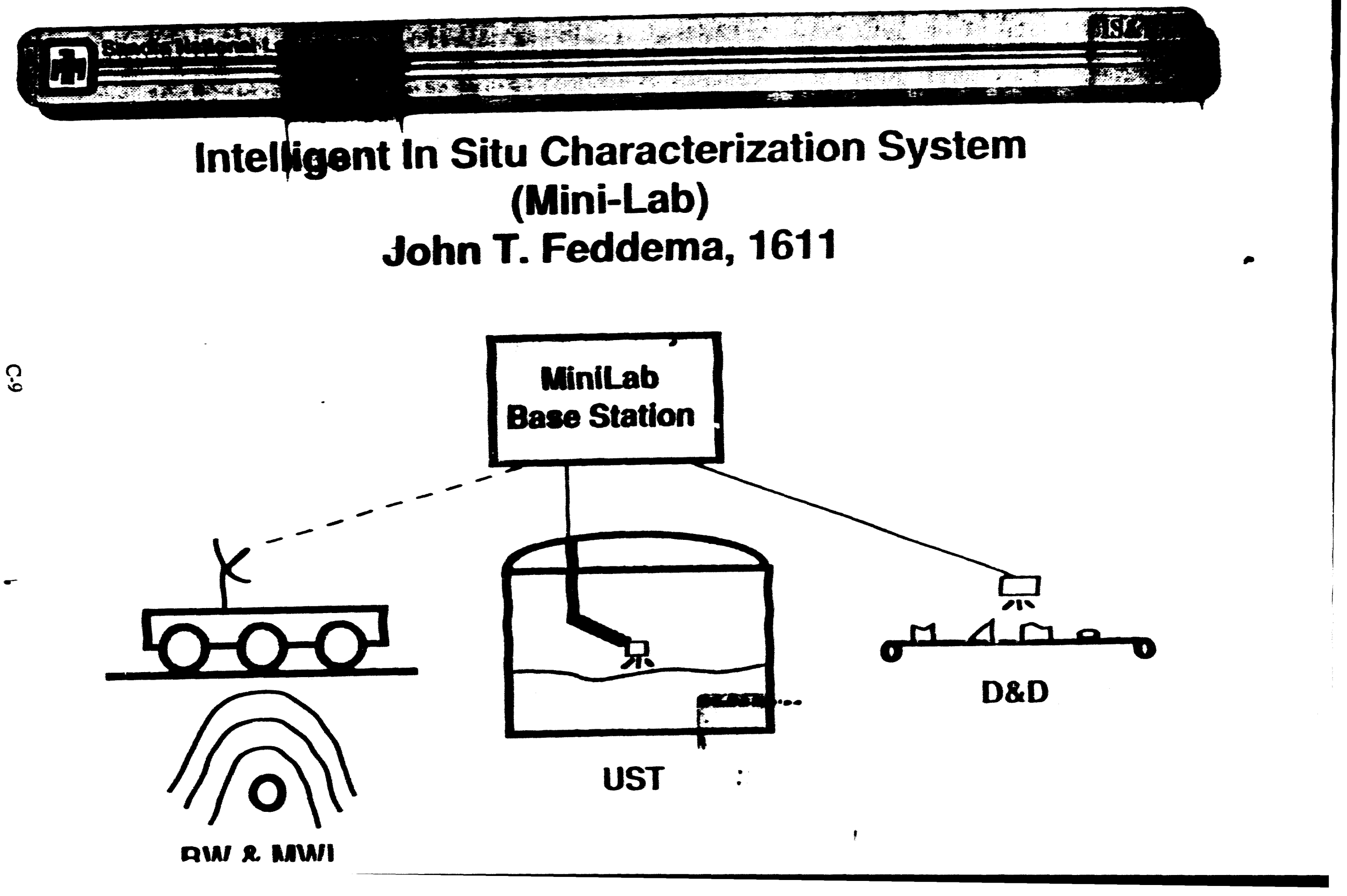




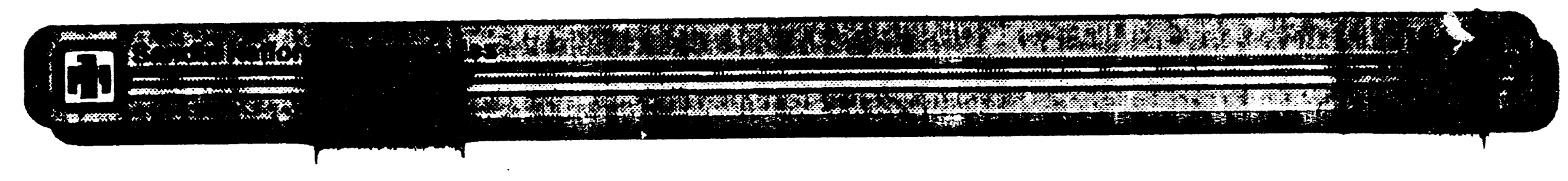

\section{Problem Statement}

- Before DOE's hazardous waste sites can be cleaned up, knowledge of physical, chemical, and radiological contents is needed to plan remediation and disposal processes.

- A single computing interface is needed between a robotic positioning system and a set of characterization sensors.

- To create site maps.

- To aid in data interpretation.

- To document the characterization process.

- To speed up the characterization pracess. 


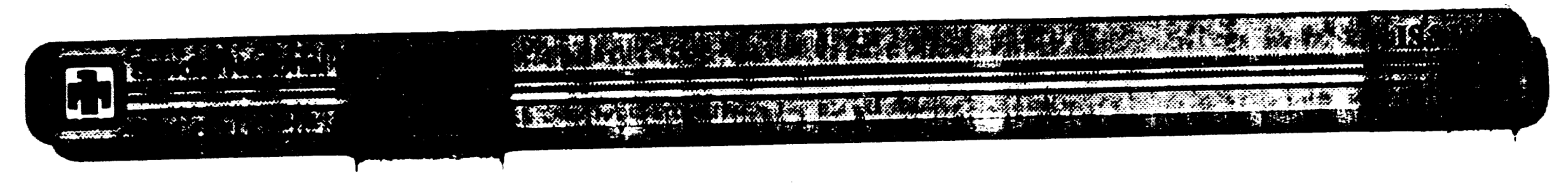

Solution

Mini-Lab previdae:

- A general software and hardware computing architecture for acquisition, graphical display, archival, and interpretation of sensor data.

$\stackrel{?}{=}$

- An interface between the characterization sensors and the robotic arm and/or vehicle.

- Automatic generation of site maps.

- Uniform menu-driven user interface for quickly connecting sensors.

- Common library of display and interpretation routines.

- Early warning and diagnostics routines.

- Commlate alidit trail ranorded in Natahage 


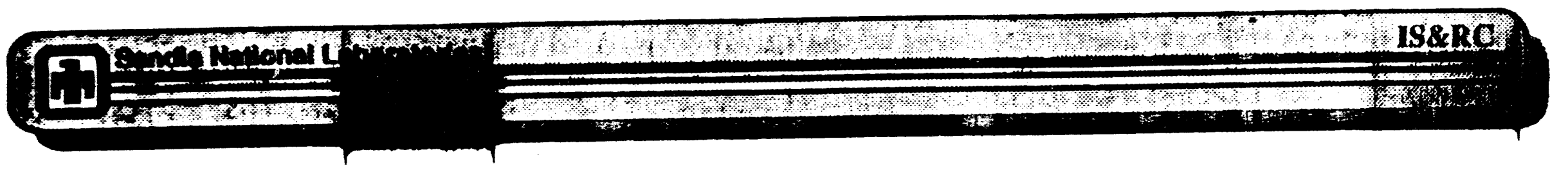

\section{Unique Capabilitieg of Mini-Lab}

- Acquires sensor data through a variety of interfaces: analog, serial, parallel, GISC, and video.

- Automatically stamps sensor data with time, date, and robot position stamp before saving to files.

- Displays both real-time and archived sensor data.

- Automatic warning when thresholds are exceeded.

- Menu-driven user interface allows rapid deployment of sensors (plug and play interface): : -....

- Sensor configurations (type, channel, displays, etc) are saved for reuse and modification. 


\section{Mini-Lab as an Intelligent Subsystem}

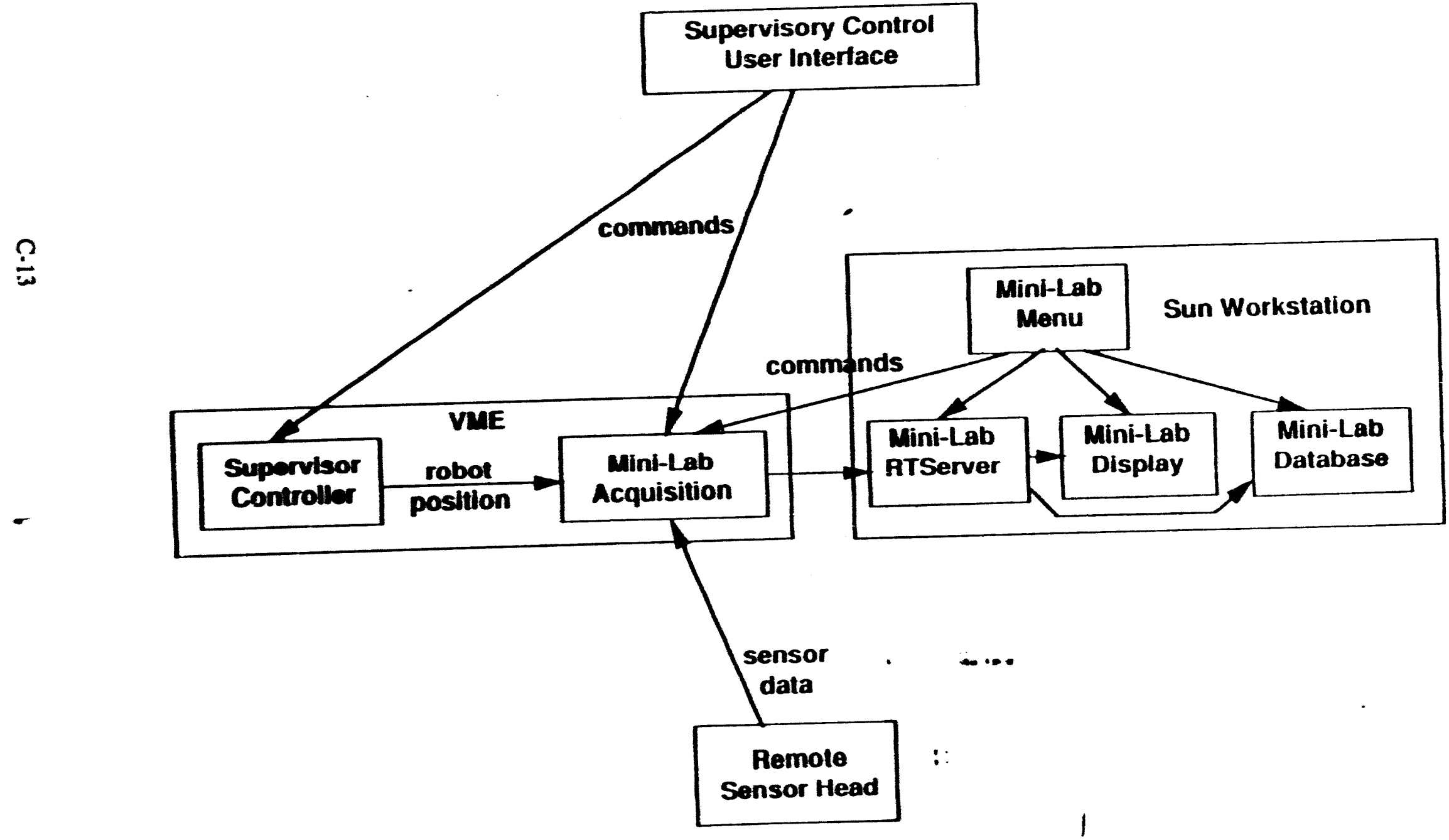




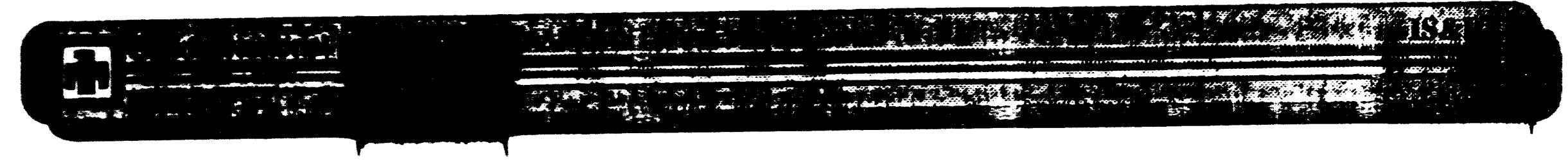

\section{Current Stapus of Mnitlob}

- Uses VME system to collect sensor data and robot position.

- Remote sensor hoads contain on-board A/D and multiplexing circuitry which acquire up to 32 channels of analog daia.

- Menu-driven interface is written in XViews (runs under Sun OpenWindows).

- Graphical display is performed using PV-Wave software.

- Documentation is under development...Plan to have a stable release in late FY93. 
Sensprs Incфrporated Into Mini-Lab So Far:

- Analog Devices

Aoing mote 16 chrannel digitizer, MUX, and high speed synchronous serial communication)

+ Sandia Hydrogen Gas, Sensor

+ Nyad Oxygen Gas Sensor

+ National Semiconductor Temperature Sensor

+ ICSensors Pressure Sensor

+ Hy-Cal Humidity Sensor

+ ARA penetrometer

- Tip Force

- Pore Pressure

- Viscosity

+ Sandia's Capacitive Based Proximity Sensor

- Serial Devices

+ MTI Gas Chromatograpirs - -...

+ Contaq Ultrasonic Prokimity Sensors

- Parallel Devices

+ Canberra Gamma Spectometer , 


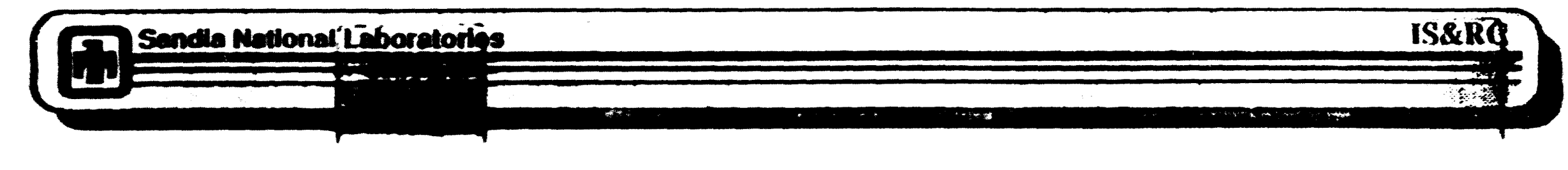

Mini-Lab is Leveraging off of Commercial Software Products:

- Só Far:

+ PV-WAVE for Data Display

+ Xviews Windowing package for menus

$\frac{?}{5}$

+ VxWork's Real-Time Operating System

- Investigating:

+ National Instrument's LabViews

+ DataViews

+ Gensyn's G2

+ Talarian's RTworks

+ NRT's ESMART

+ Advanced Visualization System (AVS) 


\section{Computer Architecture for the Intelligent In Situ Characterization System}

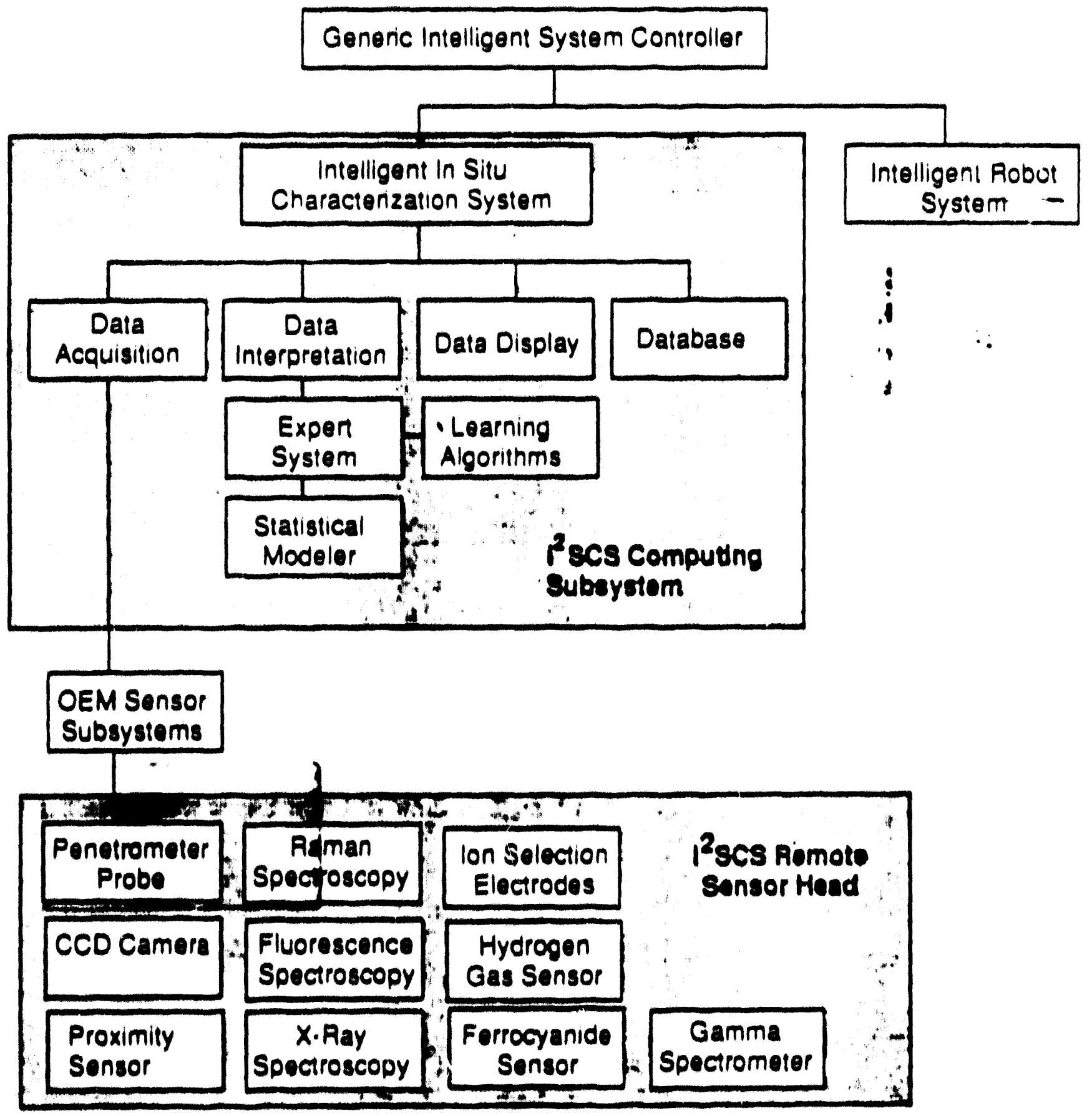




\section{Sandla National Laboratories}

Alowaveraue. Now Moxico 87185

August 16, 1993

Kevin Croft

Idaho National Engineering Laboratory

EG\&G Idaho, Inc., Mail Stop 3740

P.O. Box 1625

1955 Fremont Ave.

Idaho Falls, ID 83415

\section{Dear Kevin:}

Enclosed are the spec sheets for the ranstucers in Mini Lab. My Jure 16 letter to you gives all the appropriate model numbers for the transducers We britly discussed calibration and cutput in engineering units while I was up there. In general, the transducer outputs are fed to an amplifier to increase the sensitivity Because of this, the transducer response will nor match the spec sheets. If you need to display engineering units, I would suggest that you perform a 1 or 2 point calibration of the rransducers. This is straightforward for all sensors but the metal detector. I do no: know of an approptiate engineering unit for the metal detector.

I have a few comments on the current state of the sensorg. The proximity transducer's have been calibrated to read full output ( 4095 counts) at 2.5 inches and $20 \%$ of full count (819 counts) at 12 inches. The output will not change once outside of this range. They should not need turther calibration The pyrometer requires a bartery for operation of the cold junction compensator due to a problem with common grounds. The battery has a life of 2000 hours Untorunately, the ON.OFF switch is accessible oily by removing the Mini Lab cover. I have included a spare battery with this letter. The geiger counter is currently set on its most sensitive range. Range multipliers of $10 X$ and $100 X$ can be set using the knob on the dosimeter board. The is contigured with the HP-270 probe with the cover open. For calibration purposes, the dosimeter provides full scale output when the range switch is placed in the "Battery" position. Because of the high amplifier gain. full scale output is well beyond the range of the multiplexer. The calibration equation of the gas sensor is given in the data sheet along with a typical response plot. Notice that the sensor response is highly nonlinear. The current Mini Lab soltware can not perform nonlinear function on the displayed data

I hope this has provided the needed information. I would be happy to obtain further details on these sensors or discuss the above information. Please feel free to call me at (505)-845-9835. 
Sincerely,

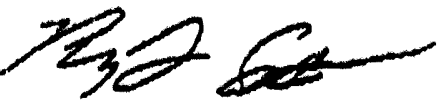

Barry Spletzer

Intelligent System Sensors and

Controls Department 1611

Copy to

INEL Nick Josten

1611 J. T. Feddema

1611 Day File 


\section{SECTION 1 \\ GENERAL}

\section{A. PURPOSE AND DESCRIPTION}

The Models E.120 and E.12UE are small, lighewsigin geiger counters for the detection and measurement of gamma (also beta with E-120E) radiation. The E.120 is iypically used with exiernal hand probe Model HP.:90 and the E.120E is iypically used tith external hand probe Model HP 190A. The models are identical except for the delestor and meter face.

Two "D" size balteples power the instrument, and special sircuitry is incorporaled to conserve baltery life.
The ballory sundicion may be shesixed by a frone paral control. The radiation intensily is read out on a large, easily reat metes itith a linea: soals. Thres switch.

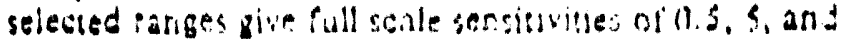
somR.h (") (O) for the E.120 and soo, ik and soh

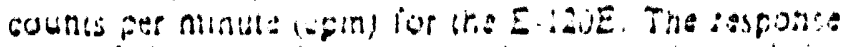
lime of the mele: is conlinuo'sly anjustasts ard ine reading may be brought 10 zero al an; ime by tha pess: contro!.

A phone culpul is piovided for the uso ol eapptiones, an

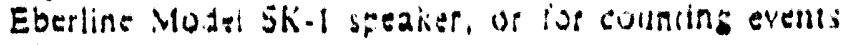
with a scaler.

\section{B. SPECIFICATIONS}

The spesifications listed are appropnate for the E.120,E.120E when used with the prote and cord listed.

\section{Detectnr}

\begin{tabular}{|c|c|c|}
\hline & E.120 with Model HP.270 Probe & E.120E with Model HP.190A Probe \\
\hline a. Geiger-Alueller Tube & $30 \mathrm{mg} / \mathrm{cm}^{2}$ halogen quenched & $\begin{array}{l}\text { Halogen quenshed, thin window, } \\
1.4 .2 .0 \mathrm{mb} / \mathrm{cm}^{3}\end{array}$ \\
\hline b. Sensilivity ("'Cs) & Approximately $1200 \mathrm{cpm}$ per $\mathrm{mR} . \mathrm{h}$ & Afproximalely 2500 ipm pet $m R$ ih \\
\hline c. Energy Response & See Fizure 1.3 & $N / A$ \\
\hline d. Dead Time & Approximately $100 \mu s$ & ApF:oximatol: $220 \mu$ \\
\hline e. Housing & Impast resistan! plastic & Piotective scresen end cap \\
\hline f. Environment & Weatherproof & Weatherproor \\
\hline B. Cable & $C A \cdot 1 \cdot 36(S T A N D A R D)$ & C.9.1.36 (STANDARD) \\
\hline $\begin{array}{l}\text { h. } 2 \pi \text { Bela Efficiency } \\
\text { with end cap } \\
\text { removed }\end{array}$ & $N / A$ & $\begin{array}{l}\text { "Sr."Y: Approximately } 39 \text { perient } \\
\text { "Tc: Approximataly } 25 \text { perceni } \\
\text { "C: Approximalely } 10 \text { petcent }\end{array}$ \\
\hline
\end{tabular}

2. Indlcator

a. Visual

(1) Scale lengih 2.37 inches $(6 \mathrm{6m})$

(2) Scals Marking:

E.120: Dual scales, $0105 \mathrm{mR}$ ih with 25 increments and $0.6 \mathrm{~h}$ spm with 30 inerements.

E.120E: 0 10 Sk cpm with 25 increments.

(3) Range: Swilch sontrulled multipliers of $\times 0.1$, $x !$ and $x ! 0$, yielding $0.5,5$, or $50 \mathrm{mR}$ ith $6000,6 \mathrm{k}$ of 6uk $\mathrm{cpm}$ ) for $\mathrm{E} \cdot 12 \mathrm{~J}$, and 500 . Sk, or $50 \mathrm{k} \mathrm{cpm}$ for E.120E.

(4) Response Time: Continuously adjustable by RESPONSE conirol from 2 seconds 1010 seconds. measured to 90 percent of firial reasing.

(s) Linearliy: Within \pm 5 purcent of full scale, eypically $=2$ percent of F.S.

(6) Saluralion: E. 120 meler will remain pegsed in 


\section{Manual Insert: MODEL HP.27O HAND PROBE}

The slandad Model HP.197C probe on this insirument has been replaced by the Madel HP. 270 The new HP. 970 uses the

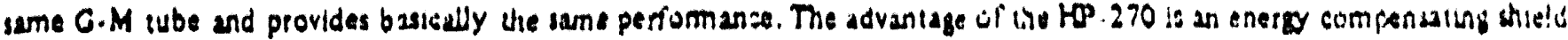

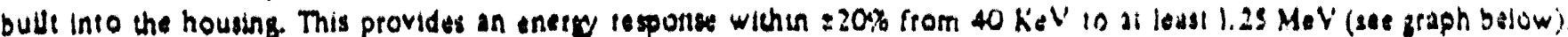
Oinet specifications tem in sunillas to the HP. $179 \mathrm{C}$.

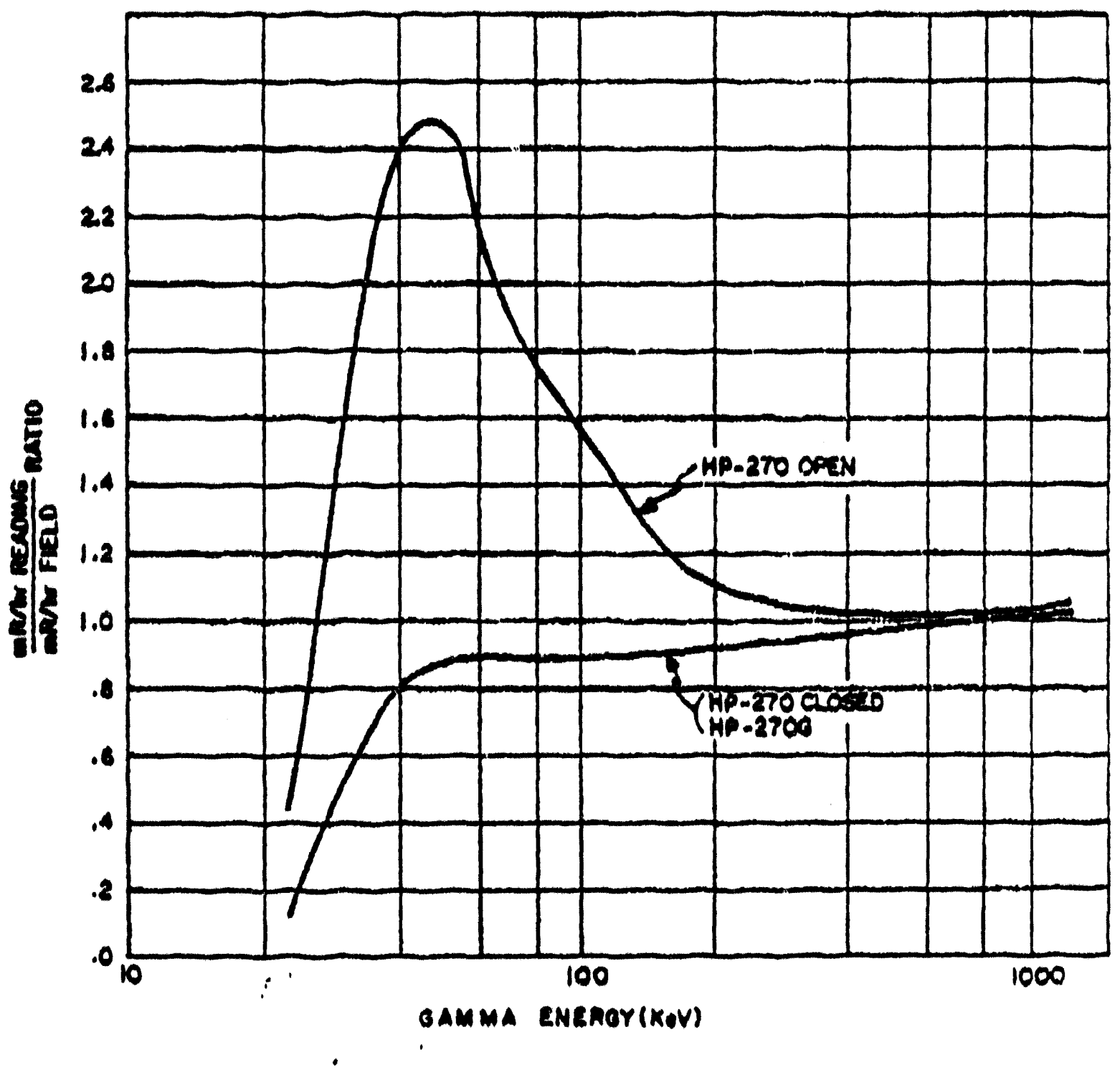

Enery Rewonse of HP.270 Hend Probe

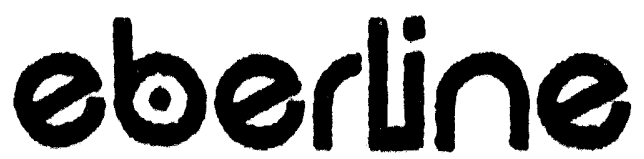

REF. NO. 1059

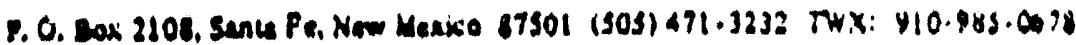


"Cs gamma fields uf 10 at least $s R / h$ when using a HP.270 probe. E.120E nol specified.

(7) Baliery Dependence: Callbration shifis lesi than 10 pescent with batiefy voliaye chanye frorn 310 IV (ne:t balleties 10 end poin!).

\section{b. Aurul:}

(1) Connes:or: Miniasuse audio style.

(2) Signal: One fulse for each event counted. Negative $2.5 \vee$ capacitively coupled.

\section{Power}

a. Battery Complement: Two each "D" size bas. reries of any lype with voltage between 1.0 and $1.6 \mathrm{~V}$ pet ballery.

b. Ballery Life: Depends on ballesy lype, age, and temperalure. Nominal life with new balleries near room temperature is:

$\begin{array}{ll}\text { Type } & \text { Life } \\ \text { C.2n } & 300 \text { hours } \\ \text { Alkaline } & 900 \text { hours } \\ \text { Ni.Cd } & 200 \text { hours }\end{array}$

\section{Envirunmenial}

a. Temperature: The insitument is coerationd from $-10^{\circ} \mathrm{F} 10-140^{\circ} \mathrm{F}\left(-10^{\circ} \mathrm{C} 10+60^{\circ} \mathrm{C}\right)$ with a typical lemperatude coefficient of 0.15 papcant per of (- 0.27 pefsent pet 'C) Maximum lemperature cceffivient 0.25

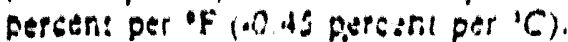

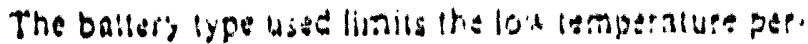
formanc: besaluse of lesminal vollag: dectease ard in. ternal impedanis instasse. For proloriged optration at low lemperalures, the following criteria ars suagesied:
Ballery Tspe
Usable 10

$$
\begin{aligned}
& \text { C.Zn } \\
& \text { Alkaline } \\
& \text { Ni.Cd }
\end{aligned}
$$
$0.5\left(.18^{\circ} \mathrm{C}\right)$ $-40 \cdot \mathrm{F}\left(+10^{\circ} \mathrm{C}\right)$ 40 " $F\left(-10^{\circ} \mathrm{C}\right)$

5. Mechonical

a. Sise

Height: $61 / 2$ inches $(16.3 \mathrm{~cm})$

Lengeh: $6 \%$ inches $(19.1 \mathrm{~cm})$

Width: $3 \%$ inches $(8.6 \mathrm{stm})$

b. Weight: Whin batterles: 3 poisnds including probe (1.4 k8).

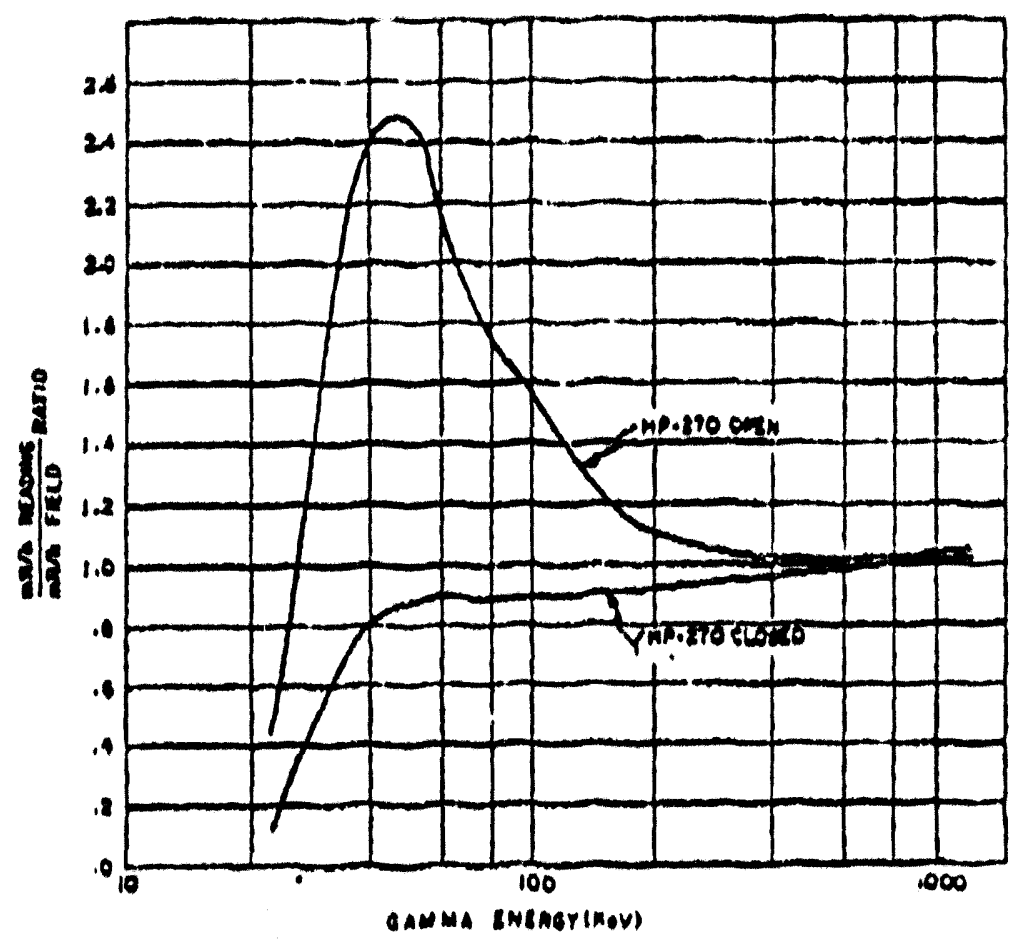

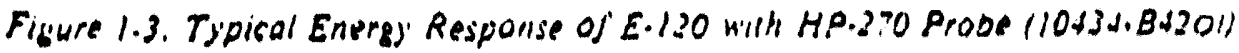




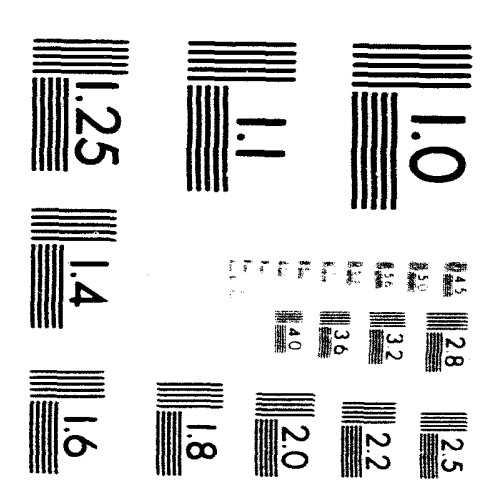



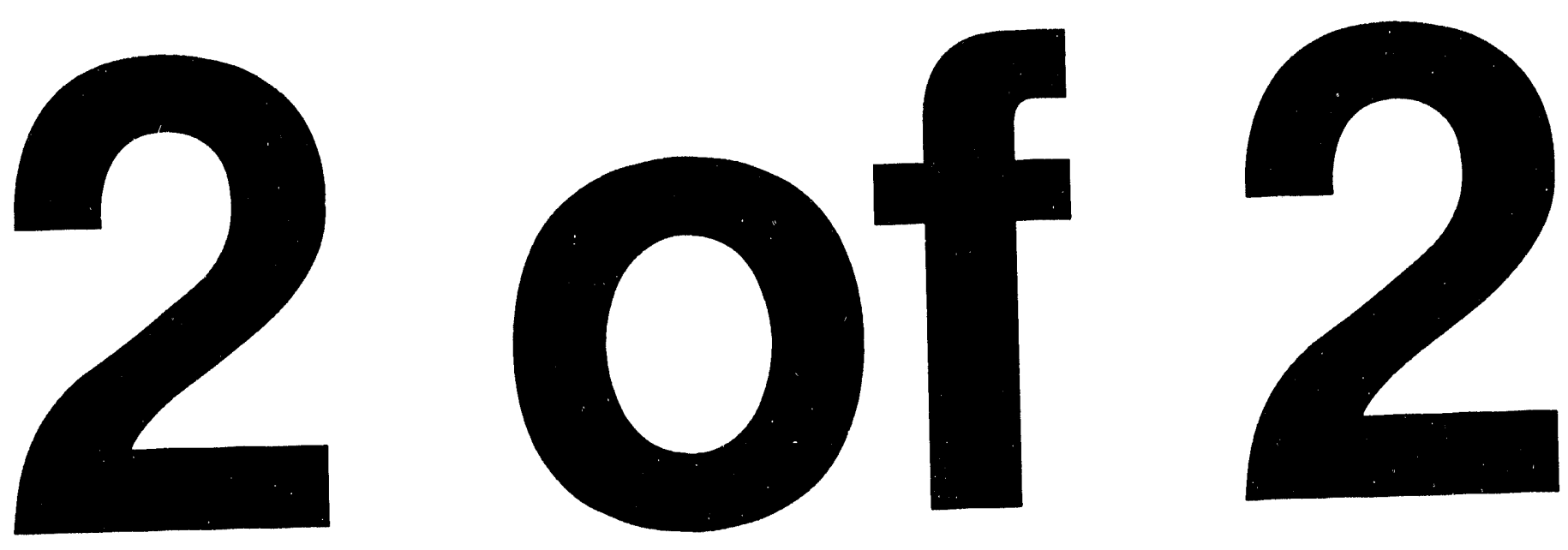


\section{SECTION II OPERATION}

\section{A. DESCRIPTION OF CONTROLS AND CONYECTORS}

\section{External (Sec Figure 2.1)}

3. Switsia Five position rotary swith that burres insteument $O F F$, chesks batuery (BATT) andition and selecis scale multipliers of $\times 0.1, X 1, \times 10$. This number must be multiplied by the meter rading to obtain the proper field intensity.

b. RESPONSE: Controls response time of meter :0 the most desirable compromise between speed and fluctuation for the particular usage.

6. RESET: Discharges integrating capacitor, bringing mele: reading to zero rapidly.

4. PHONE: Pulse output for Hise with earphone, speaier, or external scaler. Mating conneclor is Sivitcherafl \#SS0lF.

c. Detectur Cunnector: Connection to Hand Probe. BNC series coaxia!

\section{Iniernal (Se: Figure 2.1)}

a. Calibration Controls: One control for each range which individually salibrates that range 10 agree with the radiation fieid.

\section{B. PREPARATION FOR LSE}

\section{Inspection}

The instrument should be checked for physical damage.

\section{Connections}

Connect the probe cable to the detector connector.

\section{USING THE INSTRUMENT}

\section{Slarting}

Turn the switsh to the BATT chect position The mete: should indicate within the SATT OK at:2.

\section{Operation Check}

Place a theck sourae in a iepealable position adjacent to the detector and move we switch to a tange that gives an upscale reading. Note that the reading is innsitive to the position of the source. The reading may be recorded for future reference.

Push the RESET bittion and the :adinz should drop to zero rapidly, then climb bach o soura teading when the RESET is released. The RESPOVYSE may b: adj asted to gut the most desirable compromise ber'xeen sp:ed of response and meter fluctuation.

\section{Inlerprutation of Indicutions}

The neter reading must be multiplied by the scale fastor:c obsain the proper number. The fluctuation of the meter is normai and is caused by the random nature of radioactire desay.

On the E-120, either the mR/h or the eprn scale may be reac. Prime caibration at the factory is in R. h using a "Cs source. The relation bet ween the two sales is the averaze for the Geiger Mlueller lute used in tho F-120 in a "Cs field. Thus, the cpm scale will be close 10 irthe feequency and may be used without recalibration. How. ever, if sFm is to be used, and maximim aceurasy is desired, the instrument should be recalibrated using a frequency standard.

The E.120E is calitrated to read true pulse frequency. 


\section{SECTION III \\ THEORY OF OPERATION}

\section{A. GENERAL (See Figure 3-1)}

The high voluge supply develops - 200$) V$, which is applied to the geige: nube. giving it the proper operating veltage When radiation react in the geiger ree, negative pulses are generated. These pulses are coupled inio the amplifier where they are amplified. They are then coupled to the trigger circult where they are converted 10 standard size pulses oi power. These standard pulsey are applied to the meter drive: which convers them to stundard pulses of current, averages thij current and drives the meter. Thus the meter detleition is proponional to the average rate of radiation at the gaiger rube.

\section{FUNCTIONAL THEORY (See Figures $3-1$ and $6-1$ )}

\section{High Vollage Supply}

The oscillator trunsistor $Q$ ! drives $\pi$ primary and gets its feedback from Tl's red-orange winding. The voluge is slepped up by Tl's secondary. sectified, filtered, and appliec to VI. VI regulates at $900 \mathrm{~V}$. The current through VI is sensed by Q2, amplified and used 10 cuntrol the cursent through Q3. The current through Q3 controls the bias level of the oscillator Q1. This tends so hold the current through VI to a constant value, regardless of banery voltage. The result of this is that power is nor wasted with new baneries and will silll function with lower voluge batteries. This greatly extends battery life.

\section{Amplifier}

Q4 amplifies and inverts the negative input pulses frorn the detector. It is biaied just into cus - off so its out. put is near 0 V. A pulse turns it on and the resuling positive output starts the rrigger circuit.

\section{Trigger}

Integraled orouit Al is connected to orarat as a monostable mulsubrator whoue pulse width is abo-

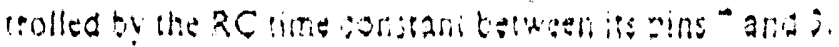

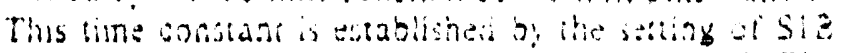

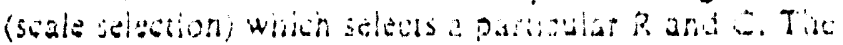

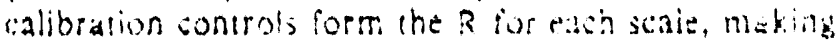
the pulse width onnunuousiy adiustdels fur caliotation.

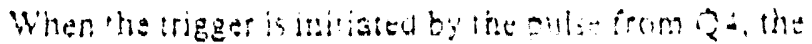
ourput at pin 6 goes positive and holds lanil the pro. decermined time (RG) elapsos.

\section{Meles Driver}

The diver QS is normuly off in no antent nows

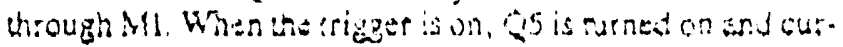
rent flows. The amoun of curtent is determined rg the voliage on the base of QS and whe value of RL. The tength of time what eurent flows is Jetermined by the pusce widen of the trigger. This (curtent times timel porms a certan charg: which is tranjierred to $C 9$ for each event counted. 69 dis. charges through $M !$, yielding a ceruin average current defendent on the rate of inpult pulses Changong the fulie with of the trizger (i.e., thanging scides or iallbration pol sering) changes the aterage eurtrin for a given input pulst rate. This allows the meter to be calibrated 10 read in $m R / \mathrm{H}$ (or $\mathrm{cpm}$ ) at the detect.j.

The response time of $M l l$ is eontrolle 1 by the RC tims consant oi Co and Rl6, the response control. With $R 16$ set 10 lox resistance the lime constisn is lasi, and at high resisiance : is is ilou.

\section{Phone Driver}

Q6 amplifies and inverts the oulput pulse from the trigger, yielding a lirge amplitude negature going pulse whish is capacitively coupled to the PHOVE connector. 


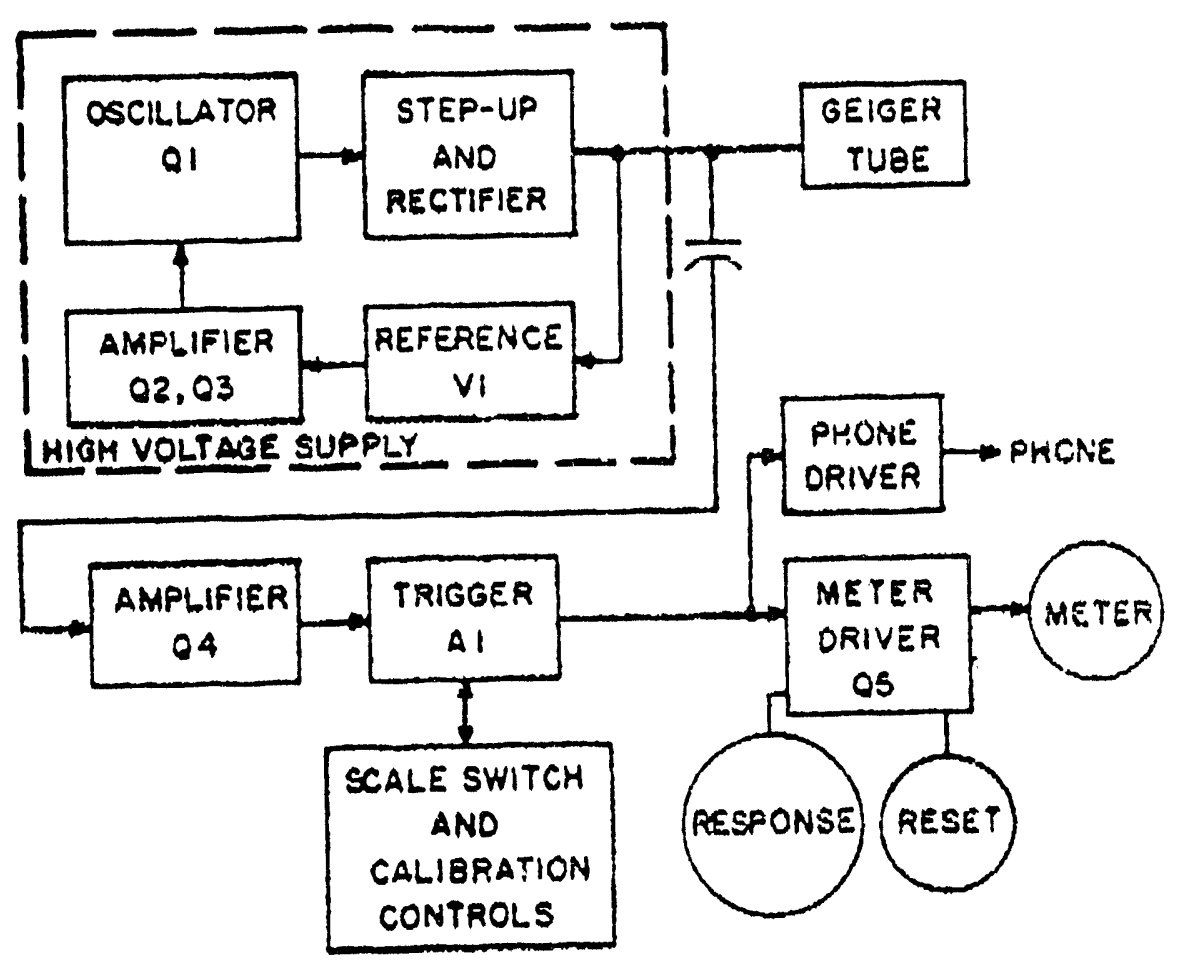

Figure 3-1. System Block Diagram 


\section{SECTION IV \\ MAINTENANCE}

\section{A. DISASSEMBLY AND REASSEMBLY}

\section{Batteries}

The baueries are secured in holders on the ecthed board Pull trie balleries from the holders. Replane by sliding the bareries inw holders, miking cerrain they ase cencered and of the correct polarity. The red teminal cover indicaiss positive polarity at thiat end. Case snould be exeecised when changing baneries because of the sharp ediges on the banery holders.

\section{Elched Board}

The etched board and sover may be separaced for rroubleshooting. Proceed as follows:

a. Remove the batieries 10 prevert elecrical damage during disassembly.

b. Remove the knob and mounting nut from the scale switch.

c. Remole the two nuts from the meter studs.

d. Separate the board and cover withou: putting undue stress on the wires.

e. For troubieshooting, place jumpers from the meter studs io corresponding points on the board and replace the batteries.

\section{f. Reajsembie in reverse ordet of disassembiy.}

\section{B. PREVENTIVE MAINTENANCE}

1. Keep the instrurrent clean and dry

2. Replace the batuaries when their sheck reading is below the acceptabie level.

3. Remove the batteries if the instrument is 10 be inactive for six months or more.

\section{CALIBRATIOY}

For maximum astlray, the instrument shudud be calibrated under the sam- ionditione as it will be used. Refer to Seation 1.B. for effects of garuma ene?gy. battery voliage, and camperalcate pacted as foldovis

1. Each ; ane is insividutil, callbiated by a caliora.

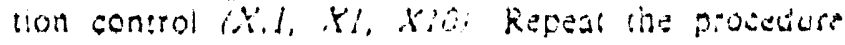
below for edst range.

a. Position the insirumett un a calibiation tange so the desector cencer is in a reld corteponding to now three-quarter soale tneter reading.

b. Expose the gamma source and roit the instid. ment reating. Adjust the calibiaticr control for the range selseled untii the frets indration agetes with the tield.

\section{Callbrations in Counts per Minute}

If courts par minute is 10 be read ins:edd of $m R / h$, then calibration should be to true trequency, Capacitively coupic is pulse generator into the probe connector using a capacilor with a $1 \mathrm{kl}$ or higher voltsge rating. The fulse aenteatcr rust ha'e a negative pulse approximately $350 \mathrm{mV}$ ampisude and frequency covering the instrumeth ming:

Adjust the pulse senerator frequency to corespond with approximtely three quarier scais meler redding and adjus: the galieration controt tor the arize jeteted onti! the moter agrees with the foeguensy. Koptat for each range $(X .1, \times 1, \times 10)$.

\section{TROUBLESHOOTING}

Typical voltages and waveforms are giver on the schematic (Figure 6.1), and component locations are shown in Figure 6.?.

Vollages are measured with a $20,600 \Omega ! v$, or greater, volimeter except the $900 \mathrm{~V}$ point. An electrostatic volumeter or voluneter with $10 \% 0 \mathrm{M}$. minimum input impedince should be used wo chsek the $900 \mathrm{~V}$ : however. if one is not available a conventional meter may be used for an indication of the presence of high voluge. 


\section{SECTION $V$ \\ PARTS LIST}

The following cable lists the electronic items incopporated in the Model E-120, E 120 E and stoult contuin any par:

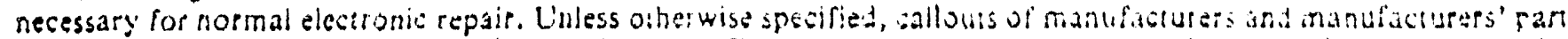
numbers are to be consider dypical examples only. There art no restrigtions against using equir alem parts with th:

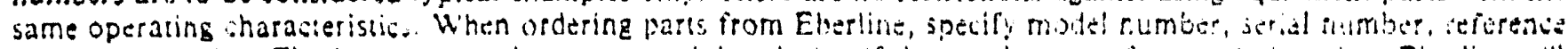
desiznation, value, Eberline nan number, or a word description if the pan has nu reference cesignation. Ebertina lyill

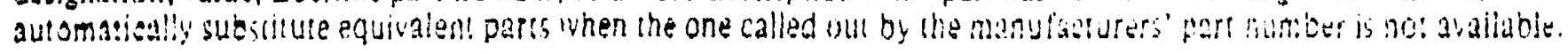

\begin{tabular}{|c|c|c|c|c|}
\hline REE DESIG & PART & DESCRIPTION & $\begin{array}{l}\text { WAVUFACTLRER ANI } \\
\text { PART VLMBER }\end{array}$ & $\begin{array}{l}\text { EBERLIVE } \\
\text { PART VEWBER }\end{array}$ \\
\hline Al & Integraled Circuit & $\begin{array}{l}\text { RTL Duil } \\
\text { NOR Cate }\end{array}$ & 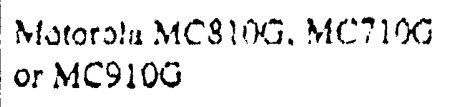 & ICRTCOS1OR(2) \\
\hline $8 T 1,8 T ?$ & $\begin{array}{l}\text { Bailesy } \\
\text { Battery Holder Kit }\end{array}$ & Alkaline "D" Cell & $\begin{array}{l}\text { Evarady rype E9S } \\
\text { or equivalens }\end{array}$ & $\begin{array}{l}\text { BTAKA(4) } \\
\text { BTBप+(S) }\end{array}$ \\
\hline $\mathrm{Cl},-9$ & Canacho: & $330 \mu F, 10 m_{0}, 54$ & Sprague 1500 of equidient & CrTa33!1904!) \\
\hline $\begin{array}{l}c 2 \\
03,010\end{array}$ & $\begin{array}{l}\text { Capacitor } \\
\text { Capacitor }\end{array}$ & $\begin{array}{l}0.247 \mu F, 10 \%, 100 \mathrm{~V} \\
3.3 \mu \mathrm{F}, 10 \%, 15 \mathrm{~V}\end{array}$ & $\begin{array}{l}\text { Spngue } 225 P 47391 \mathrm{WD} 3 \\
\mathrm{CS13}\end{array}$ & $\begin{array}{l}\text { CPFF:T3PSP(2) } \\
\text { CPTA33SP3HIS) }\end{array}$ \\
\hline $\mathrm{CH}$ & Cafachot & $0.01 \mu F, 1.6 \mathrm{kV}, 20 \%$ & CRI ED16-103 & CFCE:03FXV(O) \\
\hline CS & Capacitor & $0.001 \mu F, 3 k v, 105$ & Centralat DD:0-102 & CPCEIOAPSY $(7)$ \\
\hline $\mathrm{C} 6$ & Capacitor & $0.0008 \mu_{\mu} F, 10 \%, 80 \mathrm{~V}$ & SPRAMLE ISIPGOZSRS & CPPFES233019) \\
\hline 67 & Capasicer & $0.008 \mu F, 10 \%, 200 \mathrm{~V}$ & SFRAGUE IOZFGS3G? & CPPFOS3F $3 R(4)$ \\
\hline C\& & Capacitor & $0.68 \mu F, 10 \%, 35 \mathrm{~V}$ & $\operatorname{CS13}$ & CPTAÓ\&:F ZL $(0)$ \\
\hline CII & Capacitor & $33 \mu \mathrm{F}, 10 \%, 10 \mathrm{~V}$ & $\operatorname{csi3}$ & CPTA330H13F(1) \\
\hline$C R 1, C R 2$ & Diod: & Zenes, 3.9V & $1 N 728$ & CRZRINOIEQ(3) \\
\hline$C R S$ & Diode & & $1 N+142$ & CRS:1N4! \&807 \\
\hline CRA & Biode & High Voilage & $\begin{array}{l}\text { Electenic Devices; ine. } \\
\text { HAXSPD }\end{array}$ & CRSTVAC025(j) \\
\hline 11 & Phone Jack & Maie Panel Connecicr & Swilcherafi No. s501 MP & $\cot 5 ! 2(\theta)$ \\
\hline.$M !$ & Mater & $\begin{array}{l}0.50 \mu A \text { (E-120 Face } \\
\text { Siandard) }\end{array}$ & joweil MM.2T & MTPA23(4) \\
\hline & $\begin{array}{l}\text { Meter face ONLY } \\
\text { (for E-120E) }\end{array}$ & & & $25 \cdot 10.472127(3)$ \\
\hline Q1 & Transisior & PNP & $2 \mathrm{~N}+04$ & TROPSNACLA(2) \\
\hline $\begin{array}{l}\text { Q2. Q3, } \\
\text { Q5. Q6 }\end{array}$ & Transisior & NPN & $2 N 4124$ & TRSN2N+12+(2) \\
\hline Q4 & Transistor & PNP & $2 N 4126$ & TRSPZivt126(3) \\
\hline$R !, R 3$ & Resistor & $270,5 \%, 1 / 4 W$ & & RECC271B22(T) \\
\hline$k 2$ & Resistor & $62 k, 5 \%, 1 / 4 W$ & & $\operatorname{RECC6} 23 B 22(9)$ \\
\hline
\end{tabular}




\begin{tabular}{|c|c|c|c|c|}
\hline REF DESIC & PART & DESCRIPTION & $\begin{array}{l}\text { MANUSACTURER AND } \\
\text { PART VILYHER }\end{array}$ & $\begin{array}{l}\text { EBERLINE } \\
\text { PART NUABER }\end{array}$ \\
\hline R. & Resisior & $330,5 \%, 1 / 4 W$ & \multirow{8}{*}{ ' } & $R E C C 331822(9)$ \\
\hline $\mathrm{R}:$ & Resistor & $22 \mathrm{M}, 50 \%, 1 / 2 W$ & & RECC:268:310, \\
\hline Ro & Resssto: & $1 M, 500,1, W$ & & 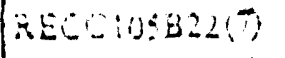 \\
\hline$R 7$ & Rasistor & $4.7 k, 500,1.4 \mathrm{~V}$ & & gecos?2822(1) \\
\hline R3 & Resisior & $2+k, 5 \% 0,1.4 w$ & & $R E C G 2+j E 22: 00)$ \\
\hline$R 9$ & Rssistor & $27 x, 5 \%, 1,+w$ & & $k E 60: 73822(3)$ \\
\hline 8.10 & Resistor & $2.2 k, 5 \%, 1 / 4 W$ & & $\vec{K} \equiv 00222022(0)$ \\
\hline$R 11$ & Resistor & $2.7 \mathrm{k}, 570,1 / 4 \mathrm{~W}$ & & REC6:272B22:5? \\
\hline$R|2, R| 3, R \mid 4$ & Potentiometef & $10 k$ & $\begin{array}{l}\text { CTSTYYe KLUIR!OSS! } \\
\text { ARR9107 }\end{array}$ & PTCO:03BOs(ii) \\
\hline RIS & Resistor & $220,5 \%, 1 / 4 \mathrm{WV}$ & & RECC:21B22(2) \\
\hline Rlá & Porentionseter & 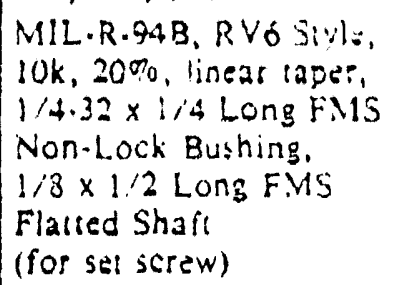 & $\begin{array}{l}\text { CTS series } 3000 \\
\text { ot equivatent } \\
\text { CTS }+2 \text { t4t }\end{array}$ & PTEGlOJEA3(1) \\
\hline R17 & Resistor & $10 k, 50,1 / 4 W$ & & $\operatorname{RECC103R22(2)}$ \\
\hline$R 18$ & Resistor & $1 k, 50 \%, 1 / 4 W$ & & RECC $102822(4)$ \\
\hline SI & Switch, Rotary & Scale & & SWRO27(9) \\
\hline S2 & Switch, NO & RESET & Graythll 30.1 & $5 \cup P B=(8)$ \\
\hline$T I$ & Transformer & & Microtran $M 7120$ & TFHV $2(0)$ \\
\hline VI & Regula:or Tube & $900 \mathrm{~V}, 2 \%$ & $\begin{array}{l}\text { Vicuoresn GV3B.9No or } \\
38+1\end{array}$ & TUVRSOO(i) \\
\hline \multirow[t]{3}{*}{12} & Connector, Prube & & $20.1098: 4$ & $\operatorname{cxen}(\hat{0})$ \\
\hline & Probe Cable & BNC.BNC. 36 "lons & & $C_{A} \cdot 1 \cdot 35(3)$ \\
\hline & Propa Cacle & BNC.BNC, OO" long & & $\begin{array}{l}\text { (STANDARD) } \\
\text { CA-1-BO(3) } \\
\text { (CTTIONAL) }\end{array}$ \\
\hline
\end{tabular}




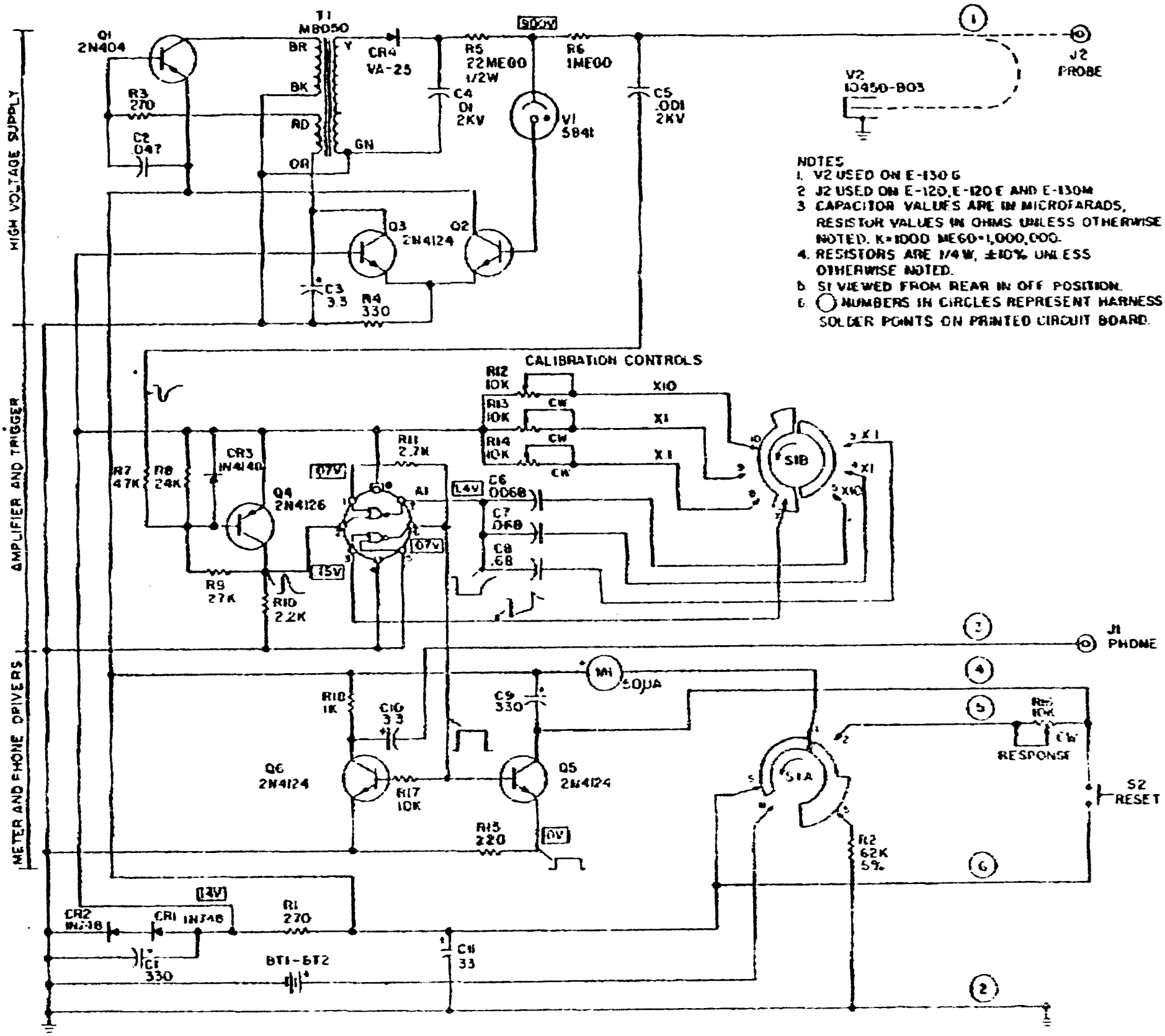




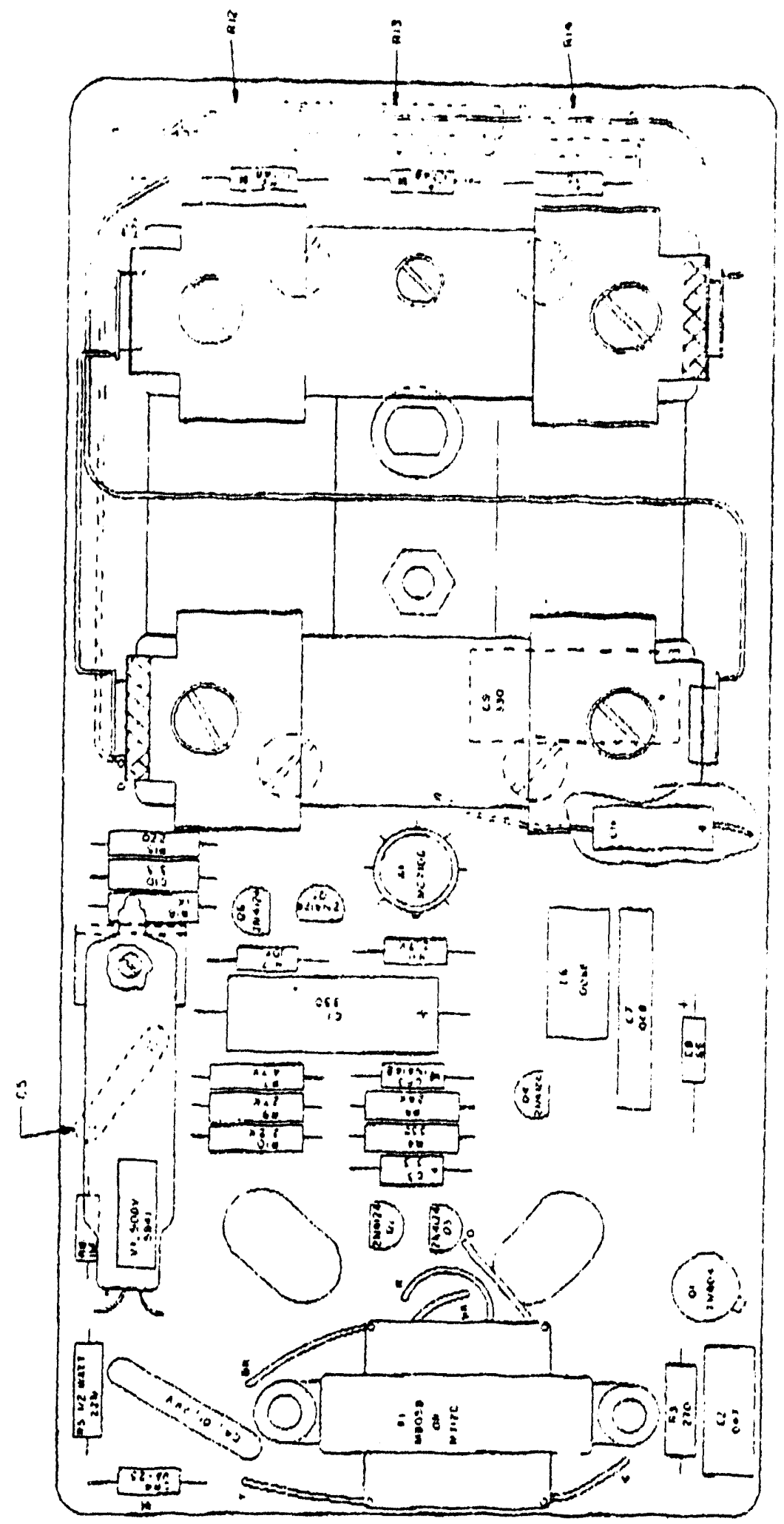



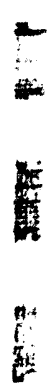

$\frac{2}{1}$

4

量 
1513

IJSEL MANITAT.
154

INTELTCENA SEISOR URHT

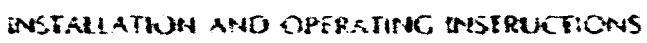

\section{COMYAT}

\section{ULTRASONIC \\ LEVEL MEASUREMENT \\ MOTION CONTROL AND \\ PROXIMITY SENSOR \\ PRODIJCTS}

\section{CONTAQ TECHNOLOGIES CORPORATION}

IS MAAN STREET

BRISTOL, VERMONTOS 443

802/453-3.332

\section{cofran:}

in riasonte fiomerts

\section{riont:}

The ISU generates measurement ditas taied in the distance if abjecos locided in front

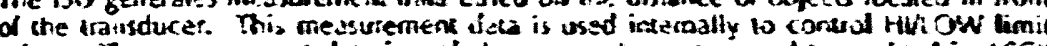
re'ays. Hise mesiure cata locmial for urits with these features. IEU uperatirg paranteters are set cither an the

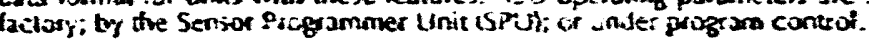

2.0 INSTALIATION:

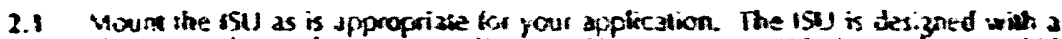

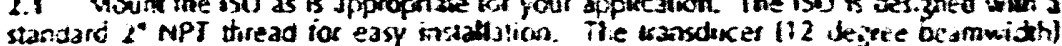

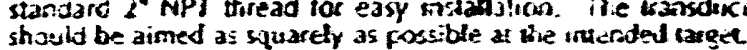

2.2 Connect the power sonuce uting the color contal leak. RED for $(+1)$ ard butCK

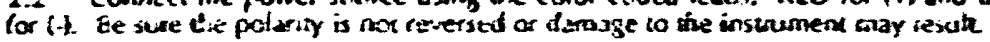

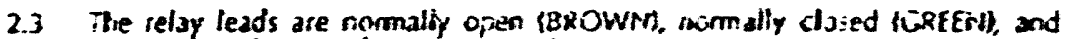
comonon iwHitel. Conneat them as requiret.

2.4 For the +1 option 4/20ma output, cunsiect the external wolkage to the OR.ivGE lead icuirent sinks and the GLCIE lazd (Eeturnd to ground. For the 85 optinn bielf excixed use TAN (tizoma souke) and Orar.je traminl.

25 If you have an isu with the RS+2z serial communications proticol. cunnect the comarnuic aticn icads as follows:

TX+ RPURPLE and TX- RELLOW: are the sigriats transmiaing da!a trom the ISI) and should be connezied wi the aporopriale ceceiver.

$R X+$ (PINKi and PX- IGREY are the signals receiving commands foom the retricte computer or kerriad and thak $k$ be connected to the afpropistle Irasminter.

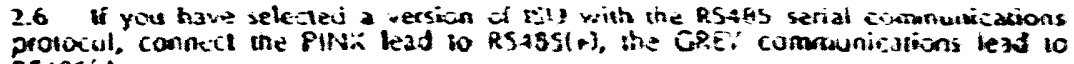
RS465i-:

3.0 PUWES ON:

3.1 Su legins operating and mahir. 3 meajurements as soun is power is agolied. This is indicated by an sudible chiking from the sensos; ifuth the slate sa in interinal tetaps; 

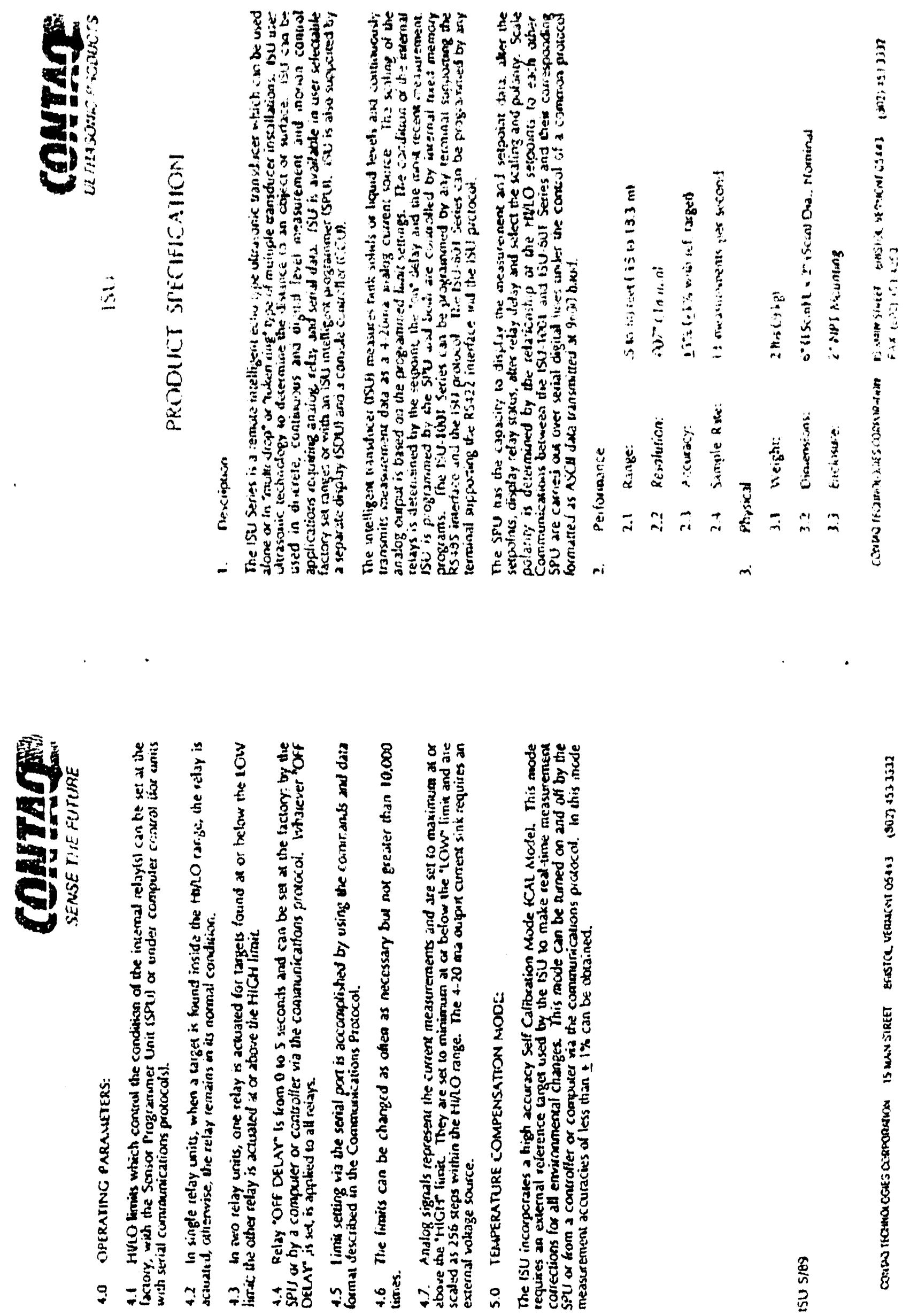

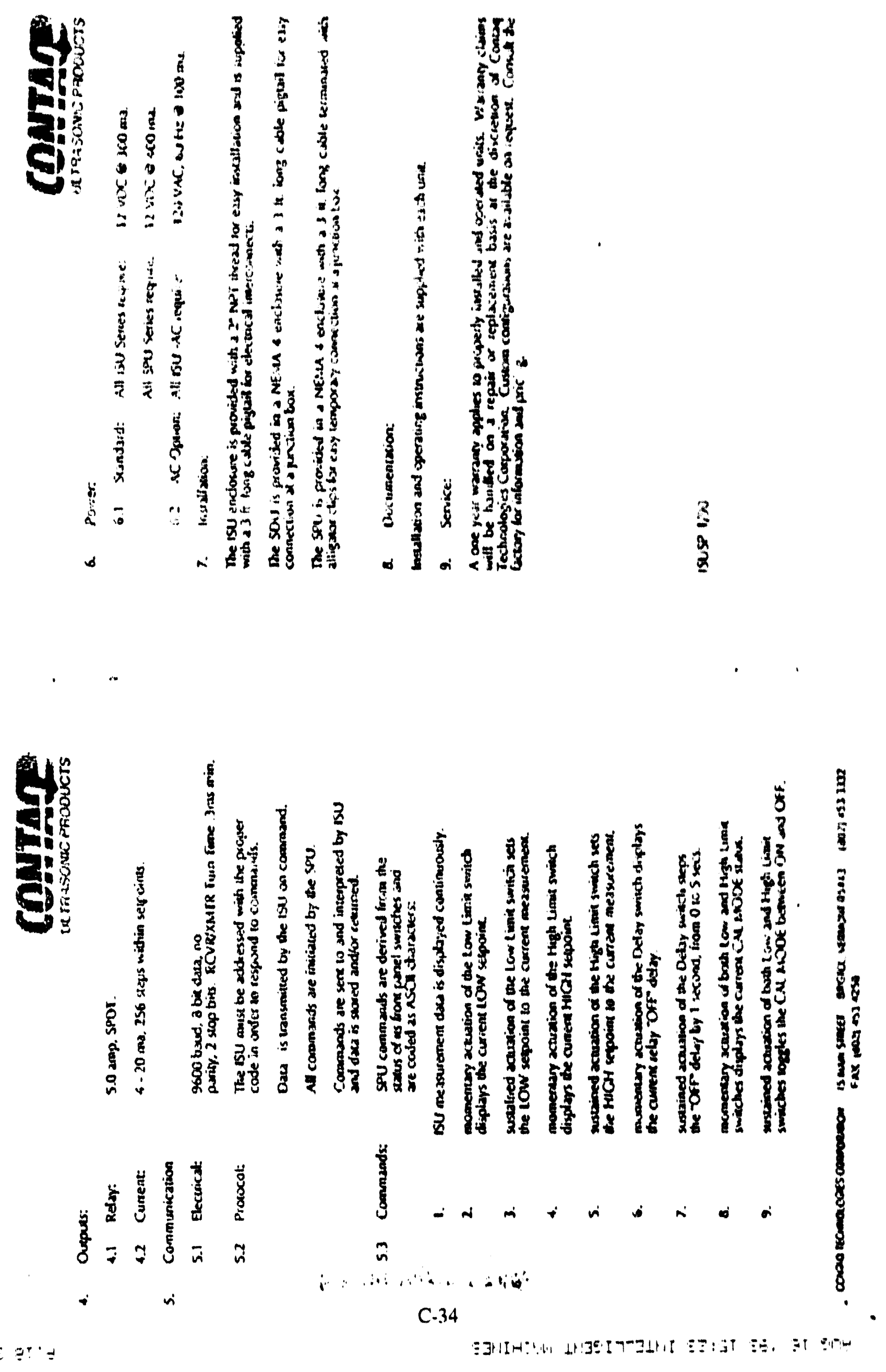


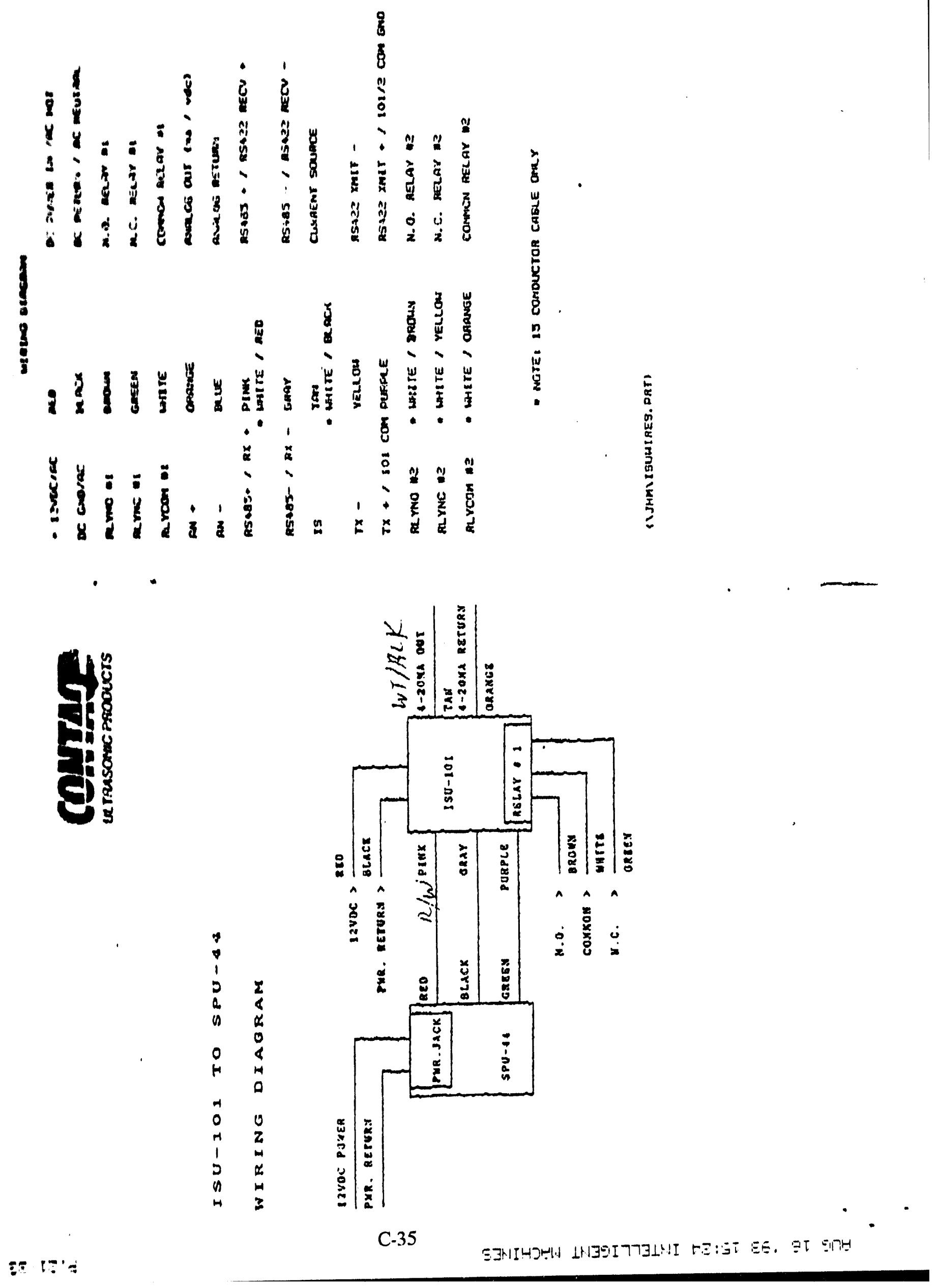




\section{ISU-EN2 OPTION OPERATING INSTRUCTIONS}

\section{Description}

1.1 The ISU.EN2 option allows two or more ISU's to operate in a synchronized, noninterfering mode, located within one inch of each orher. The ISU-EN2 will also operate as a standard ISU when not interconncoted as described in paragraphs $2.1,2.2$ and 2.3 .

NOTE: When an SPU is connected to any ISU in the LOOP to ser the HIGH: LOW limits, DISCONNECT all WHITE-BROWV to WHITE-ORANGE WIRES to increase the speed of communications. Fatlure to do this will result in siover SFU data acginision and display.

\section{Operating Instructions}

2.1 Connect the WHITE-BROWN WIRE of ISU \#1 To the WHITE-ORAVGE WIRE of IS \# \#

2.2 Connect the WHITE-BROWN WIRE of ISU \#2 to the WHITE.ORANIGE WIEE of ISU \#3 etc.

2.3 Connect the WHITE-ORANGE WIRE of ISU \# IT the WHITE-BROWN WIRE of the LAST ISU in the loop.

2.4 Apply power to the ISU's.

2.5 All other instructions / specifications are standard ISU. 


\section{ISU}

\section{COMMUNICATIONS PROTOCOL}

1. Description

The iSU-1001 and 1SU-801 Series are intended ypocifically for networhed applicitions in "multi-drop" or Token ring" mpe of multiple uansolucer irsstalfations. Antulis-drop applications are based on the RS 485 electrical interface ard will support up 1032 nodes. Token Ring spe of network applications are based on the RS422 electrical inkerface and

An SPU Series programmer can be used with an individual ISU wo display and control its operating parameters.

A lerminal, compuster or programmatle lozic controller capabte of ASCil vo can be used to display and control the operating parameters of ndivisual and networked iSUs.

Communicaticns between the $15 U-1001$ and ISU-801 Sesies are carried out over serial digital tines under the control of a common protocol formatted as ASCII dat addresses. One addess will be serialized and unique 20 the paricular iSU and the other address vill be a witdcand for use by the SPt

2. Communication

2.1 Electrical:

9600 baud. 8 bir data no parit\% 2 stop biss. RCURIXMTR Turn timé: . $3 \mathrm{~ms}$ min.

2.2 Protocol:

The ISU must be addressed with the proper code in order to respond to commanids. This code is the Asch character' " 2 " followed by the serial number of the selection isU.

Data is uansmitted by she 154 on cormmind.

Alt commands are initidted by the external device or driver.

Corrmunds are sent to and interpreted by ISI and dal 3 is stored andior returnid.
2.3 Commands

2

ro

$+$

L"

$* a$

' $R$ '

o

$\because$

.2

$T$

- $v$

$\gamma$

•E⿻

$e_{0}$

pe

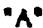

" $\mathrm{C}$

"H*

$\cdot N$

-p*

$M$

' $\mathrm{k} \cdot$

$\checkmark Q$

$\cdot \%$
Cominands di: Codied as ASCIl chalaciers:

Preface to node address.

ISU measureinent data is relumed on command.

returns the currenc LoW sctpoirs

sets the LOW setpoint io the current measurement

returns the current Hictr stcpoinc

sets the HiGlt setpuint to the current measusement

rewins the cursent retay off" delay.

increments the "Off" defay by 1 sec, from 0 to $S_{R}$

returns the Current CHL ATODE stalus.

sets the CAL MUOOE to ON.

sets the CAL MOOE to OFF.

returns RELAY I conirul status.

ISU RELAY I CONUOL Eviable.

ISU RELAY I control disable.

IeTURAS RELAY I stzlus.

RELAY I activate.

RELAY 1 deactivate.

returns RELAY 2 coritrol status.

ISU RELAY 2 control endule.

ISU RELAY 2 couldud disade.

returns RELAY 2 slatus.

RELAY 2 delivale.

RELAY 2 deactivate. 


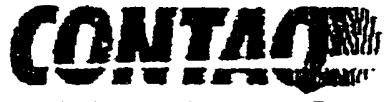 SENSE THE FUTURE}

3. Programming Examples:

3.1 Read Data: ISU Serial Number 3456

Coniroller Sends: 23456:U[CR]

ISU Rewrns: 1234SFCRI

3.2 Check Refay I Control Swous, Disable isU Control and

Acivale Relay I lom Contraller.

Contraller Sends:" Z3456:)(CR)

15U Returns: $\quad$ ON(CR)

Controlter Sends: Z3456:F(CR)

ISU ReRurns: OFFICR

Cantealler Sends: 23456:G(CR)

ISU Resurns: ONICR

3.3 Scaling: Inches $=\{$ Raw Cound $\times .007324218$

4. Consult the factory for further information and pricing on currently available

ISUCOM 689

is

10

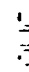

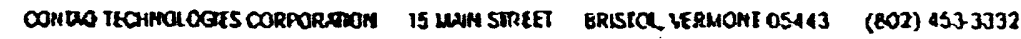




\section{$=j \mathrm{GARO}$ \\ HODUST INFORWATON}

\section{TGS 822 - for the detection of Organic Solvent Vapors}

\section{Features:}

* High sensitivity to organic solvent vapors such as ethanol

* High stability and reliability over a long period

* Long life and low cost

* Uses simple electrical circuit

\section{Applications:}

* Breath alcohol detectors

* Gas leak detectors/alarms

* Solvent detectors for factoriss, dry cleaners, and semiconductor industries

The sensing element of Figaro gas sensors is a tin dioxide ( $\mathrm{SnO}_{2}$ ) semiconductor which has low conductivity in clean air. In the presence of a detectable gas, the sensor's conductivity increases depending on the gas concentration in the air. A simple electrical circuit car convert the change in conductivity to an output signal which corresponds to the gas concentration.

The TGS 822 has high sensitivity to the vapors of organic solvents as well as other volatile vapors. It alco has sensitivity io a varicty of combustible gases such as carbon monoxide, making it a good general purpose sensor. Also available with a ceramic base which is highly resistant to severe environments as high as $200^{\circ} \mathrm{C}$ (model\# TGS 823 ).

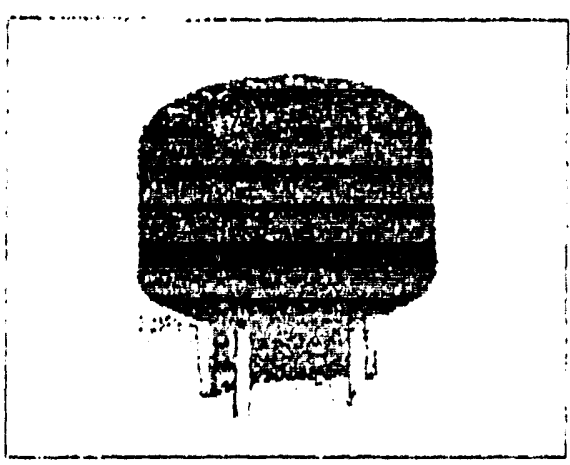

The figure below represents typical sensitivity chiaiacreristics, all data having been gathered at standard test concitions (see reverse side of this sheer). The $Y$ axis is indicated as sensor resistance ratio (F.s/Ro) which is defined as follows:

Rs = Sensor resistarice of displayed gases ar various concentrations

$R_{0}=$ Sensor resistance in 300 ppm etinanol

Sensitivitu Characteristics:

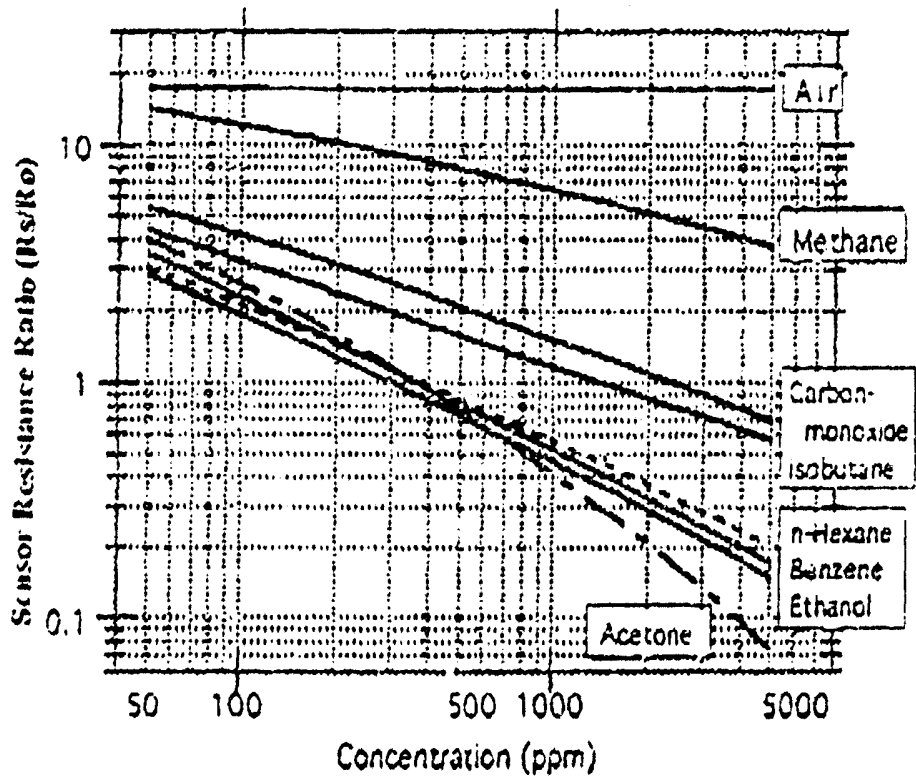

The figure below represents typical :emperature ard humidity dependency characteristics. Agtin, the $Y$ axis is indicazed as sensor resistance ratio (Rs/Ro), defined as follows:

RS = Sensor resistance at 300ppm of ethanol at various temperatures/hunidities

Ro $=$ Sensor resistance ar, $3 C 0$ ppm of ethanol at $20^{\circ} \mathrm{C}$ and 65 si R.H.

Temperature/Humidia Dependenoxi

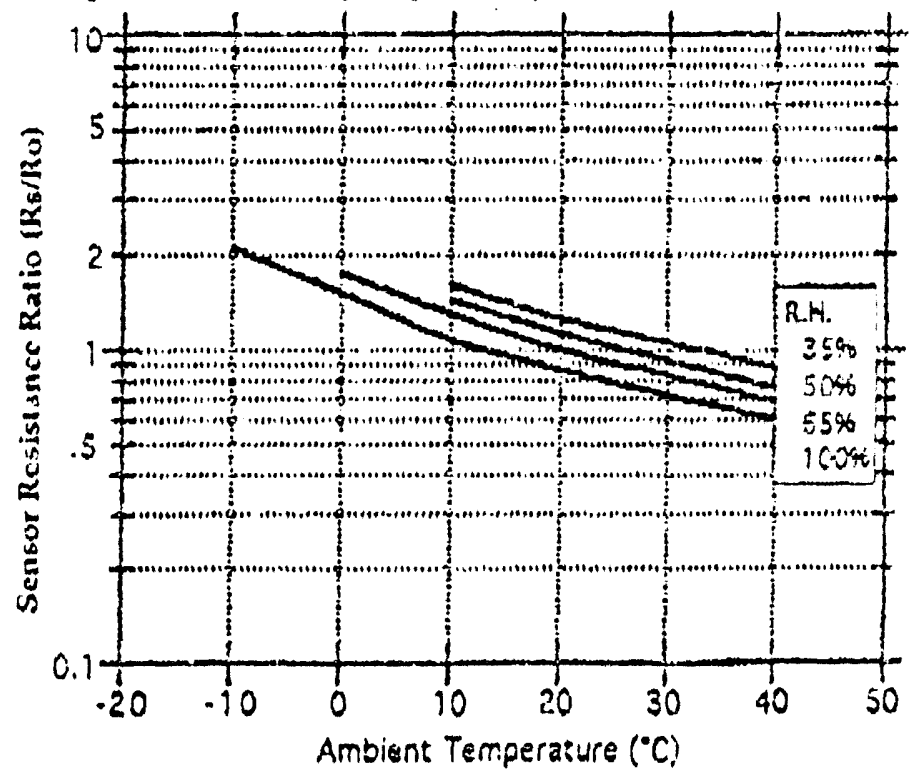




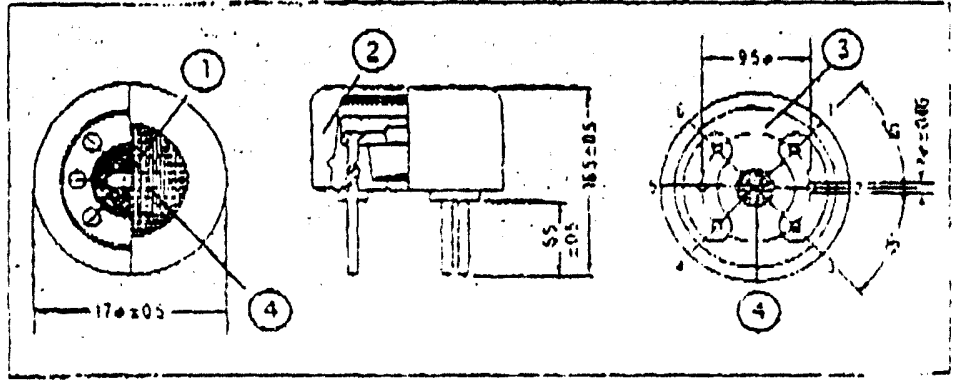

(1) Sensing Element:

$\mathrm{SnO}_{2}$ is sintered to forml a thick film on the surface of ari alumina ceramic tube

(2) Cap: whlch contains an internal heater.

Nylon 65

(3) Sensor Base:

Nylon 66

Flame Arrestor:

Pin Connection and Easic Meáuyrizs Circult

The numbers shown around the sensor symbol in the circuit diagram at the right correspond with the pin numbers shown in the sensor's structurs drawing (above). When the sensor is connected as shown in the basic circuit, output across the Load Resistor ( $V$ RL) increases as the sensor's resis:ance (Rs) decreases, dopencing on gas concentration.

\section{Standard Circuit Conditions:}

\begin{tabular}{|c|c|c|c|}
\hline uspom & sembol & Gatoovotuos & Kegrorks \\
\hline Herso votckgos & $V_{n}$ & $5.0=0.2 \mathrm{~V}$ & $A C$ or $D E$ \\
\hline 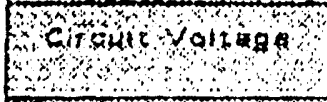 & $V_{G}$ & $M i x .241$ & $\begin{array}{l}A C \text { Oi } D C \\
\text { P PSIISNiW }\end{array}$ \\
\hline WoSR RASIGTRRGA & $R_{i}$ & Variable & $-m S=15 \mathrm{mw}$ \\
\hline
\end{tabular}

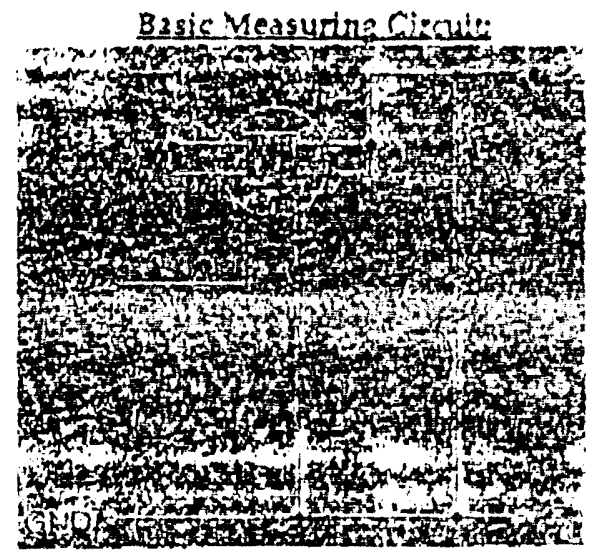

\section{Elecrisal Characleristics:}

\begin{tabular}{|c|c|c|c|}
\hline $\begin{array}{r}\text { Rem } \\
\text { Ir }\end{array}$ & symbal & 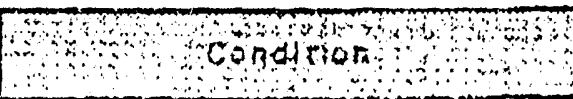 & Solociflcalion \\
\hline Stnsor Pesistance lo & Rs & Etrianol at 30 Dppm/Air & $1 k \Omega-10 k \Omega$ \\
\hline $\begin{array}{l}\text { Change Rata at } \\
\text { StnSor Resistanos }\end{array}$ & RSIRO & 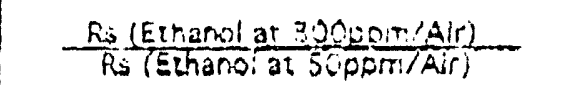 & $0.40 \pm 0 . ?$ \\
\hline Hedter Peslatance & $R_{H}$ & Room tertiperatu:e & $38.0=3.0 .2$ \\
\hline 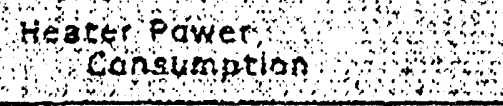 & $P_{H}$ & $V H=5.26$ & $660 \mathrm{~mW}=55 \mathrm{~mW}$ \\
\hline
\end{tabular}

\section{Standard Test Conditions:}

TGS 822 complies with the above electrical characteristies when the sensor is :Ested in standard conditions as specified Delow:

Test Gas Condirions: $20^{\circ} \pm 2^{\circ} \mathrm{C}, 65 \pm 5 \% \mathrm{R} . \mathrm{H}$.

Circust Conditions: $\quad V_{C}=10.0 \pm 0.1 \mathrm{~V}(A C$ or $D C$ ), $V_{H}=5.0=0.05 \mathrm{~V}(A C$ or $D C)$, $R_{L}=10.0 \mathrm{~K} \Omega \pm 1 \%$

Preheating period before resting: More than 7 days

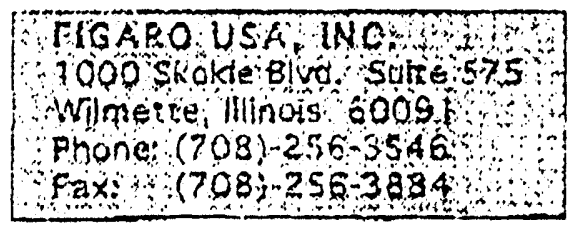

Sensor Resistance (Rs) i\$ caiculated by the following formila:

$$
R S=\left(\frac{V_{C}}{V_{R}}-1\right) \times R_{L}
$$

Power dissipation across sensor elecirojes $\left(P_{S}\right)$ is calculateo by the following furmula:

$$
P_{S}=\frac{V_{C}{ }^{2} \times R_{S}}{\left(R S+R_{L}\right)^{2}}
$$




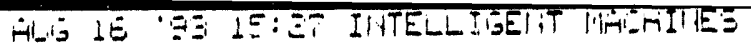

\section{IR $\mathrm{t} / \mathrm{C}^{\mathrm{TM}} .2$ Specifications}

A.ddendum to IR Vo brochure. Please refer to standard in V'o speciflcations in the brochure or manual with the following exceptions:

Signal Output: Thermocouple type $J$ and $K$ (iype $T$ and $E$ avaiable by special order).

Output Impedaṇce: $4 \mathrm{~K} \Omega-10 \mathrm{~K} \Omega$ nominal (depending on model)

Repeatability: $\pm 1 \%$ over sensing range

Sensing Temperature Range: Blackbody (emissivity= i) target temperature lange of $0^{\circ} 102000^{\circ} \mathrm{F}\left(.18^{\circ}\right.$ io $\left.1100^{\circ} \mathrm{C}\right)$ for all models

Case Operating Temperature: $0^{\circ} 10212^{\circ} \mathrm{F}\left(-18^{\circ}\right.$ to $\left.100^{\circ} \mathrm{C}\right)$

(Sensor may be operated in ambient of $250^{\circ} \mathrm{F}\left(121^{\circ} \mathrm{C}\right)$ if air purge system used, higher ambients require air or water cooling of sensor)

Field of Vlew: Nominal 2:1 (at distance $x$, spot size diameter is $1 / 2 x^{\prime}$ )

Minimum Spot Size: 0.16 inch $(4 \mathrm{~mm})$

Dimenslons: $2.45^{\mu}$ length $\times 0.5^{\mu}$ diameter $(0.2 \mathrm{~cm} \times 1.3 \mathrm{~cm})$

Alr-Purge Adaptor: Brass hexnut $.75^{\prime \prime}$ span $\times .312^{n}$ thick (19mm $\times$ : $8 \mathrm{~mm}$ ) inclucied

To Order: IR ic.2...... (example: IR U/c.2.K-140F-3)

$-J, K, T, E$

$\because 98.6 \mathrm{~F} / 37 \mathrm{C}, 140 \mathrm{~F} / 60 \mathrm{C}, 180 \mathrm{~F} / 90 \mathrm{C}, 240 \mathrm{~F} / 1200,280 \mathrm{~F} / 1400,340 \mathrm{~F} / 170 \mathrm{C}, 440 \mathrm{~F} / 2200$

".cablo longth $3 \mathrm{ft}(.9 \mathrm{~m})$ standard; additional lengths optional

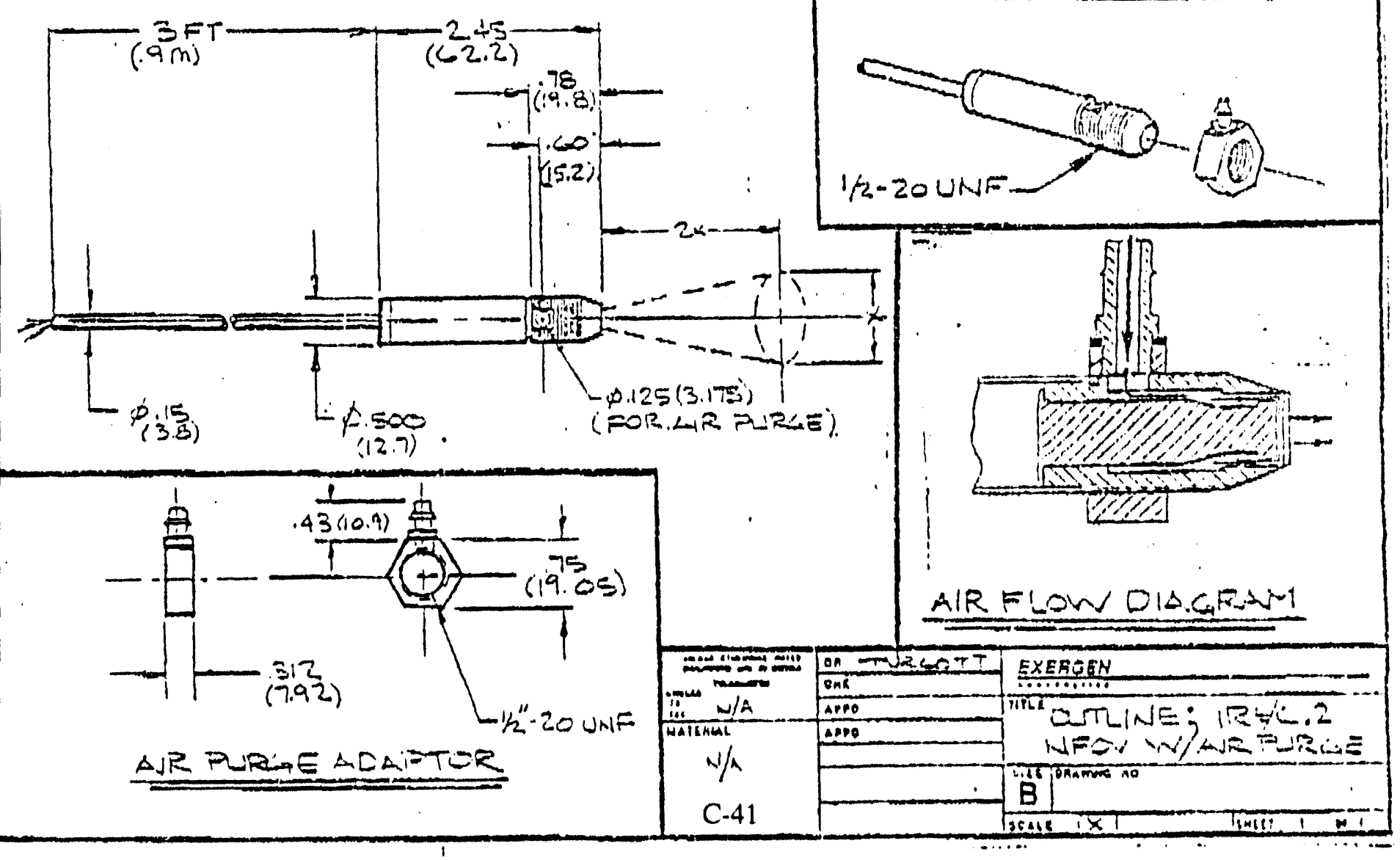


C. 42 
1.

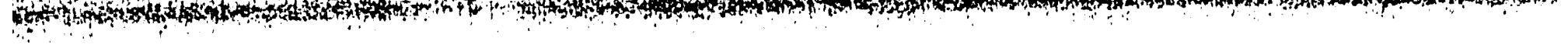

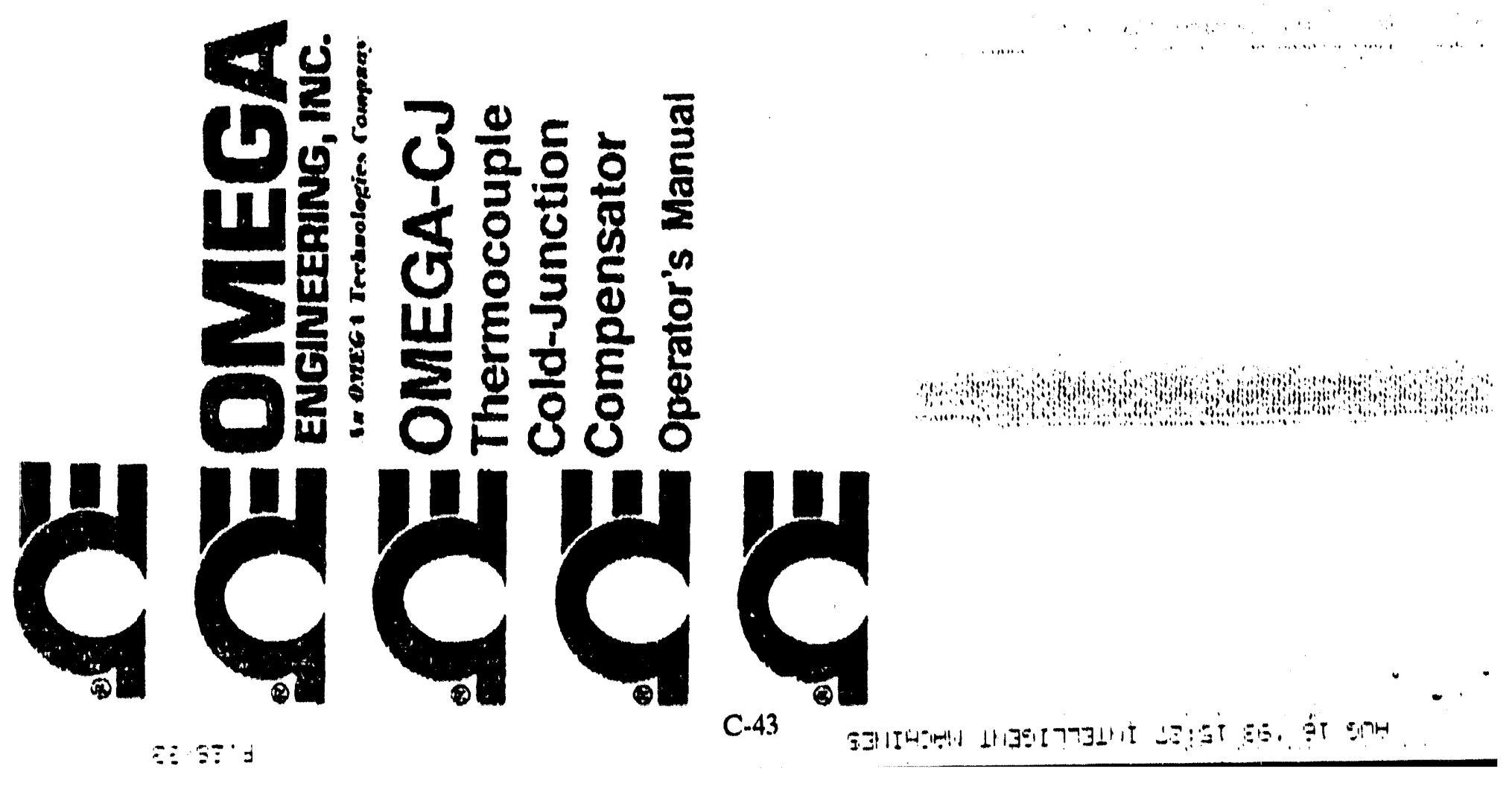




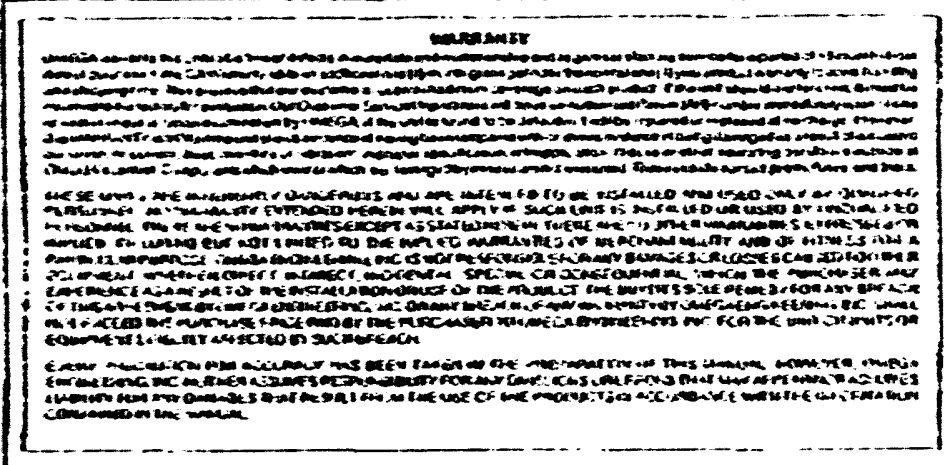

\section{CIOMEGA}

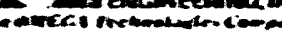

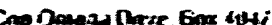

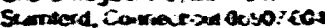

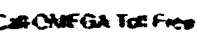

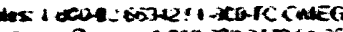

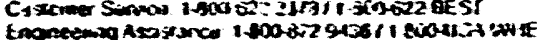

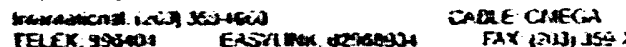

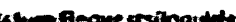

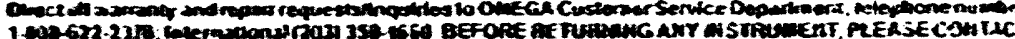

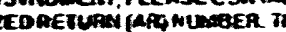

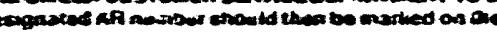

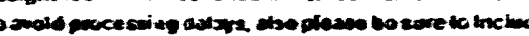

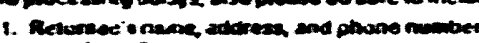

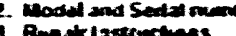

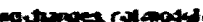

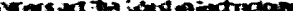

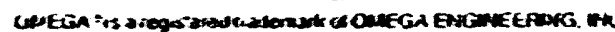

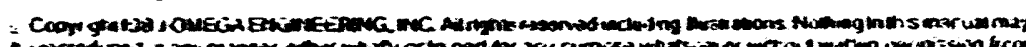

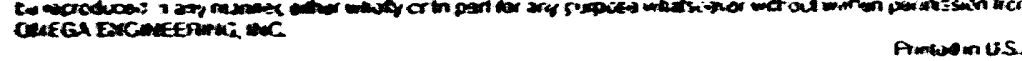
光?
II

$\$ 484 i 0289$
TABLE OF CONTENTS

OAEGA-CI THERHOCOUPLE COLD JUNCTION COMPENSATOR

\section{SECTION}

PAGE

SECTION 1 NTRODUCTION $\ldots \ldots \ldots \ldots$

11 General Eescription . . . . . . . . . . . . . . .

1.2 Features $\ldots \ldots \ldots \ldots \ldots \ldots$

SECTYON 2 UNPACKING $\ldots \ldots \ldots \ldots \ldots \ldots \ldots \ldots$

SECTION 3 OPERATLN . . . . . . . . . . . . . . . .

3.1 Dreatinty Procedure $\ldots \ldots \ldots \ldots \ldots \ldots \ldots \ldots \ldots$

32 Battery Piealacement. . .

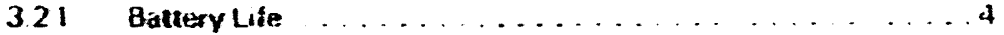

322 Replacmog the Eattery ................. 4

SECTION 4 THEORY OF UPERATION . . . . . . . . . . 5

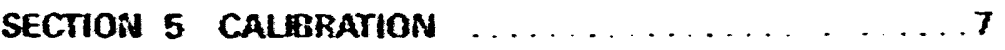

SECTION 6 SPECIFICATIONS $\ldots \ldots \ldots \ldots \ldots \ldots \ldots . . .6$

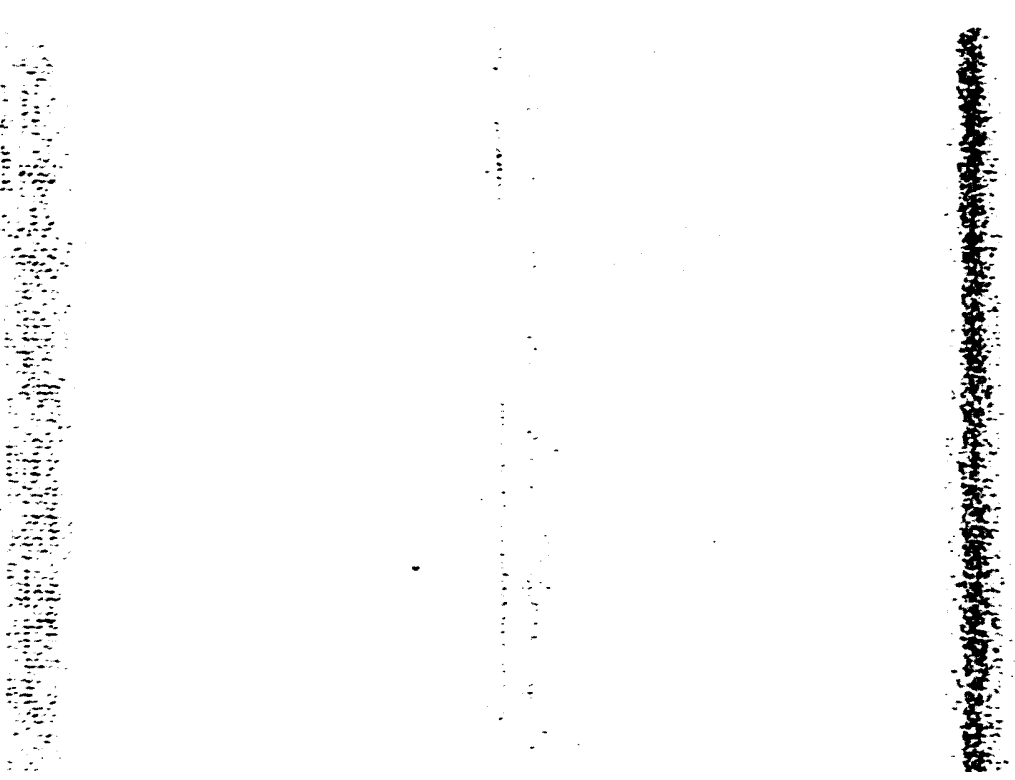




\section{SECTION 1 INTRODUCTIOA}

\section{GENEAAL DESCFMTION}

$\therefore$

$\because$

The ONKGA* CJ is a portable battery-pomered automatic cold puncThe compre

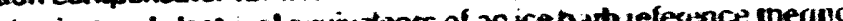
cousle at $0^{\circ} \mathrm{C}$ or $32^{\circ \mathrm{F}}$.

Themocouples can be ghugged directly naw the OMEGACA A puick desconnect malte plux and ourfut pack ivith bankna piugs jee provin ed for connecting the CJ to potentiometers as well as to ineters and reconders of high incun impedance

\subsection{FEATUFES}

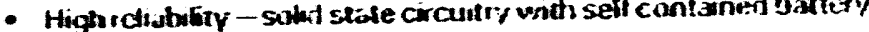

- Rugged construction

- Calor coded thermocouple cabbratron

- Instanlarequs ivaemi-up

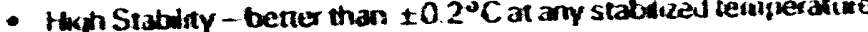
over its full $+10^{\circ}$ to $50^{\circ} \mathrm{C}$ range

- Exveme versatitity - unit con the plugged dinectiy wito a ther mucouple or snto a jack pane

- Lorig batsery bfe-1500 hours or knger depending ori calibratun

\section{SECTION 2 UANPACKING}

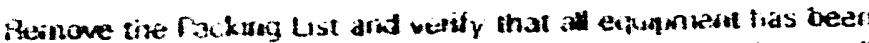
received if the:re are any rituestions thout the shiprivent, piease call

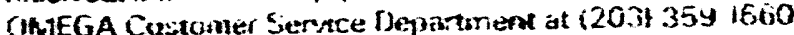

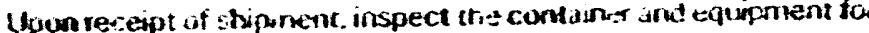

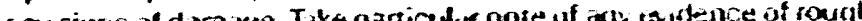

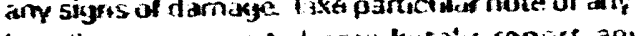

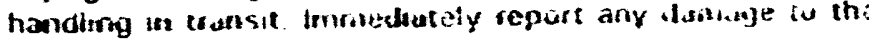
stupping agent

$$
\text { MOTE }
$$

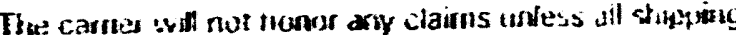

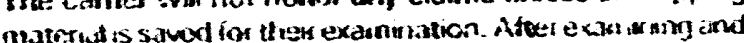

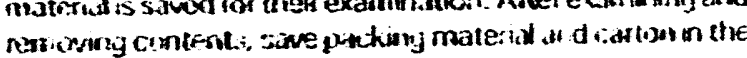

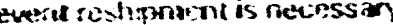

\section{SECTKON 3 OPERATION}

\section{OPERATWG PROCEDUAE}

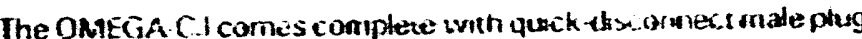
ind ontpult jack with barkana plugs for comectar in to potentionesers

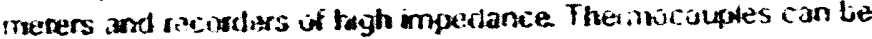
ikugg? ditectly and the CAMEGA CJ 


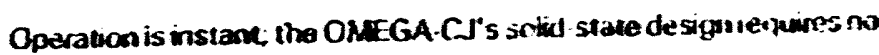
verm-up

1. Comect outout 10 OMEGA-CS (TO INST PUMENT) to readout instrumeat. Coppez wire extension le ads must be usind

2 Connez: thermocouple to other end of OMEGA.C.J iTO IHEPHOCOUPLEF. If themocouple probe is nor directly con pled to OMEGACW, in is nocessary to use thermoconshitu exten sion mies from the thermucouple to the OMEGA-CJ

3. Move ON-iff stide swich to On to energize unit.

4. The readout instnument wils move indicare the artual temperature unaffected by ambient temperature changes.

\section{MOTES}

OMEGA-CJ has an internal resistance of to to 250 chrns depending on calturation; therefore, radount instruments dependiang on calibration; therefore, radount instruments of high input resis

Follovirig uso, always move ON OFF slide switch to OFF to conserve the battery.
3.2

3.2 .1

\section{BATTEFY REPLACERAENT}

The self-cuntulned dinitay is a mercury rell-1.35 " Mla!lary

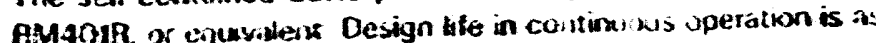
fotins:

Calibrotion.

\section{Approximale Lile}

(Hours)

Chromet-Aunvi

inoti)

i500

Copper-Cunstanton

Clmant Cimstantian

3to.

Pullo\% fantit

1350

28003

PUt3\% Fin.PE

WW

5000:

W; $5 \%$ Fiz-Wh26\% Re

5000

wh $3 \%$ Re-WH:5\%, At

\subsubsection{Raplacing the Battery}

The intic stor an itwe face of the OAHEGA-CJ, energized by depress ing the BAT TEST pust button indicates when vatiery replacement is nociession. Tha bisttery should be replaced witer the indicatior

bocomes dun. 


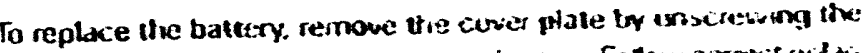

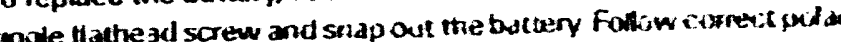
ty wher instaling the sat acentens tuattery

NOTE

Fin extended sibelfible of the mescury biattery. audid storage at liayth temperalures.

\section{SECTION 4 THEOAY OF OPERATION}

The OAtEGA-CJ introduces an emt into the curcult whish is equivilent to an ice b.3th. This enf is regulated iny a temptidature

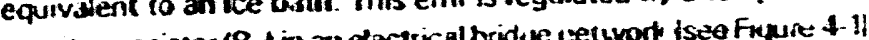

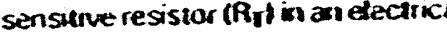
ivtucin compensates for anberist temperature changes. always maritduing a $0^{\circ} \mathrm{C}$ or $32^{\circ} \mathrm{f}$ reference equiviant.

The temuerature sersitive resistor $\left(R_{5}\right)$ is themally hotegrated with

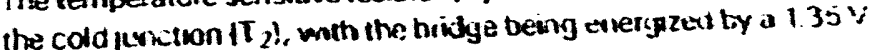
n.ercury iattery

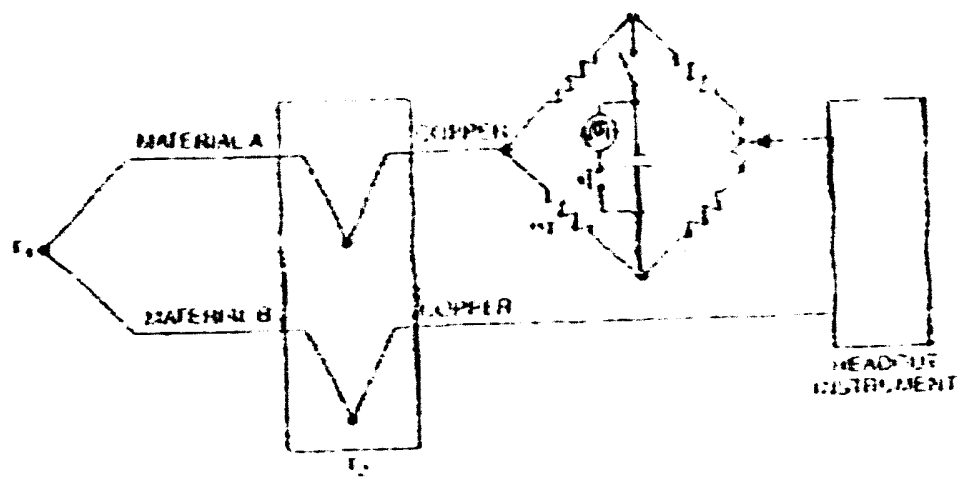

Fivere 4.1. Wising Disyram

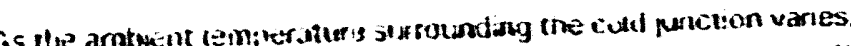

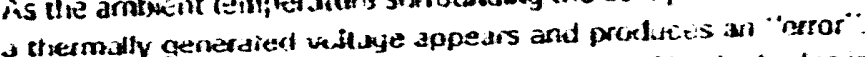

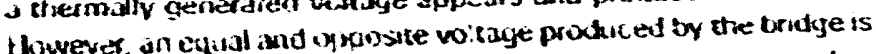

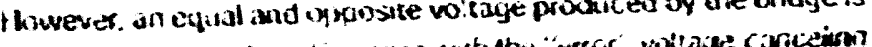

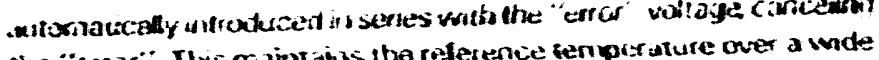

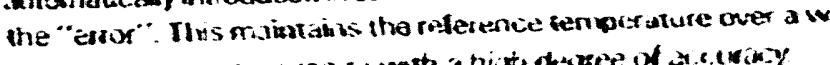

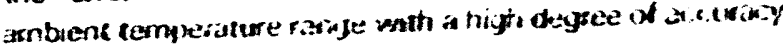

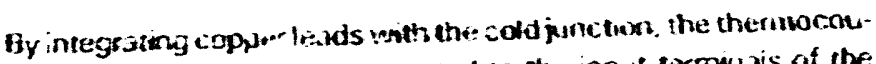
the inaterial itself is mot connected to the input termwixis of the fle inaterial itself is mot connected to the inpotit remwis of the 


\section{SECTION 5 CALBAATION}

1. Remove the cover plate by unscrening the single thartead screw tocated on the back of the unit isee figure 5-11.

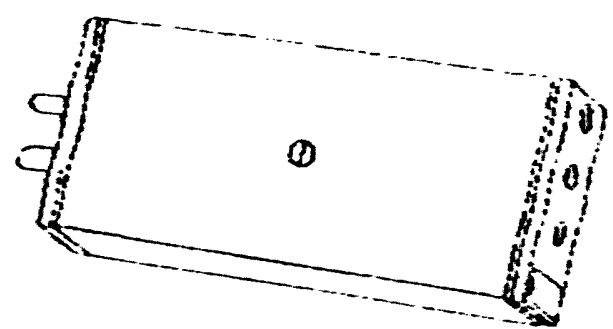

Fignes 5-1. Onega-cs

2. Coanect CJ to the thermocouple peobe and sedout instnumert.

3 Place the themocouple probe unto an icebath and wat about 10 munutes for system to stabiluze

4 Adist the ZERO POTENTIOMETEA Rocated on the pronted cin ouk boand inside the $C$ I unt the readour instrumidat shows " $\sigma$ " [zero]

5. Replace cover plate and secure with screvi.

\section{SECTIOA 6 SFECIFICATIOAS}

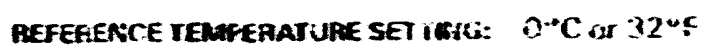

conperasamon accuracy:

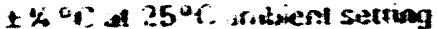

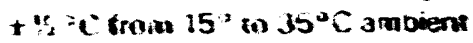

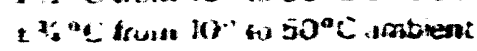

STORACE IEAMERATUPE-

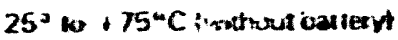

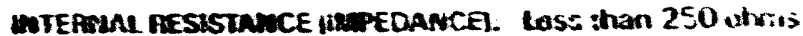

CALBRATKOUS RUARABE:

$$
\begin{aligned}
& \text { Chresnd Akent } \\
& \text { yon rocrsisum. } \\
& \text { Copper Constanim } \\
& \text { Cheomul-Cunsiartian }
\end{aligned}
$$

BATTER:

DMAERSWONS

MEgGT
1.35 V Malkon anercury cell IfMathin

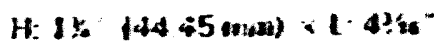
(W) 56 numi - lit $\div-119.05 \mathrm{~mm}$

12 ac. $(3420 \mathrm{~g})$ 


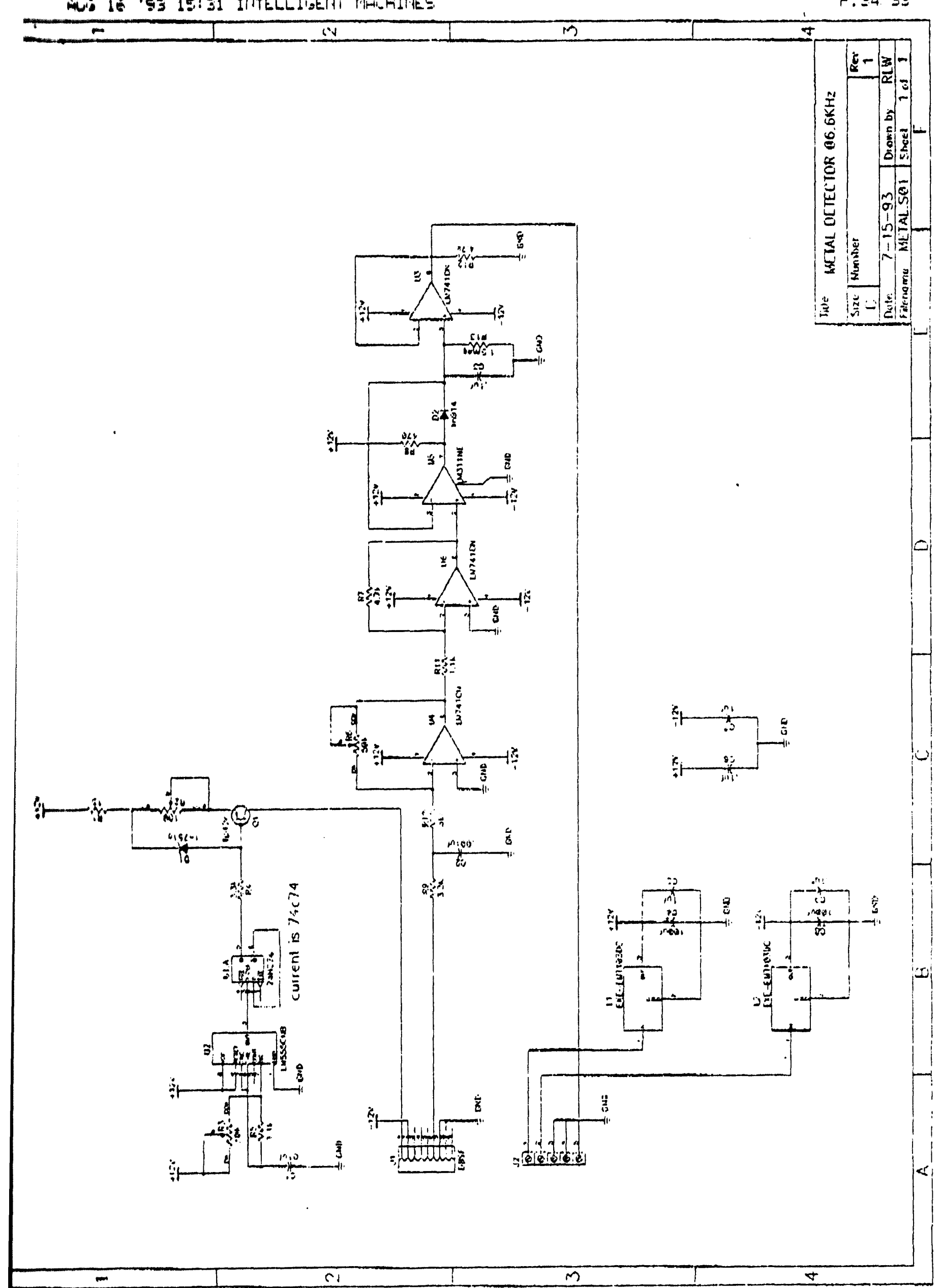



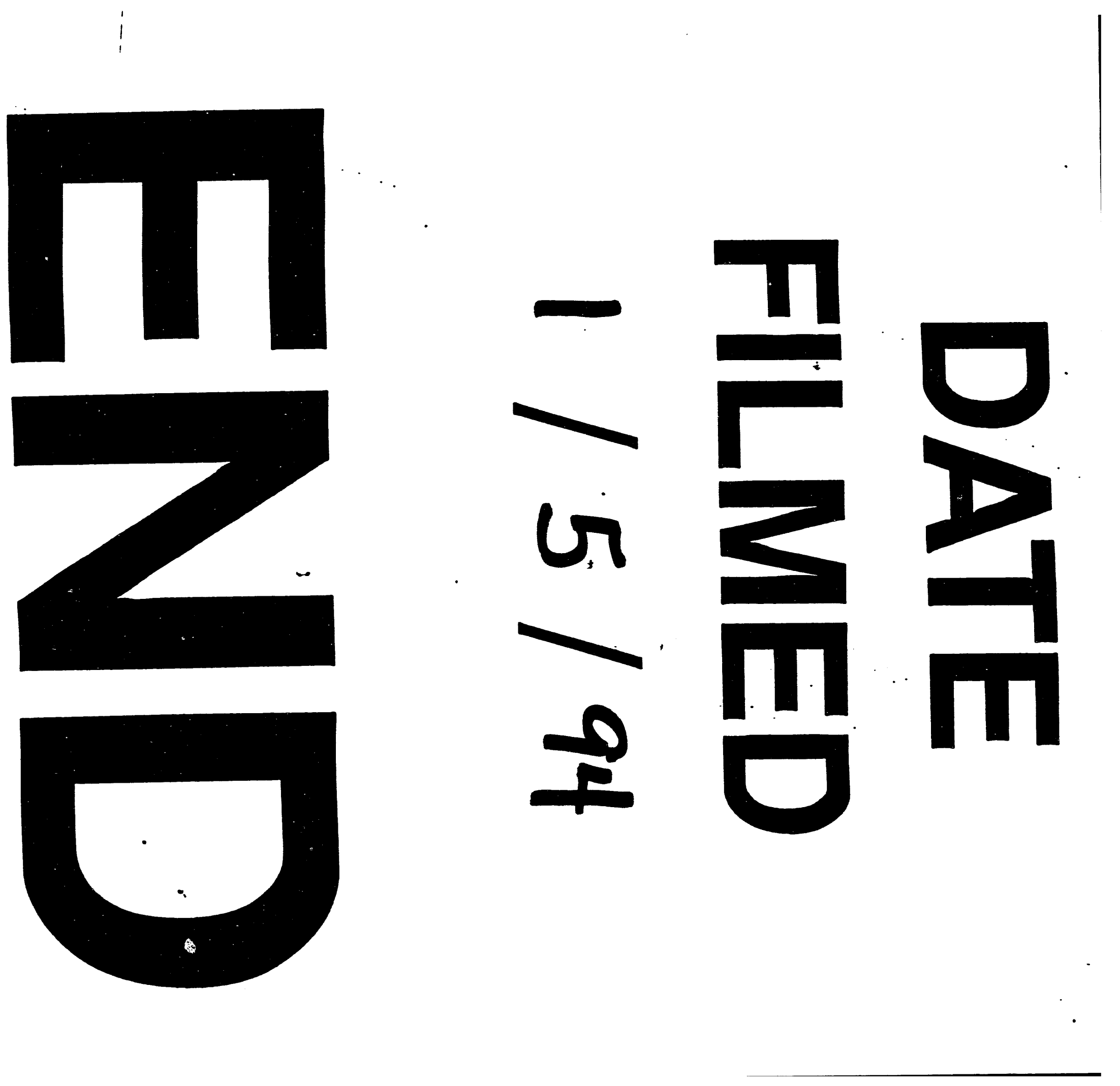


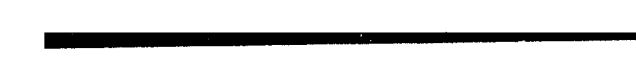

